\title{
THE APPLICATION OF METACOGNITION TO BUSINESS DECISION MAKING
}

\author{
BY \\ EVIE TURNER-WALKER
}

\begin{abstract}
A thesis
submitted to Victoria University of Wellington

in partial fulfilment of the requirements for the degree of

Master of Commerce

in Management.
\end{abstract}

Victoria University of Wellington

2016 


\section{Acknowledgements}

I would like to acknowledge and thank all those who helped me with my thesis:

Mum and Dad, for all your love, support and weekly phone calls checking that I was still alive and eating more than toast and smoothies. Thank you both for showing me the benefits of hard work and dedication because that has truly been a source of inspiration.

Dr Paul McDonald, without whom this work would not have been possible. Thank you for sharing your wealth of knowledge and depth of understanding, it provided much needed reassurance throughout the whole process. I really appreciate the help you gave me, the thoughtful feedback and the generosity of time and effort you put into my work.

The Honours/Masters cohort, in particular Alice, Erin, Cass, and Hamish, thank you for providing support, feedback and entertainment on a daily basis. I don't think I could have come out of this sane if it wasn't for you all.

Lastly, my friends and family, who proved to be great distractions as well as great support. Thanks for providing me with much-needed excursions away from university work and good excuses to make me feel a little less guilty about it. You are all awesome and I'm glad I have such amazing people in my life. 


\begin{abstract}
One of the challenges facing managers in modern-day business is the ability to make effective decisions amidst complexity. Complexity manifests in many aspects of business, in particular the competitive environment. Complexity causes uncertainty and ambiguity which force businesses to think creatively in order to be adaptive and responsive. Traditional practices of decision making are often inadequate to deal with the challenges of modern-day complexity. Recognition is growing that modern businesses need to enhance their decision-making processes and systems to better reflect the current business environment.
\end{abstract}

Traditional models of decision making are based on rational and intuitive decisionmaking processes. The present study draws upon insights from the emerging field of neuroscience to explore cognitive processes of decision making. In particular, the process of metacognition (the ability to think about what one is thinking about) is examined. The central proposition underlying the study is that awareness of metacognition can improve decision-making ability at the individual level of analysis.

The literature on metacognition and decision making provide a foundation for integrating across the two disciplines. Theoretical and operational models are developed from these literatures. The main aim of the research is to introduce the concept of metacognition, a phenomenon salient in the neuroscience literature, to the process of decision making within the modern business context.

The study tests the influence of understanding metacognition in relation to decision making through an experimental design, including use of experimental and control groups. The experimental group receives advance exposure to metacognitive strategies, including thinking aloud and visualisation, whereas the control group approaches the decision making exercises without special instructions. Decision making is measured by three exercises: problem solving, memory retention and lateral thinking. Each exercise is examined and tested individually to determine the extent of the influence of metacognitive awareness. Baseline metacognitive ability is assessed through a Metacognitive Awareness Inventory for both groups as a control variable. 
Ninety students across four Victoria University of Wellington business school undergraduate courses voluntarily participated in the experiment. The students were randomly divided into two groups: an experimental group and a control group. Each participant was given a questionnaire requiring approximately 30 minutes to complete, with a number of problem statements and exercises that tested problem solving, memory retention and lateral thinking ability.

The findings from the study demonstrate that the experimental group, who were cued in advance to apply metacognitive strategies, performed better at problem solving and memory retention. There was no significant difference in means between the experimental and control group for the lateral thinking exercise. These results are discussed in detail.

The research suggests that teaching students about the concept of metacognition along with developing skills in the application of metacognitive strategies have the potential to enhance decision-making capacity, which in turn will address the challenges of complexity. It is proposed that the findings from this study may be relevant within the managerial context and that similar interventions might be considered for future management development programmes. These findings support the current literature which has primarily focused on the school sector. Limitations are recognised, including generalisability, and avenues for future research are proposed, including further applications of metacognition, along with other insights from neuroscience, to enhance processes of business decision making. 


\section{Table of Contents}

Acknowledgements ..........................................................................................i

Abstract ....................................................................................................... ii

Table of Contents .........................................................................................iv

Illustrations ............................................................................................................ vii

Chapter 1: Introduction.........................................................................1

1.1 The challenge of business decision making amidst complexity …................................... 1

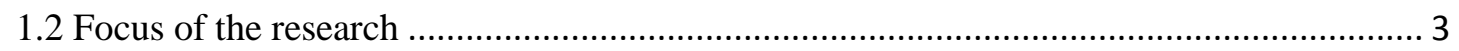

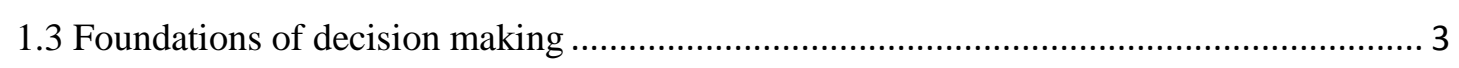

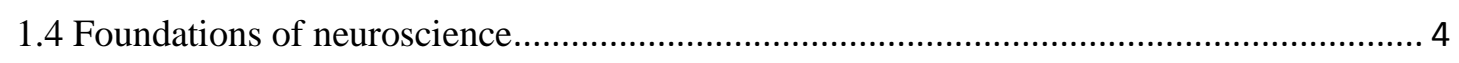

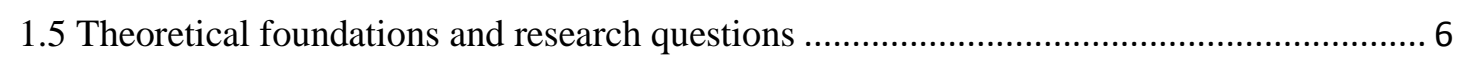

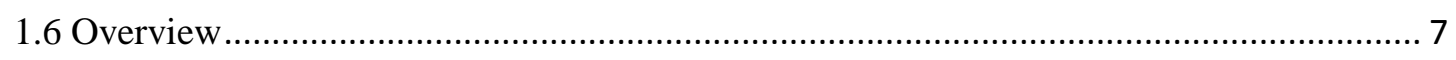

Chapter 2: Literature review .............................................................9

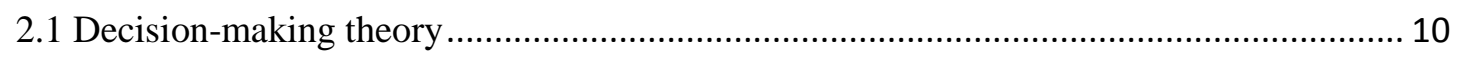

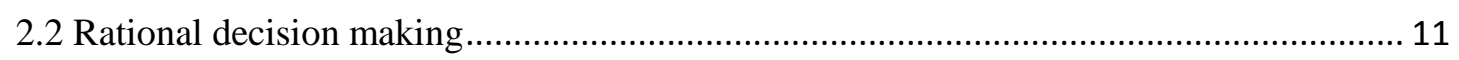

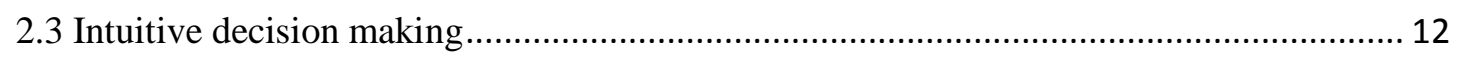

2.4 Combination of rational and intuitive processes .......................................................... 13

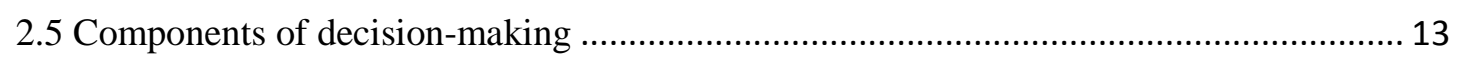

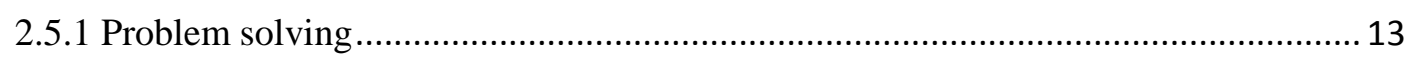

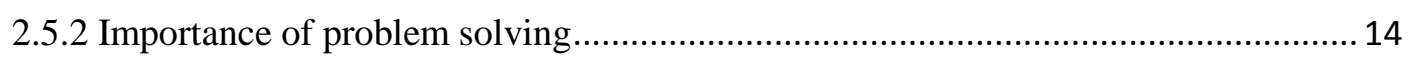

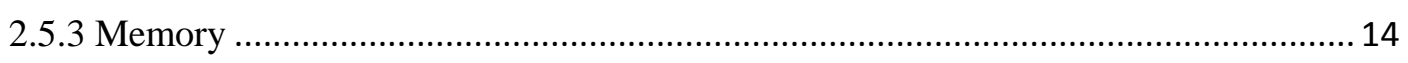

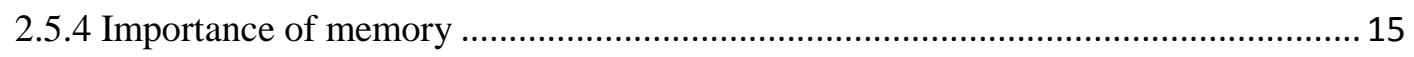

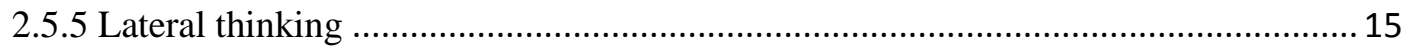

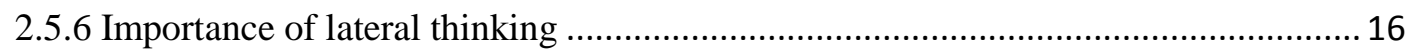

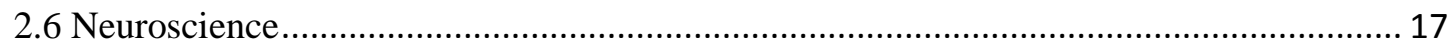

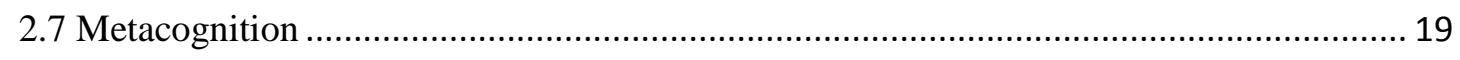

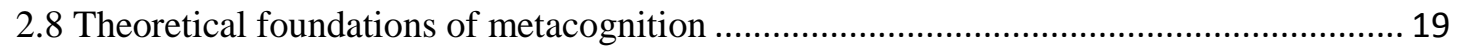

2.9 The evolution of metacognition research.......................................................................... 21

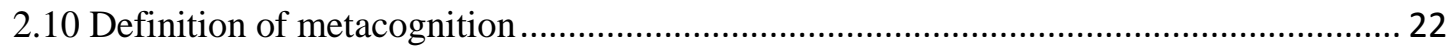

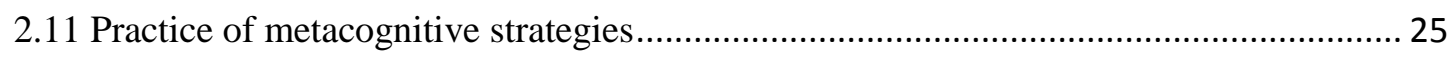

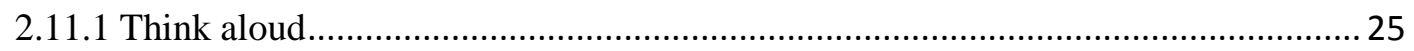

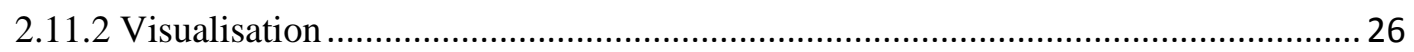




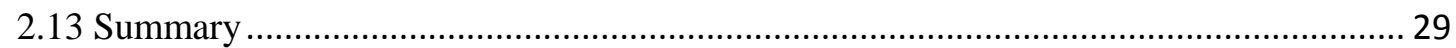

Chapter 3: Conceptual framework........................................................................30

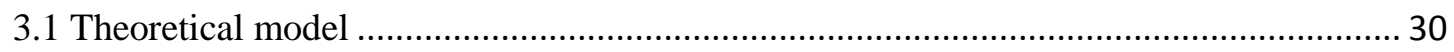

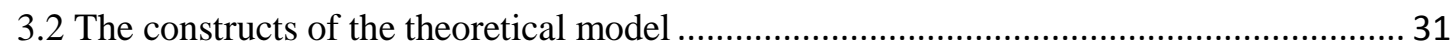

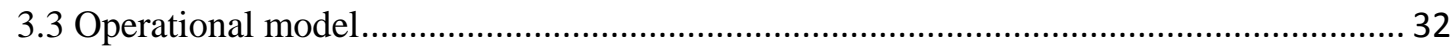

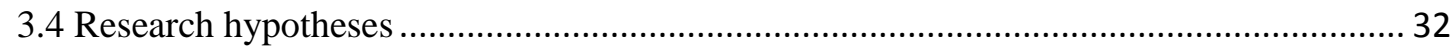

Chapter 4: Methodology .............................................................................................34

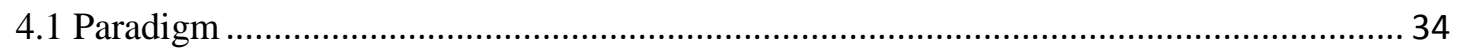

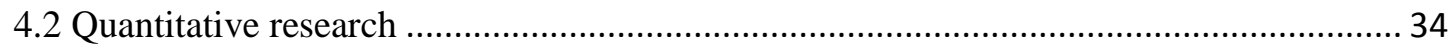

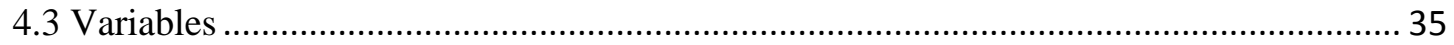

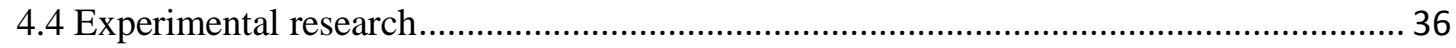

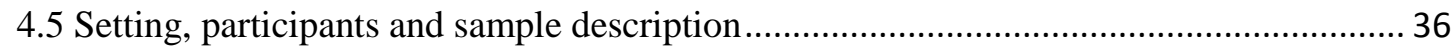

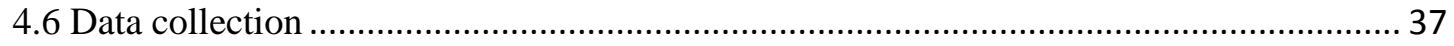

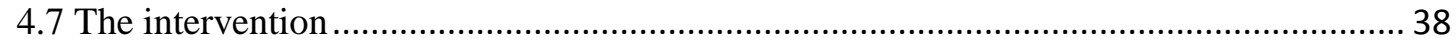

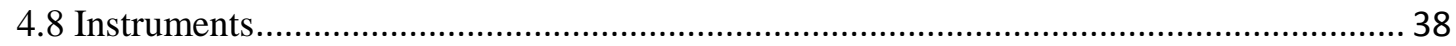

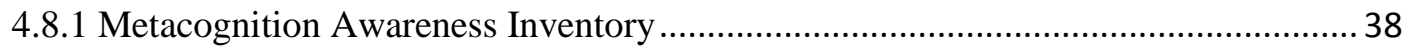

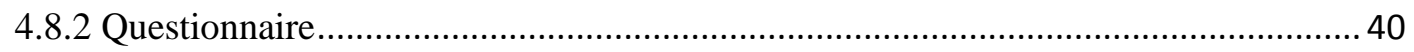

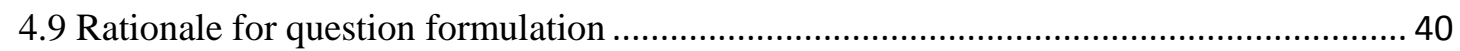

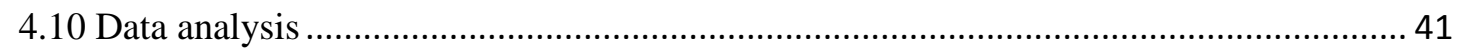

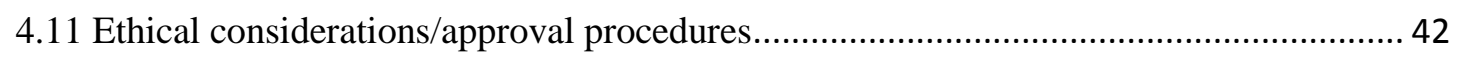

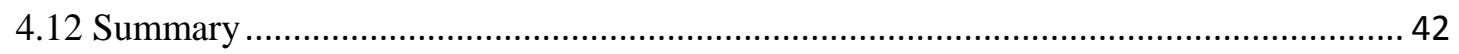

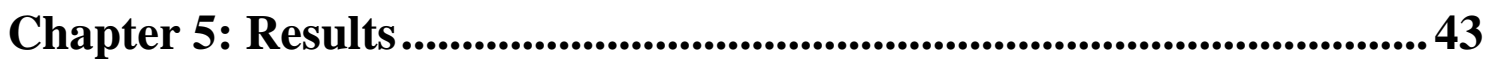

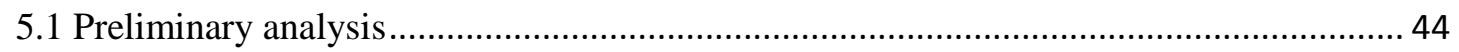

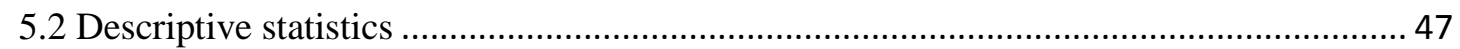

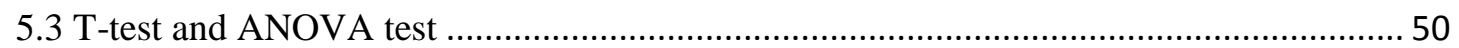

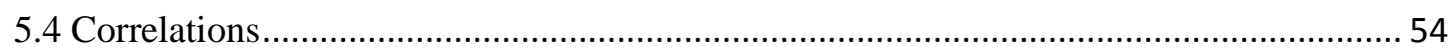

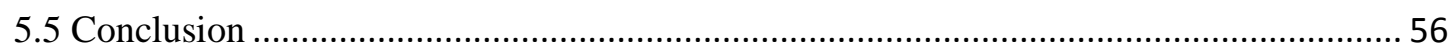

Chapter 6: Discussion and conclusions ................................................57

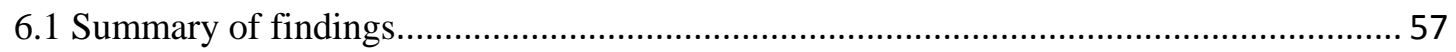

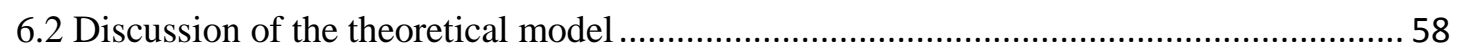

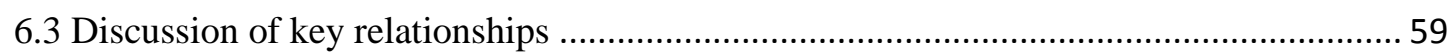

6.3.1 The relationship between metacognition and problem solving ................................59

6.3.2 The relationship between metacognition and memory retention.............................. 60 
6.3.3 The relationship between metacognition and lateral thinking .61

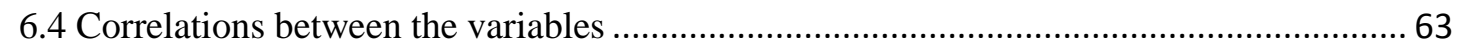

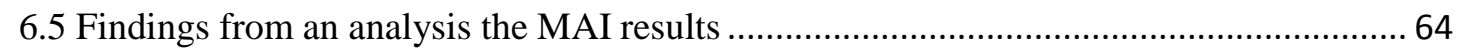

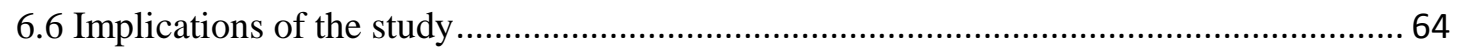

6.7 Limitations of the study and recommendations for future research..................................66

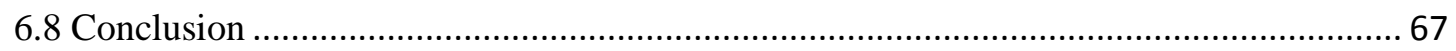

References ......................................................................................................69

Appendices ..................................................................................................................... 100

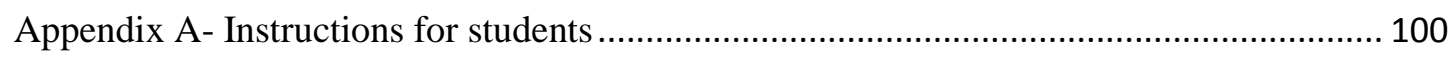

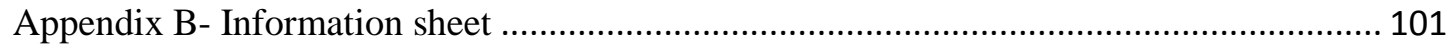

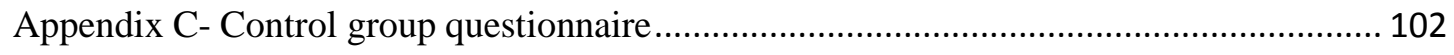

Appendix D- Experimental group questionnaire ……........................................................... 106

Appendix E- Metacognitive Awareness Inventory ............................................................. 110 


\section{Illustrations}

Figure 2-1: Rational process of decision making ............................... 11

Figure 3-1: Research model ............................................... 31

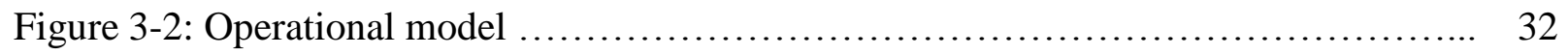

Figure 5-1: MAI skewness and kurtosis distribution .............................. 46

Figure 5-2: Memory retention skewness and kurtosis distribution $\ldots \ldots \ldots \ldots \ldots \ldots \ldots \ldots \ldots . \quad 46$

Table 2-1: Definitions of metacognition ....................................... 23

Table 2-2: Studies assessing decision making and metacognition ..................... 28

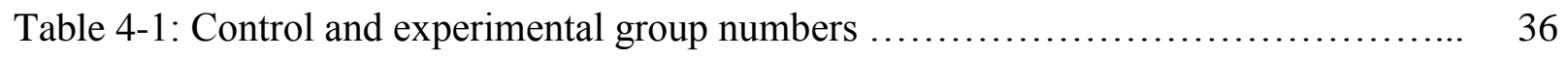

Table 4-2: Gender participant numbers ..................................... 37

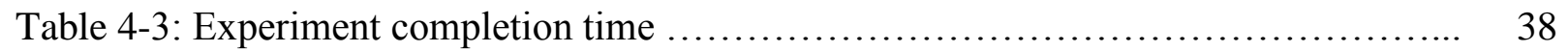

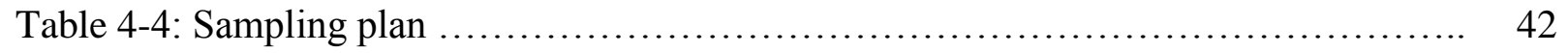

Table 5-1: Coding for the nominal variables ................................... 44

Table 5-2: Experiment results of both the control and experimental groups ............. 47

Table 5-3: Control group results ............................................... 47

Table 5-4: Experimental group results ....................................... 48

Table 5-5: Table 5-5: Section C (LatThink) results ........................... 49

Table 5-6: MAI descriptive statistics results ................................... 50

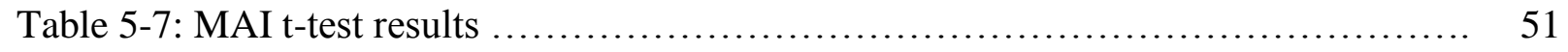

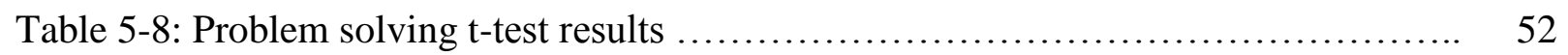

Table 5-9: Memory t-test results ........................................ 52

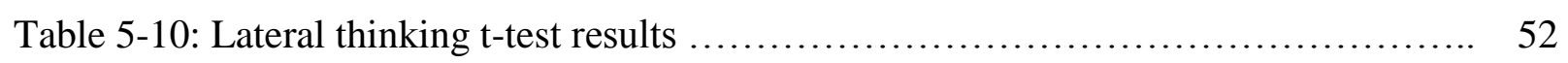

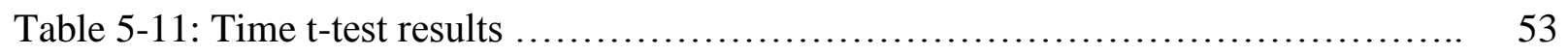

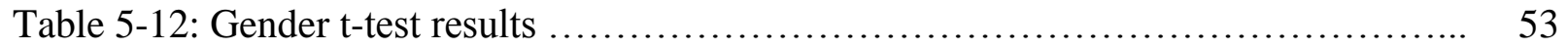

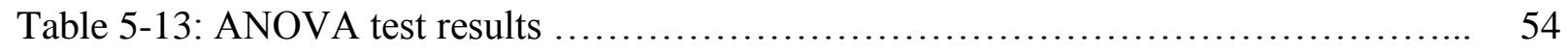

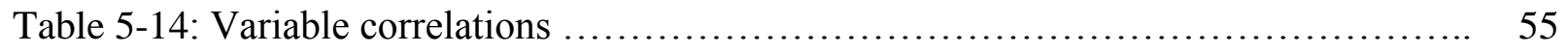




\section{Chapter 1: Introduction}

The aim of this study is to address business decision making within the context of everincreasing complexity. This study will use research insights from neuroscience, particularly the concept of metacognition (thinking about thinking), as potential for enhanced decision making. The central proposition underlying the research is that awareness and application of the process of metacognition will improve the quality of business decision making.

\subsection{The challenge of business decision making amidst complexity}

Business decision making is a critical function for any modern-day business, as it is how organisations create their future (Steinhouse, 2014). In recent decades, the business environment has changed, increasing the level of complexity and thereby challenging decision-making processes. The increase in complexity can be attributed to a number of political, economic, social, technical, and environmental factors (Liebowitz, 2014). These factors include increases in the volume of information, advancements in technology, the development of global markets, an increase in regulation, rising outsourcing, improved communication, increased sophistication of products, and escalating customer demands (Cunningham et al., 2011; North \& Macal, 2007; Rainer \& Cegielski, 2009).

While these factors, along with others such as globalisation, advancements in technology and changing social patterns, bring with them a wealth of opportunities, they also bring risk. The risk of global competition is one example of such risk as it can affect the way a company operates (Ferrell \& Fraedrich, 2016). Global competition can increase the threat of new entrants and the intensity of competitive rivalry, which can in turn significantly influence the number of competitors in the market, as well as the strength of competition (Cullen \& Parboteeah, 2013; Tribe, 2015). Moreover, other issues such as the rise in free trade agreements, due to blurred market boundaries, are: "forcing organisations to engage in sophisticated high-level decision-making processes" (Pol and Thomas, 1997, p. 8). Another example of such risk is the escalating demands of customers, which can significantly influence the spending patterns of consumers (Wetherly \& Otter, 2014) and 
can affect business conditions (Pol \& Thomas, 1997), in turn influencing business decision-making processes.

Consequently, these changes and accompanying complexity give rise to a number of challenges relevant to modern-day business decision making. The scope of this study will focus on three specific aspects of business decision making:

- the ability to conduct enhanced problem solving,

- the retention of information, and

- the ability to think laterally.

This research proposes that insights from the evolving field of neuroscience have the potential to offer solutions. Specifically, the neuroscientific concept of metacognition has relevance to the application of enhanced problem solving, memory retention and lateral thinking.

The ability to problem solve is becoming increasingly challenging because of changing business dynamics and environments. In business, competing in a complex landscape requires structures and conditions that promote adaptability, learning, and creative problem solving (Seijts, Crossan, \& Billou, 2010). Modern-day business emphasises competition, large markets, strategic planning, performance appraisal, and so on, which creates the need for new problem-solving strategies (Hicks, 2013). Therefore, in the face of increasing complexity managers need new and novel approaches to the challenges of business decision making.

The retention of information is also an issue in modern-day business due to information overload. Information overload refers to "the fact that there are finite limits to the ability of human beings to assimilate and process information during any given unit of time" (Jacoby, 1977, p. 569). The need to process information increases as the amount of information grows (Ruff, 2002). However, a point is arrived at in which the decisionmaker has received too much information, and their decision-making ability decreases. Beyond this point information can no longer be processed and may cause confusion or have a negative impact on the decision-maker (Eppler \& Mengis, 2004). Because of this, information overload can cause delays or complete inertia (Robbins, 2014) and can decrease people's decision-making ability (Ruff, 2002). 
Lastly, creativity is becoming increasingly important in the current competitive environment (Pink, 2005). Lateral thinking is a way in which to think creatively or 'outside of the box' (Jesson, 2012). Originally coined by Edward de Bono (1967), lateral thinking is an important skill to possess in order to process decision-making scenarios that do not lend themselves to a logical process (Butler, 2010). However, people are predisposed to vertical thinking; that is, they solve problems using conventional logical processes and often ignore emotion and intuitive feelings (Proctor, 2014). But due to the evolving context within which businesses compete there is a growing demand for greater integration of deliberate (rational) and intuitive thinking processes (Matzler, Uzelac, \& Bauer, 2014). Therefore, the ability to think laterally is becoming increasingly important.

\subsection{Focus of the research}

In light of the need for increased decision making ability this study aimed to examine the field of metacognition in relation to business decision making. In particular, through an experimental design, the effect of cognitive conditioning, involving particular metacognitive strategies, was measured against decision-making ability. As mentioned earlier, decision making in this study was measured by problem solving, lateral thinking, and memory ability. By doing so, this study aimed to integrate research from cognitive neuroscience to the world of business and contribute to the research within the field of organisational cognitive neuroscience. The central proposition underlying the research was that the experimental group, who were encouraged to use metacognitive strategies, would perform better than the control group, who approached the tests without any guidance as to the nature of metacognition. The specific metacognitive strategies employed in this study included think aloud and visualisation. In addition, the baseline metacognitive ability of all participants was measured.

\subsection{Foundations of decision making}

Decision making is a "multifaceted and multi-dimensional phenomenon" (Batool, Riaz \& Riaz, 2015, p. 148) that originates from disciplines such as psychology, economics, mathematics and sociology (Buchanan \& O'Connell, 2006). Researchers Guo and Pedrycz (2014) note that the study of decision making has evolved through four stages 
"(1) Preoccupation with the rational, (2) critiques and extensions of the rational tradition,

(3) creation of fully articulated alternatives to the rational, and, finally (4) a multiperspective view of decision-making" (p. 132).

As Guo and Pedrycz note, 'preoccupation with the rational' was concerned with decision making as a rational process where decision makers made decisions based on the expected utility maximisation. Research in this area assumed decision makers were rational when they considered options. Here they would generally choose the option that they consider would give them the greatest value. However, critiques of the rational decision model arose as scholars began to identify the limitations of decision making, for example, the inability to take into consideration all alternatives and possible outcomes for a decision. In response to the critics raised, alternatives to rational choice theory were proposed. These approaches often viewed decision making as a more intuitive approach. In light of this efforts were made to develop a multi-perspective method to decision making. This was to demonstrate that decision making was more than just a rational process, rather it included other aspects such as cognitive processes, emotions and group behaviour.

For the purpose of the study decision making is defined as a multiple perspective process which involves the integration of both rational and intuitive processes. Further discussion of both intuitive and rational decision making and the rationale behind defining decision making as both a rational and intuitive process is offered in Chapter 2 .

\subsection{Foundations of neuroscience}

Neuroscience is an interdisciplinary field in which neuroscientists strive to investigate the structures, processes and functions of the brain and nervous system (Holley, 2006; Pardo $\&$ Patterson, 2013). Some of the first pioneers of the field of neuroscience are said to be David Rioch with his work at the Walter Reed Army Institute of Research, Francis Schmitt with his work at the Neuroscience Research Program, and Stephen Kuffler, who helped form the first neurobiology department at Harvard University (Cowan, Harter, \& Kandel, 2000). In the decades following their work, the field of neuroscience has evolved significantly. This evolution can be attributed to technological advancements and the salience of neuroscience research. 
Technological advancements, such as the creation of functional Magnetic Resonance Imaging (fMRI), Electroencephalography (EEG) and Transcranial Magnetic Stimulation (TMS), have enabled scientists to view the brain in action, revealing insights into neuro functions that would not have previously been possible (McBride \& Schmorrow, 2005; Scarlett, 2016). The speed at which these technologies are being developed has accelerated dramatically over the past decade (Jorgenson et al., 2015) and has provided strength and reliability of results (Andrews, 2014).

The prominence of neuroscience and references to neuroscience have also increased significantly over the past few decades (O'Connor \& Joffe, 2013). This has brought with it a better understanding of the brain and its functions, in turn creating new areas of cognitive research (Johnson \& De Haan, 2015). This research, largely within the $21^{\text {st }}$ century, has improved both the recognition and credibility of the field. Today, further advancements in the literature are beginning to bridge the gap between neuroscience and other academic disciplines. Academic fields such as neuroeconomics, neuroaccounting, neuromarketing, and neuroethics are growing (Ahmad, 2010). The growth of the field has also allowed researchers to look at certain aspects of the brain such as the behaviour of humans, the central nervous system, and the function of the nervous system. This has caused the development number of sub-fields of neuroscience, such as social neuroscience, cellular neuroscience, cognitive neuroscience, organisational cognitive neuroscience, computational neuroscience, and developmental neuroscience (Lee, Senior \& Butler, 2012; Northoff, 2014).

The fields of cognitive neuroscience and organisational cognitive neuroscience are of particular relevance to this study. According to Jääskeläinen (2012) cognitive neuroscience is a "young but rapidly growing discipline of science that aims at solving the intriguing question of how the brain (or, more generally, the body) gives rise to the human mind; how the brain enables one to think, plan, remember other people, see, hear and move about" (p. 10). Organisational cognitive neuroscience, on the other hand, can be defined as the "cognitive neuroscientific study of organisational behaviour" (Senior, Lee, \& Butler, 2011, p. 804). From this, researchers have begun to examine fields, such as metacognition to provide further insight into the processes of the human brain that affect processes such as decision making in an organisational context (Fleming \& Dolan, 2012). 


\subsection{Theoretical foundations and research questions}

Research foundations from the literature on metacognition and decision making will be explored. First, metacognition will be examined through using the metacognitive strategies 'think aloud' and 'visualisation'. Second, decision making will be assessed by observing and measuring problem solving, lateral thinking, and memory ability.

The central research question is:

To what degree does an understanding of the cognitive process of metacognition lead to enhanced business decision-making ability?

From this central question a number of sub-questions are considered:
- A. Does metacognition improve the ability to solve problems?
- B. Does metacognition improve memory retention?
- C. Does metacognition improve the capacity to think laterally?

The principal proposition for this research is that using metacognitive strategies has implications for decision-making ability. This research aims to examine this relationship in order to contribute to existing research and offer practical implications for practice. The relationship is examined by conducting an experiment in which the experimental group is encouraged to apply metacognitive strategies. It is hypothesised that the use of metacognitive strategies will improve participants' decision-making ability. The reasoning behind this is that metacognition has been specifically linked with both intelligence and thinking ability (Petroselli, 2008). Those who have greater metacognitive ability are generally better thinkers and learners (Petroselli, 2008); therefore, they should have better decision-making ability.

This study is significant as there is a paucity of research exploring the relationship between metacognition and decision making with particular reference to problem solving, memory retention, and lateral thinking ability. It is also proposed that the findings from this study will be able to be generalised to a business context to provide a partial solution to the growing complexity of business decision making. Many current studies highlight the positive effects of metacognitive strategy use; however very few have provided such insights with particular relevance to a business context. 
This study aims to contribute to the research literature by:

1. Applying insights of cognitive neuroscience, in particular metacognition, to the process of decision making.

2. Adding to the existing knowledge and providing new insights that support and acknowledge the relationship between metacognition and decision making.

3. Adding to the knowledge that supports the use of particular metacognitive strategies to facilitate decision making and how these particular metacognitive strategies can be harnessed in the context of business decision making.

\subsection{Overview}

- This introductory chapter has presented the nature of the study, its significance, the research methodology, and the research questions it aims to address.

- The literature review, presented in Chapter 2, will present an overview of the current research in the fields of decision-making and of neuroscience, in particular metacognition, relevant to this study. The chapter is divided into two parts. First, the theoretical foundations of decision-making are discussed. Second, the academic field of neuroscience is introduced, with particular focus on metacognition.

- Chapter 3 then develops a theoretical model, based on literature concerning metacognition and decision making, such as Kumar (1998); Enos, Kehrhahn and Bell (2003); Mitchell, Shepherd and Sharfman (2011), and more, suggesting there is an interface between metacognition and decision making. This theoretical model is subsequently used for the basis of the study as it highlights the relationship between metacognition and decision-making ability.

- A detailed description of the methodology is offered in Chapter 4. In particular, this chapter discusses the study's paradigm (positivism and a quasi-experimental design), operational model, hypotheses, processes, details of participants, data collection, data analysis, and ethical considerations.

- Chapter 5 presents and discusses the key findings, including the validity and significance of the results.

- Lastly, Chapter 6 addresses the degree to which the hypotheses have been validated by the new research and the extent to which the research findings can 
support the existing findings in the current literature. It also provides a discussion of the research questions posed, identifies the implications of the study, discusses the limitations of the study, and concludes with the direction and areas for future research. 


\section{Chapter 2: Literature review}

This research is founded on two distinct literatures, business decision making and neuroscience. The evolution and advancement of each literature domain are discussed in general to develop a contextual backdrop. This will enable exploration of the specifics of problem solving, memory retention, and lateral thinking in relation to metacognition. This chapter is structured such that previous studies and literature relating to decision making and metacognition are reviewed separately.

The literature relating to decision making is examined first, with particular reference to the theoretical foundations of the field. The literature on decision making suggests it is a multifaceted and multidimensional area of research. A key finding in this literature is that traditional trends, in both theory and research, limit decision makers to either a rational or intuitive strategy in decision making (Batool et al., 2015). The literature on intuitive decision making suggests that intuitive decision making is better for decisions amidst complexity, whereas rational decision making is better for situations where the decision has to be based on data, facts, and reason (Morcol, 2006). For the purposes of the current research, business decision making is conceived as a phenomenon that embraces both deliberation and intuition. Decision making is explored with respect to three specific abilities: problem solving, memory retention, and lateral thinking.

The literature on neuroscience is discussed to examine the development of the field. This examination provides a background for the rise of metacognition. The literature on cognitive neuroscience and organisational cognitive neuroscience are of significant relevance to metacognition. The theoretical foundations and the evolution of metacognition are discussed to demonstrate the progression of the field and the development of a construct relevant to decision-making processes. A number of definitions of metacognition are then explored, concluding with the definition that will be used for the purpose of the study. Finally, the chapter ends by discussing the application of metacognition to the field of decision making. 


\subsection{Decision-making theory}

The study of decision making originates from disciplines such as psychology, economics, mathematics and sociology (Buchanan \& O'Connell, 2006) and has been examined in numerous other fields such as education, sociology, and organisational behaviour (e.g., Heller \& Yukl, 1969; Smith, 2003; Thomas, 1955). The process of decision making includes comparing a set of alternatives and choosing a preferred course of action or option (Wang \& Ruhe, 2007). Decisions are often based on routine (Naylor, Pritchard \& Ilgen, 1980), can be made quickly without effort or conscious thought (Smyth, Collins, Morris, \& Levy, 1994) and occur in an environment where the goals, constraints, and consequence of potential actions are not precisely known (Bellman \& Zadeh, 1970).

Decision making is often viewed as the heart of the management process as generally managers are at the forefront of the decision making process (Mann, 1976). Authors such as Band and Partridge (1999) support this as they believe that decision making is an essential element of all management functions. Here, the decisions managers make can help their organisations develop their strategies, accomplish their business plans, and distribute their resources. However, as previously noted, complexity is a common reality in modern-day business therefore, decision making is getting more difficult. Therefore, there is a growing need for better decision making processes.

Decision making is broadly separated into two areas: rational decision making and intuitive decision making. For the purpose of this study, decision making will be viewed as a multidimensional process. Ample evidence supports this view (Batool et al., 2015; Dean \& Sharfman, 1993; Elbanna \& Younies, 2008). A consideration of both rational and intuitive processes is needed for strategic decision making (Pondy, 1983; Simon, 1987) as there is a growing need for a combination of both rational and intuitive decisionmaking processes amongst the increasingly complex environment. One dimensional perspectives only provide a partial understanding of the decision making process, therefore moving away from a one-dimensional perspective will provide a better understating of the complex process of decision making (Chakravarthy \& White, 2002). Rational and intuitive decision making will be discussed accordingly. 


\subsection{Rational decision making}

Rational decision making is the traditional approach used to understand individual decision making (Huczynski \& Buchanan, 2001). A rational process involves following a defined sequential process, as shown in Figure 2-1. According to Huczynski and Buchanan (2001), rational decision-making theory is "equated with scientific reasoning, empiricism and positivism and with the use of decision criteria of evidence, logical argument, and reasoning" (p. 740). Based on the idea of optimisation, where rational decision makers seek to optimise the utility from a decision, rational decision makers are assumed to have a comprehensive picture of the alternatives and their effects (Keast \& Towler, 2009).

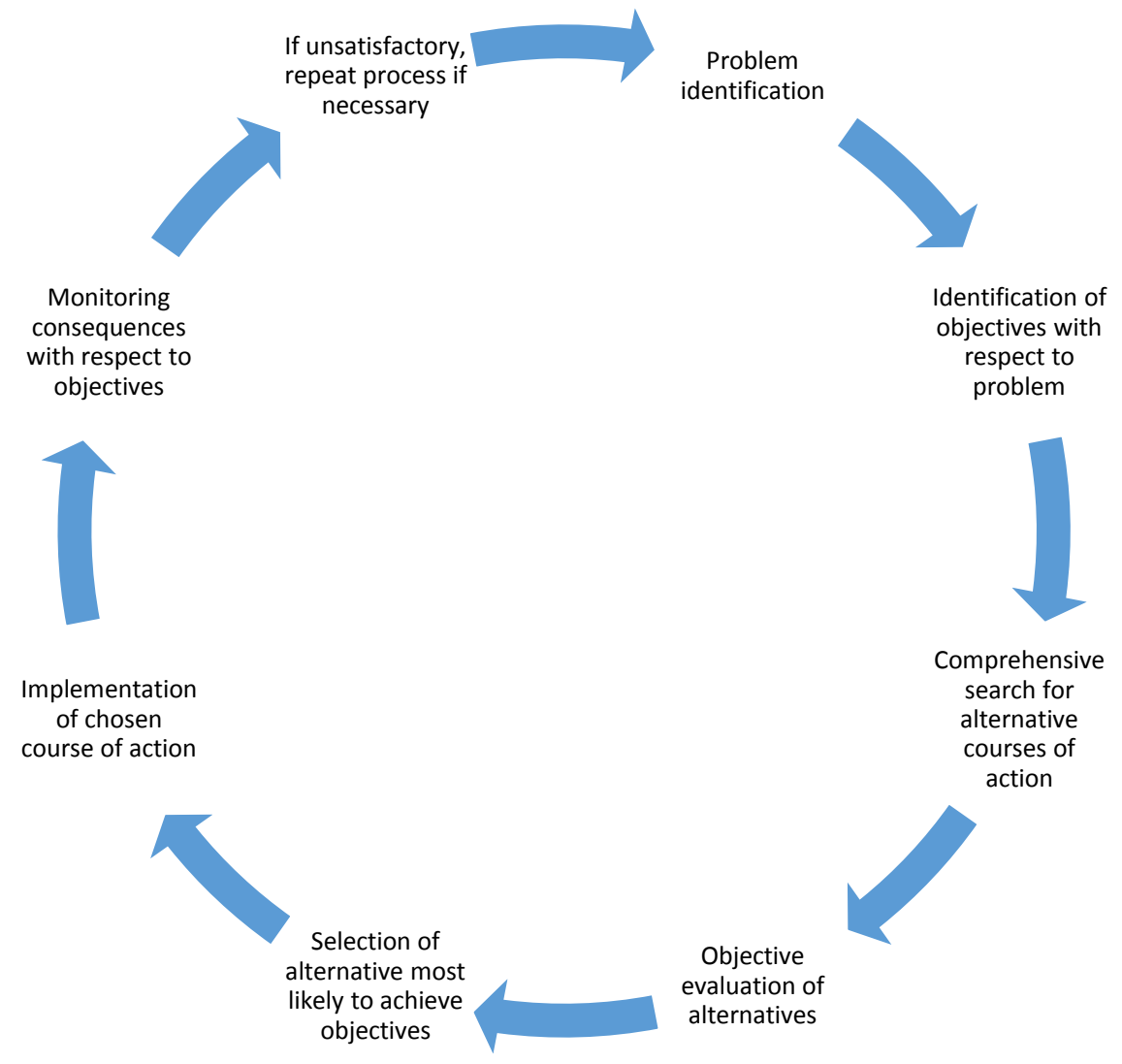

Figure 2-1: Rational process of decision making. ( $\mathrm{Li}, 2008$

While rational decision making may be suitable in stable environments numerous authors have criticised its generalisability. For example authors such as Naqvi, Shiv and Bechara (2006), Smith (2003) and Zadeh, Klir and Yuan (1996) do not believe the classical model 
of decision making is fully representative of how people typically make decisions. These authors highlight the weakness of decision theory and decision theory models, as decision theory and decision theory models assume the process is rational and that decision makers have more information and knowledge of alternatives and outcomes than they actually do. Rational decision making is also said to fail to address "fuzziness and impression of human judgement, perception and modes of reasoning" (Zadeh et al., 1996, p. 340). Moreover, it is believed that the decision situations managers often face can rarely be addressed by decision analytic techniques, as many decisions are uncertain and it is difficult to address a situation given that particular events or conditions can easily change the outcomes (Smith, 2003).

\subsection{Intuitive decision making}

In contrast to rational decision making, intuitive decision making is based on experience, feelings, emotions, subconscious thought, and/or personal values (Burke \& Miller, 1999). It is conceptualised as more of a gut instinct, a personality trait, sixth sense, and an accrual of experience (Shirley \& Langan-Fox, 1996). While much early literature clutched on to the idea of perfect rationality, Chester Barnard, James March, and Herbert Simon moved towards a more intuitive approach to decision making. Chester Barnard led the way as he introduced both the rationality-based logic and intuition-based illogical process of decision making (Batool et al., 2015; Novicevic, Hench, \& Wren, 2002). Following from his work Simon (1957) proposed the theory of bounded rationality as an alternative to classical omniscient rationality. Organisational theorist, James March, later expanded on the theory of bounded rationality (March, 1978). Prior to this, his work with Herbert Simon, Organisations (March \& Simon, 1958), established the field of behavioural organisation theory.

Since these works it has been recognised that intuitive decision making is more appropriate in times of uncertainty, risk, complexity, and ambiguity (Batool et al., 2015). Intuitive decisions evolve from experience and learning (Isenberg, 1984; Simon, 1987) and "consist of the mass of facts, patterns, concepts, techniques, abstractions, and generally what we call formal knowledge or beliefs, which are impressed on our minds" (Barnard, 1938, p. 302). However, like rational decision making, intuitive decision making has limitations and disadvantages. Thagard (2008) notes that intuition may be 
based on inaccurate or irrelevant information. Moreover, Sauter (1999) notes that managers who use intuition become "impatient with routine, details, or repetition... [and] may reach conclusions too quickly, ignore relevant facts, or follow an inspiration when it is clearly bad." (p. 111).

\subsection{Combination of rational and intuitive processes}

In light of both the advantages and disadvantages of rational and intuitive decision making there is a growing recognition of the effectiveness of combining the two processes (Kessler, 2013). Rational and intuitive processes can be regarded as equal partners, where they can provide a context in which both can operate (Pondy, 1983). While both rational and intuitive approach have their advantages and disadvantages, a combination of the two can allow the decision maker to benefit from the advantages of both. As cited in Eling, Langerak, and Griffin (2015), researchers such as Sadler-Smith and Shefy (2004) and Dane and Pratt (2009) have hypothesised this view. In their study, Eling and colleagues (2015) assessed the benefits of the combination of intuitive and rational decision making. The authors note that a combination of rational and intuitive decision making, in practice, "could thus mean using intuition to sense the decision problem, rationality to gather information and to generate and analyse the decision options and, then again, intuition as a 'synthesiser' to arrive at a final decision" (p. 466).

\subsection{Components of decision-making}

For the purpose of the current study, decision-making ability will be operationalised through three components of decision making: problem solving, memory retention, and lateral thinking. The discussion below explains each in detail and highlights the importance of each within an organisational context.

\subsubsection{Problem solving}

Decision making and problem solving are often viewed as interchangeable terms (see Fisher, 1990; Negulescu, 2014). This is because the problem-solving and decisionmaking literatures largely overlap (Horan, 1979; Klein, 1999). Decision making is viewed 
as an activity that is similar to problem solving, as often one is regarded as being a subset of the other (O'Sullivan, 2010). However, for the purpose of this study, the two terms will be regarded as distinct concepts.

Authors such as Parrillo (2008) and Pownall (2012) support this view. In particular, Parrillo (2008) defines decision making as a broad concept, in which problem solving is a process within that is needed to help formulate a plan for executing the solution to a particular problem, issue, or conflict. Pownall (2012) defines decision making as an action that occurs "when a judgement must be made between the merits and demerits of different choice processes" (p. 17), whereas problem solving is defined as the action that "generates the choice process in the first place" (p. 17). For this, the problem can be either an obstacle or difficulty that prevents a goal being achieved, or can be a decision to be made (Gross, Akaiwa, \& Nordquist, 2010). Therefore, depending on the circumstance, one will come before the other.

\subsubsection{Importance of problem solving}

Problem solving is becoming increasingly important in modern-day business. The world is more turbulent than it used to be, therefore is more susceptible to rapid and unpredictable change (Mason, 2007). Problems are often considered a burden; however, effective problem solving can turn a problem into an opportunity to develop and achieve a better future (Hicks, 2013). Past problem solving approaches, such as "one-off" trial approaches, are becoming unsatisfactory and more emphasis is being placed on systematic and flexible problem-solving strategies (Hicks, 2013), thus highlighting the need for enhanced problem solving ability.

\subsubsection{Memory}

Memory is a key component of cognition and plays an important role in decision making (Nutt \& Wilson, 2010). Memory can be analysed by looking at working memory capacity (WMC) and working memory. WMC is the limit to how many items the mind can hold at once (Cowan, 2010). An individual's rational processing ability is said to be constrained by working memory capacity (Barrett, Tugade, \& Engle, 2004). On the other hand, working memory, first coined by Miller, Galanter and Pribram (1960), is a term 
that can be broadly defined as the mechanism responsible for the storing and processing of information (Richardson et al., 1996).

\subsubsection{Importance of memory}

A number of studies have examined the relationship between memory and decisionmaking (e.g., Alloway \& Alloway, 2013; Drost 2013; Fletcher, Marks, \& Hine, 2011). These studies, and many others like them, have found a positive correlation between working memory and/or WMC and decision making. That is, the greater the working memory or WMC the better the decision-making ability. Memory, in relation to decision making, is important as the decision maker must "activate and integrate a number of working pieces of information in order to make a final decision" (Alloway \& Alloway, 2013, p. 188). WMC is of particular importance because it facilitates this process as it helps store and manipulate information, allowing the decision maker to make optimal decisions (Alloway \& Alloway, 2013). Working memory is also a limiting factor in decision making (Endsley, 1995), as working memory can only hold a certain amount of information. Working memory span is of particular importance as a limited working memory span can negativity effect processing time, with the lower the memory span, the longer the processing time (Tucker \& Warr, 1996).

\subsubsection{Lateral thinking}

According to Hernandez and Varkey (2008), "Lateral thinking is a step-by-step method of creative thinking with prescribed techniques that can be used consciously" (p. 28) Lateral thinking uses reasoning that may not be immediately obvious and generates ideas that may not have been available if traditional logic was used (Ivancevic \& Invancevic, 2007). Generally people are predisposed to vertical thinking. While vertical thinking rewards the depth of knowledge, which often produces decisions based on evidence and supported by literature, lateral thinking incorporates reasoning and imagination, in which new ideas or different solutions can be born (Hernandez \& Varkey, 2008). However, rather than being a replacement for vertical thinking, lateral thinking is complementary (Doede, 2013). 
Creativity is becoming crucial in modern-day business as the increase in competition is forcing business to become more innovative (Okpara, 2007). Although conventional wisdom has been used extensively in the past to tackle business issues, Hall (1996) suggests that convention wisdom "will stifle the full potential of the techniques, which depend upon paradigm-breaking change" (p. 115). Therefore, Hall believes a new attitude must be developed through the exploration of creativity and innovation. Within his work he explores the stages of thinking, which are categorised into the first stage and the second stage. The first stage thinking is "focused entirely upon the generation of the inputs, prior to the second stage processing" (p. 116). Here, less conventional thinking, such as lateral thinking, can be used to simplify the second stage of thinking. However, as Hall addresses, the absence of a willingness to support lateral thinking processes, "coupled with an assumption that there is only one interpretation of the data as presented" (p. 116), can hinder the ability of managers to discover innovative solutions.

Lateral thinking is also important for business decision making as it can help create solutions that otherwise would have been ignored through the standard method of vertical thinking. As not all business problems are able to be solved through a straightforward process (Butler, 2010), lateral thinking offers a way in which to approach the problem through a new lens, turning the reasoning around and reversing procedures (Butler, 2010; Doede, 2013).

This section has reviewed the literature on decision making, covering the evolution of both deliberate, rational methodologies as well is intuitive judgements. It also revealed the importance of viewing decision making as both an intuitive and a rational process. It focuses on three distinct decision-making capabilities: problem solving, memory retention, and lateral thinking. The next section will explore the literature on neuroscience, culminating with insight into the process of metacognition and its potential to enhance the quality of business decision making. 


\subsection{Neuroscience}

Originating from Western biology, medicine, and philosophy (Gross, 1987), neuroscience is a rapidly growing field. The field of neuroscience has advanced significantly in the last two decades and has made important progress in understanding the parts of the brain system that support cognitive performance in a variety of domains, such as memory, decision making, and perception (Fleming, Huijgen, \& Dolan, 2012). As discussed in Chapter 1, this progress can be attributed to recent advancements in technology and the progress of neuroscience research. Development in the area of brain sciences in the $21^{\text {st }}$ century, commonly known as the "Decade of the Brain" (Goldstein, 1994), has been said to have "lift[ed] mankind into a state of enlightenment about its own intellectual foundations" (Hagner \& Borck, 2001, p. 508). With the aid of advanced techniques and knowledge, neuroscientists were able to grasp the "understanding of three basic domains of neuroscience: the structure and functioning of neuronal signalling, neuronal circuits and neuronal systems" (Sirageldin, 2001, p. 171).

Also mentioned in Chapter 1, the field of cognitive neuroscience and organisational cognitive neuroscience are of particular relevance to this study. Originally coined by Michael Gazzaniga and George A. Miller in the 1970s (Bruer, 2009), cognitive neuroscience is an academic field of enquiry aimed at understanding the cognitive functions of the brain. According to Ochsner and Kosslyn (1999) "The goal of cognitive neuroscience is to understand how brain function gives rise to mental abilities such as memory, reasoning, vision, or movement, and to understand how such abilities interact with the systems underlying emotion.” (p. 320). According to Pardo and Patterson (2013), often, research in the field of cognitive neuroscience looks for relationships between "the brain and the various powers, abilities, and capacities that we associate with the mind and mental life such as decision making, knowledge, memory and consciousness" (p. xxxii). This area has provided great insight into the functions of the brain, however, Senior and colleagues (2011) note that while "key theories and methods of behavioural, cognitive, and social psychology are entrenched in organizational research, advances in cognitive neuroscience have failed to permeate through organizational and/or business research to the same extent" (p. 804). The development of the field of organisational cognitive neuroscience is said to bridge this gap. 
Organisational cognitive neuroscience is an academic field of inquiry that has applied research insights from neuroscience to gain a deeper understanding of organisational processes (Butler \& Senior, 2007). This, in turn, leads to a more "integrated science of influence" (Viswanathan et al., 2015 p. 1). According to Lee, Senior, \& Butler (2012) organisational cognitive neuroscience is "symbiotic with ON (organisational neuroscience) ... as well as its older cousin, SCN (social cognitive neuroscience) to form a detailed theoretical framework that helps scholars to understand the complexities of the social behaviour that occurs within organisations" (p. 923). Organisational cognitive neuroscience addresses an area in research that cognitive neuroscience has failed to permeate (Senior et al., 2011) and addresses the questioning of whether there are benefits for the science and practice of management in understanding human brain functions (Lee et al., 2012). Organisational cognitive neuroscience is particularly relevant for this study as it generates insights into the relationship between organisational behaviour, such as managerial decision making, and brain functions in areas such as metacognition (Butler, O’Broin, Lee, \& Senior, 2015).

A growing number of studies are emerging in the fields of cognitive neuroscience and organisational cognitive neuroscience. In the field of cognitive neuroscience the relationship between metacognition and decision making, in particular problem solving, lateral thinking, and memory recollection, is beginning to be explored. For example, works such as those by Swanson (1990) on problem solving, Autin and Croizet (2012) on memory, and Hargrove \& Nietfeld (2015) on creative performance, highlight the practical benefits of using metacognition. These studies are beginning to uncover and increase the credibility of particular metacognitive strategies that facilitate decision making. While organisational cognitive neuroscience is a new field of study, and the field remains small in comparison to the field of cognitive neuroscience, it is of growing importance. Works within the field create potential for advances in neuroscientific research to create enhancements in the organisational sciences (Becker, Cropanzano, \& Sanfey, 2011; Lee et al., 2012). Specifically, Lee and colleagues (2012) note:

For almost a decade, a small but growing body of researchers has sought to address a singular research question, with implications for management scholars across the globe; namely, what benefit can an understanding of the human brain have for the science and practice of management? (p. 921) 
This study aims to contribute to this area of knowledge to provide greater insight into the effect of metacognition on decision making.

\subsection{Metacognition}

Metacognition can be simply defined as "thinking about thinking"; however, it can be further described as a higher order thinking process that involves control over cognitive processes we engage in while learning (Livingston, 1997). Originally coined by developmental psychologist John Flavell in his work "Metacognitive Aspects of Problem Solving" (Flavell, 1976), metacognition plays an important part in successful learning, as successful learners possess metacognition (Thamraksa, 2005).

Over the last 40 years metacognition has grown to be one of the main fields of cognitive developmental research (Papleontiou-louca, 2003). Metacognition has been extensively utilised by the research community in fields such as psychology, clinical psychology, memory, science education and neuroscience (e.g., Papageorgiou \& Wells, 2001; Eggen \& Schellenberg, 2010; Zohar \& Dori, 2011; Shimamura, 2000). It has also been applied in a variety of domains such as attention, visual perception and social cognition (e.g., Lysaker et al., 2013; McCurdy et al., 2013; Miller \& Weiss, 1982). These works have not only brought about a deeper understanding of metacognition but have also developed a number of detailed theoretical models and methodologies that have helped assess and analyse metacognition and metacognitive activities (Hacker, Dunlosky \& Graessser, 1998; Larkin, 2009).

\subsection{Theoretical foundations of metacognition}

According to Akturk and Sahim (2011), metacognition research emanates from three theoretical paradigms: cognitive development psychology (Piaget, 1950), cognitive psychology (Hart, 1965), and social development psychology (Vygotsky, 1962). Cognitive psychology is the study of mental processes, primarily focusing on the way humans process information; cognitive development psychology is a field of study that looks at a child's development in areas such as information processes, language learning, 
and other areas of neural development; and social development psychology looks at the role of social interaction in the development of cognition (McLeod, 2007).

Piaget (1950), was the first to acknowledge the phenomenon of metacognition. Prior to Piaget's work, behaviour theory dominated the field of learning; for example, Pavlov's work on classical conditioning, and Thorndike and Watson's extension into stimulus and response learning contexts (Edgar, 2012). Piaget created a learning model to describe how people gather and organise information to make sense of the world. More than a decade after the work by Piaget, Vygotsky examined metacognition in relation to children's learning. Vygotsky did not specifically state that it was a study of metacognition; however, his findings concluded that learning is achieved through socialisation and that metacognition is learned once children interact with others (Vygotsky, 1962). Not long after this work, Hart (1965) pioneered the study of metacognition. Hart was the first to measure metacognition, but not name the term, with his work on feeling-of-knowing judgements.

A major development in the field of metacognition occurred within post-Piagetian development psychology research (Perfect \& Schwartz, 2002). Examples of postPiagetian work include Flavell (1979), Brown and DeLoache (1978) and Siegler (1978). Post-Piagetian development psychology refers to work that has modified Piaget's conception of cognitive development by incorporating the authors' own empirical findings (Inagaki, 1992). Flavell's (1963) work was fundamental as it not only established the field of metacognition but created a dramatic shift away from behavioural theory to cognitive constructivism (Schinka, Velicer \& Weiner 2003), which is a constructivist view that focuses on "individual, internal constructions of knowledge" (Applefield, Huber, \& Moallem, 2000, p. 7). This shift in psychological theory and research in the 1960s and 1970s resulted in a deviation from research concerning conditioning, toward research concerning cognition (Schunk, 2008). Here greater emphasis was placed upon human learning rather than environmental variables, allowing for human functioning, such as encoding, processing, storage, and the retrieval of information (Schunk, 2008). 


\subsection{The evolution of metacognition research}

While Flavell's early work was fundamental in establishing the field of metacognition the term "metacognition" was not formally used until his later work (Flavell, 1976). Flavell's work contributed significantly to the field as it added to the capability of understanding complex cognitive phenomena (Devine, Railey, \& Boshoff, 1993).

Despite the popularity of metacognition in the 1970s, by the beginning of the 1980s many were beginning to scrutinise its validity. Researchers, such as Wellman (1983) and Cavanaugh and Perlmutter (1982), regarded metacognition as a fuzzy concept and began to critique the reliability of metacognition. They highlighted the problems associated with many metacognitive measures. In response to this, research of the $1980 \mathrm{~s}$ aimed to determine whether metacognitive judgements were accurate (Perfect \& Schwartz, 2002). This research, along with that from the 1990s, focused more on developing detailed theoretical models and sophisticated methodologies that helped assess and analyse metacognition and metacognitive activities (Hacker et al., 1998; Larkin, 2009). This development provided some clarity in the field of metacognition.

Developments in the literature of the 1980s and 1990s also helped toward the understanding of metacognition and how it could be used to facilitate learning. PeñaAyala (2014) provides a comprehensive, but not exhaustive, list detailing the orientation of relevant work produced within this time. Metacognition literature of the 1980's focused largely on areas such as: comprehensive mentoring (Markman, 1981); cognitive knowledge and executive control (Kluwe, 1982); learning, remembering, and understanding (Brown et al. , 1983); performance (Forrest-Pressley \& MacKinnon, 1985); metacognitive skills (Duell, 1986); reading comprehension (Garner, 1987); strategies (Pressley, Borkowski \& Schneider, 1987); motivation (Weinert \& Kluew, 1987); and cooperative learning (Brown \& Palincsar, 1989). Whereas literature within the 1990s examined other areas of research, such as self-esteem (Borkowski, Carr, Rellinger, \& Pressley, 1990), metamemory (Nelson \& Narens, 1990), metacognitive judgements (Schwartz, 1994), and development of metacognition in children (Alexander, Carr, \& Schwanenflugel, 1995). It is works such as these that have helped develop and advance the field. 
Metacognition has also been applied to the field of neuroscience to bring about a better understanding of particular areas of the brain that effect mental processes. This is of particular relevance to this study. According to Shimamura (2000) early accounts of the neural basis of metacognition are found in neuropsychology studies. For example, studies by Nolde, Johnson, and D’Esposito (1998) and Rugg, Fletcher, Chua and Dolan (1999) suggest that the frontal cortex of the brain, in particular the prefrontal areas, contribute to metacognition. Moreover, a recent review by Fleming and Dolan (2012) examined a number of studies that have harnessed methods in cognitive neuroscience to draw relationships between brain function and metacognitive ability. They provide examples of neuropsychology studies such as Hirst (1982), who studied the effect of Korsakoff's syndrome (a syndrome often caused by alcohol misuse) on metamemory, and Shimamura and Squire (1986) who also studied Korsakoff's syndrome found that participants with Korsakoff's syndrome have an impairment in making feeling-of-knowing judgements.

The past two decades have seen the introduction and growth of cognitive neuroscience and organisational cognitive neuroscience, as discussed above. Despite this, literature bridging the gap between cognitive neuroscience and metacognition remains scarce. A recent book by Fleming and Frith (2014) is said, by them, to be the "first attempt to take stock of the rapidly developing field of the neuroscience of metacognition in humans and non-human animals, and in turn examine the implications of neuroscience data for psychological accounts of metacognitive processes." (p. 1). More research is needed in this field to bring about a better understanding of how metacognition, in particular metacognitive strategy use, can be applied to organisational practices.

\subsection{Definition of metacognition}

While early literature argued that metacognition could not be separated from cognition (Flavell, 1979; Garner \& Alexander, 1989; Jacobs \& Paris, 1987) this view has been challenged. Advances in literature have set about defining the differences between the two concepts. These definitions separate the two concepts in that metacognition is a term that can be defined as and involves overseeing cognitive goals to ensure they have been met, whereas cognition is the set of all mental abilities and processes related to knowledge (Livingston, 1997). Therefore, metacognition usually precedes cognition, and often 
occurs when cognition fails; for example, when someone does not recognise how to solve a problem (Livingston, 1997).

Since its original conception metacognition has been simply defined as "thinking about thinking" or "knowing about knowing" (Livingston, 1997). However, as will be discussed, many other authors offer wider definitions of the term. These various approaches highlight that the concept has many components, which can be interpreted in a number of different ways. An example of some of the works defining metacognition are summarised in Table 2-1.

\begin{tabular}{|l|l|}
\hline Author(s) & Definition \\
\hline Jacobs and Paris, & $\begin{array}{l}\text { "..we define metacognition as any knowledge about cognitive } \\
\text { states or processes that can be shared between individuals. That is, } \\
\text { knowledge about cognition can be demonstrated, communicated, } \\
\text { examined and discussed" (p. 258) }\end{array}$ \\
\hline $\begin{array}{l}\text { Cross and Paris, } \\
1988\end{array}$ & $\begin{array}{l}\text { "The knowledge and control children have over their own thinking } \\
\text { and learning activities" (p. 131) }\end{array}$ \\
\hline Hennessey, 1999 & $\begin{array}{l}\text { "Awareness of one's own thinking, awareness of the content of } \\
\text { processes, an attempt to regulate one's cognitive processes in } \\
\text { relationship to further learning, and an application of a set of } \\
\text { heuristics as an effective device for helping people organise their } \\
\text { methods of attack on problems in general" (p. 3). }\end{array}$ \\
\hline $\begin{array}{l}\text { Holton and Clarke, } \\
2006\end{array}$ & $\begin{array}{l}\text { "By metacognition we mean any thinking act that operates on a } \\
\text { cognitive thought in order to assist in the process of learning or the } \\
\text { solution of a problem." (p.133) }\end{array}$ \\
\hline
\end{tabular}

Table 2-1: Definitions of metacognition

While these works provide some clarity of the field, the work by Flavell (1976, 1979, 1987) will be used as a foundation for the current study. Flavell's work was fundamental in understanding the features of metacognition.

Flavell's (1976) definition will be used as the main definition in this study, which is: 
In any kind of cognitive transaction with the human or non-human environment, a variety of information processing activities may go on. Metacognition refers, among other things, to the active monitoring and consequent regulation and orchestration of these processes in relation to the cognitive objects or data on which they bear, usually in service of some concrete goal or objective (p. 232)

According to Flavell $(1979,1987)$, and many other authors (Cross \& Paris, 1988; Schraw \& Moshman, 1995; Whitebread et al., 1990), metacognition has two constituent parts: knowledge of cognition and regulation of cognition.

Flavell (1979) defines knowledge of cognition as ones knowledge about their own cognitive strengths and limitations. Flavell breaks this concept down further into three classes: person, task, and strategy. The person class refers to how people, as cognitive processors, think (Haynie, Shepherd, Mosakowski, \& Earley, 2010; Scott \& Levy, 2013). An example of this is the belief that you understand complex equations or that you understand a piece of writing. The task class refers to how knowledge is used differently in a variety of contexts. It incorporates how the nature of the information will affect how it is used or dealt with (Flavell, 1979; Scott \& Levy, 2013). Lastly, the strategy class refers to procedures for ensuring that an appropriate strategy is used for a particular situation or to achieve a desired goal. This section also incorporates both the person and task classes (Scott \& Levy, 2013).

The regulation of cognitive encompasses the strategies people use to help monitor cognitive progress. These help ensure a cognitive goal, such as understanding a difficult equation, has been met. A person with high metacognitive skill uses actions or strategies to aid and oversee their learning process. In his work, Flavell identified that metacognitive experiences generally foreshadow or follow strategy use. The difference between cognitive strategies and metacognitive strategies is that cognitive strategies help a person to achieve a goal, whereas metacognitive strategies ensure it has been accomplished (Livingston, 1997). 


\subsection{Practice of metacognitive strategies}

The use of metacognitive strategy has been regarded as one of the most powerful tools in the area of cognitive engineering (McKeachie, 1988; Palincsar \& Brown, 1984; Volet, 1991). This is demonstrated in recent studies, many of which have proven the effectiveness of strategy use in improving ability in areas such as learning, mathematical understanding and knowledge and reading comprehension (e.g. Akbaria, Khayerb, \& Abedi, 2014; Garner, 1987; Goos \& Galbraith, 1996; Kolić-Vehovec \& Bajšanski,, 2001; Montague, 1992). Examples of some metacognitive strategies include: self-questioning, think aloud (verbalisation), visualisation, double-entry journals, self-administered checklists, and portfolio registries (Fogarty, 1994; Gilbert, 2005). For the purpose of this study, the metacognitive strategies "think aloud" and "visualisation" will be discussed.

\subsubsection{Think aloud}

Originally popularised by Newell and Simon (1972) and legitimised by Ericsson and Simon (1980), think aloud is a method used to get people to say aloud what is passing through their head while reading or completing a task (Katalin, 2000). Development of the think aloud strategy occurred in the 1930s when Otto Selz, a cognitive psychologist, used the think aloud method to study creative reasoning processes (Van Someren, Barnard, \& Sandberg, 1994). Furthermore, in the 1940s, de Groot (1946) used the think aloud method to study the thought processes of chess masters, and in the 1960s the University of Amsterdam offered a course in think aloud designed by Jan J. Elshout and his colleagues (Van Someren, Barnard, \& Sandberg, 1994). The think aloud method is now based in the field of cognitive psychology (Charters, 2003).

Despite this, it wasn't until the 1980s that think aloud was actually defined and established as a legitimate qualitative research methodology through the work of Ericsson and Simon (1980). Ericsson and Simon contributed to the current research on the think aloud methodology by providing an in-depth discussion on the validity of the method. Since then the think aloud method has allowed researchers to gain a more direct view of the processes people engage in while reading and examining a piece of text (Katalin, 2000). It has been established that verbalisation increases learning abilities, as a number of studies show that students who are more vocal and ask more questions are more likely 
to enhance their understanding of a particular topic, issue, or problem-solving situation (Bereiter \& Bird, 1985; Henjes, 2007; Teong, 2003).

Think aloud has also been directly assessed with regards to metacognition in a number of studies across the past two decades. For example, McKeown and Gentilucci (2007) examined the think aloud strategy as a metacognitive strategy for improving comprehension of expository text, Bannert and Mengelkamp (2008) assessed whether or not metacognitive skills, using think aloud, effected learning, and Montague and Applegate (1993) assessed the relationship between verbalisation (think aloud) and overall mathematical performance.

\subsubsection{Visualisation}

While there is a lack of clarity surrounding the definition of visualisation, for this study's purpose it will be regarded as an activity and/or a process of physically or mentally creating a visual and/or graphical representation of something (Bishop, 1989; Vavra et al, 2011). The process of physically creating a mental image encompass the "what" and the "how" of visualisation (the "what" referring to the product, object, or visual image and the "how" referring to the process or activity) whereas mentally creating a visual image can be defined as "the process of creating a graphical representation or as a synonym for visual imagery" (Vavra et al, 2011, p. 22).

Visualisation is important as it can help learners develop a consciousness of their mental representations, "which may help foster conceptual change and knowledge transfer" (Wang \& Jacobson, 2011, p. 1). In relation to visualisation as a visual process Harvey and Goudvis (2007) note that "when we create scenarios and pictures in our minds while reading, our level of engagement increases and our attention doesn't flag” (p. 7). Visualisation also allows the reader to 'see' what is happening, where they can run a scenario in their head to gain a better comprehension of it. Other the other hand, in relation to visualisation as a physical process, drawing is said to be a powerful tool for both thinking and communicating (Roam, 2009) and has been shown to improve learning (Van Meter, 2001; Van Meter, Aleksic, Schwartz, \& Garner, 2006). 
Visualisation has been examined in a number of research domains, with numerous studies showing the positive effects of visualisation. For example, authors such as Rapp and Kurby (2008), Arroio and Honorio (2008) and Ferreira and Arroio (2009) discuss visualisation in relation to science education to help understand how visual representations are transferred into knowledge, to assess the skills that it takes to interpret and process an image, and to see the significance of training mental models. Visualisation has also been observed in relation to students' reading abilities and mathematical achievement, for example in studies such as Booth and Thomas (1999) and Rubman and Salatas Walters (2000), where it is shown that there positive correlations between visualisation and an increase in students' abilities.

For the current study, in regards to visualisation as a physical process, it is particularly important to distinguish between pictorial and schematic visualisations. Jacobse and Harskamp (2012) describe the difference between the two. Schematic visualisations are "an expression of sophisticated metacognitive regulation in mathematical problem solving, especially giving insight in the episodes of analysing and exploring a problem" (p. 163). Schematic visualisations include sketches, diagrams, or schema. In comparison, pictorial visualisations are said to show low metacognitive regulation, where participants do not yet understand how to explore the problem.

\subsection{The influence of metacognition on decision making}

Metacognition is important in decision making for a number of reasons. Firstly, the use of metacognitive strategies can prevent a mistake happening again and can help avoid committing too much time or resources to a decision that may be based on untrustworthy or unreliable evidence (Yeung \& Summerfield, 2012). Metacognition can also help regulate information and facilitate the self-reflection of one's cognitive and memory processes (Koriat, 2006). In addition, metacognitive skills include many of the competencies needed for critical thinking, active learning, problem solving, and decision making (Dawson, 2008). Within the complex the business environment, thinking techniques such as metacognitive strategies can be employed so that decision makers can perform effectively in changing and novel contexts (Haynie et al., 2010). 
The relationship between metacognition and decision making has been examined in a number of studies. A summary of examples of such studies is presented in Table 2-2.

\begin{tabular}{|l|l|}
\hline $\begin{array}{l}\text { Ormond, Luszcz, } \\
\text { Bann, and }\end{array}$ & $\begin{array}{l}\text { This study conducted a metacognitive analysis of decision making in } \\
\text { adolescence. }\end{array}$ \\
\hline Kumar (1998) & $\begin{array}{l}\text { This was the first study to look at the influence of metacognition on } \\
\text { hiring decision making. Here Kumar noted that "knowledge of } \\
\text { cognition explains the reflective aspect of decision-making" (pp. 66- } \\
\text { 67). Knowledge of cognition includes three subcomponents, 1) } \\
\text { procedural knowledge, 2) declarative knowledge, and 3) conditional } \\
\text { knowledge. }\end{array}$ \\
\hline $\begin{array}{l}\text { Enos, Kehrhahn, } \\
\text { and Bell (2003) }\end{array}$ & $\begin{array}{l}\text { This study highlighted that metacognitive knowledge and self- } \\
\text { regulation can influence managers' learning capabilities and the } \\
\text { ability to transfer learning. They believe managers' metacognitive } \\
\text { skills need to be developed in order to "engage in informal learning } \\
\text { opportunities and effectively transfer skills that they have learned" (p. } \\
\text { Sharfman (2011). }\end{array}$ \\
\hline $\begin{array}{l}\text { Yeung and } \\
\text { Summerfield }\end{array}$ & $\begin{array}{l}\text { This study discussed confidence and error monitoring in regards to } \\
\text { metacognition and decision making. } \\
\text { erratic strategic decision making. The results indicated a positive } \\
\text { relationship between metacognition and decision making, where } \\
\text { managers with greater metacognitive experience (which involves the } \\
\text { use of metacognitive strategies or regulation (Brown, 1987)) make } \\
\text { fewer erratic decisions. }\end{array}$ \\
\hline This study compared the metacognitive experience of managers to \\
\hline
\end{tabular}

Table 2-2: Studies assessing decision making and metacognition

More specifically, a number of studies have shown how the three components of decision making that the current study addresses (problem solving, memory retention, and lateral thinking) are affected by metacognition. In relation to problem solving, works by authors 
such as Swanson (1990), Teong (2003), and Sahin and Kendir (2013) show that metacognition positively impacts the problem-solving ability of participants. Authors such as Whitebread (1999), Autin and Croizet (2012), and Partanen, Jansson, Lisspers andd Sundin (2015) assessed the effect of metacognition on working memory, with results from their studies showing that metacognition can increase working memory capability. Lastly, authors such as Runco and Chand (1995) and Hargrove (2013) assessed the significance of metacognition on creative ability. The findings from these studies indicate a strong relationship between metacognition and creative ability.

\subsection{Summary}

The literature provides evidence that metacognition can aid decision-making ability amidst complexity. However, there is still an area within the literature bridging metacognition and decision making that is nascent. This study aims to address this area and add to the literature within the field of organisational cognitive neuroscience and cognitive neuroscience that supports the relationship between decision-making and metacognition, within a business setting. It is suggested that this is an important contribution because the increasing complexity of the business world. Understanding the nature of the complexities of the business environment and encouraging strategy use may provide better outcomes for business decision making. 


\section{Chapter 3: Conceptual framework}

As discussed, one of the underlying assumptions of this study is that research in the area of neuroscience can give insights in the realm of business, in particular decision making. Therefore, this study is part of a bigger "cognitive revolution" (Hannah et al., 2013, p. 406) which looks at management from a more biological perspective. Research in this area has bought a better understanding of people's mental processes and how these can explain human behaviour and effectiveness (Hannah et al., 2013). The theoretical model presented is a graphical representation of the relationship between metacognition and decision making. This model aims to provide greater insight into the cognitive function of metacognition and to offer a model that is generalisable to a larger population.

\subsection{Theoretical model}

As discussed in Chapter 2, the application of metacognitive strategies leads to enhanced decision making. This chapter brought to light a number of studies that examined this relationship to provide insight into the influence of metacognition on decision making. For example, Kumar (1998) discussed decision making in response to hiring, Ormond and colleagues (1991) discussed decision making in adolescence, and Mitchell, et al. (2011) discussed erratic strategic decision making. Other studies, such as Swanson (1990), Whitebread (1999), and Hargrove (2013), have also shown that metacognition can affect the three components of decision making that are assessed within this study: lateral thinking, problem solving, and decision making.

Based on this previous research a theoretical model is proposed. This theoretical model, shown in Figure 3-1, depicts the influence of the application of metacognitive strategies on decision-making ability. This model provides an opportunity to gain insight at a theoretical level into the dynamics of specific cognitive processes that can enhance decision-making ability. 


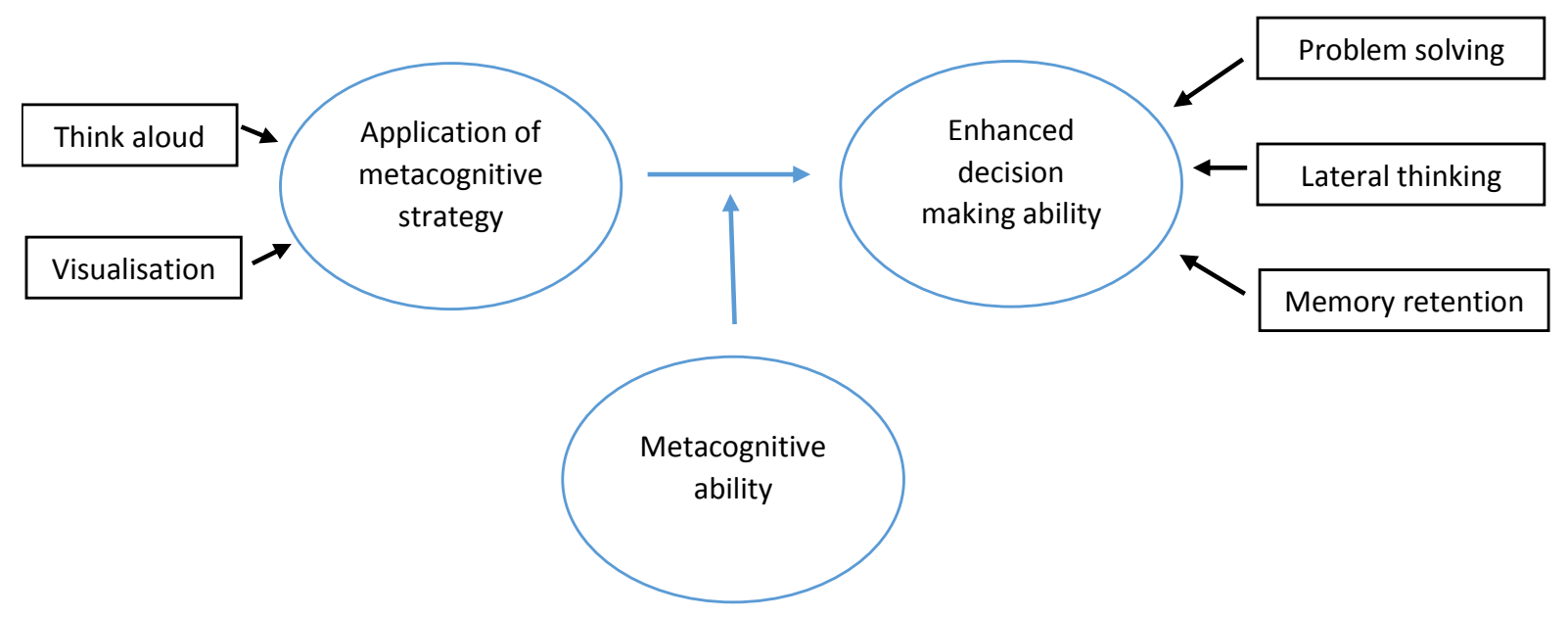

Figure 3-1: Research model

\subsection{The constructs of the theoretical model}

The constructs in the model (Figure 3-1) are defined as follows:

Application of a metacognitive strategy - For the purpose of the study, application of a metacognitive strategy refers to the application of think aloud or visualisation, notwithstanding these are two of several metacognitive strategies. These strategies will be used to increase decision-making ability, for problem solving, lateral thinking, and memory retention of the participants in the experimental group.

Enhanced decision making - This construct is measured by the participants' problem solving, lateral thinking, and memory retention abilities. These three sub-components will be the independent variables of the enhanced decision-making construct. This construct will be discussed in further detail in the next chapter.

Metacognitive ability - For the purposes of this study, this relationship will be moderated by a base level of metacognitive ability. Research has found that different individuals vary in metacognition ability (their ability to think about what they are thinking) and therefore it is important to understand which participants may have a priori ability to metacognate. 


\subsection{Operational model}

The operational model is presented in Figure 3-2 to detail the application of the metacognitive strategies think aloud (the process of saying aloud what you are thinking while reading or competing a task (Katalin, 2000)) and visualisation (the process of graphical depiction (Vavra et al., 2011)) with regards to the three decision-making components. Each of the components of decision making are assessed differently. Problem solving is assessed through five problem solving questions, memory retention is assessed through a hiring scenario, and lateral thinking is assessed through a mathematical problem. While these assesments (the questions within the questionnaire) are not largely business questions, as this study does not focus on decision making in a business context, they are generic decision making questions undertaken by business students. A more in-depth explanation of each variable is offered in Chapter 4.

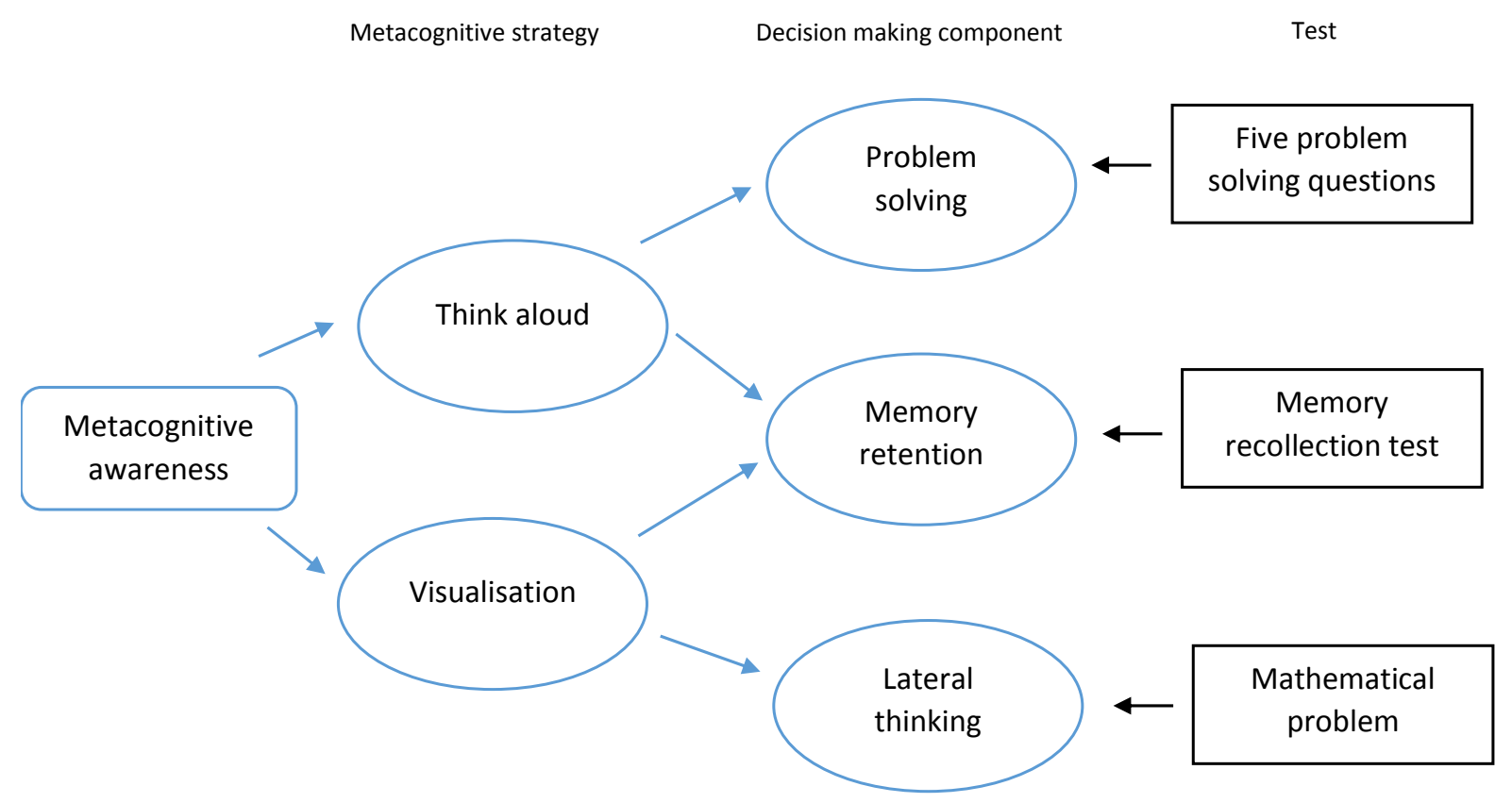

Figure 3-2: Operational model

\subsection{Research hypotheses}

The research question posed in Chapter 1: "To what degree does an understanding of the cognitive process of metacognition lead to enhanced business decision-making ability" is expanded upon in this section through hypothetical relationships that will be tested. The testing of these hypotheses will be through the methods and procedures described in 
Chapter 4. Three main hypothetical relationships arise from the operational model. These hypotheses are as follows:

Hypothesis 1 - Participants who have been encouraged to think aloud (the experimental group) will score higher on the problem-solving test relative to the control group.

Hypothesis 2 - Participants who have been encouraged to both visualise and think aloud (the experimental group) will exhibit higher memory retention than those in the control group.

Hypothesis 3 - Participants who have been encouraged to visualise (the experimental group) will score higher in lateral thinking ability than those in the control group.

While these hypothetical associations are the focus point of the research investigation of other possibilities is not precluded. Therefore, in addition to these hypothesised relationships, other avenues of the research are also explored, for example, the consideration of demographic influences. 


\section{Chapter 4: Methodology}

This chapter provides a discussion of the methodological underpinnings of the research. The chapter begins with a brief discussion of the research paradigm, positivism. It then discusses quantitative and experimental research, which the positivist paradigm supports. Finally, the chapter describes the research design, including the procedures, sampling, instruments used, data gathering and analysing techniques, and ethical considerations.

\subsection{Paradigm}

The current study aims to examine the relationship between metacognition and decision making, therefore, a positivist approach was considered most appropriate. The positivist paradigm aims to finds a cause and effect relationship between two variables (Baxter \& Babbie, 2003). Positivism is, in nature, built on the assumption "that features of the social environment constitute an independent reality and are relatively constant across time and settings" (Gall, Gall \& Borg, 2003, p. 23). A positivist research paradigm believes that the world is external (Carson, Gilmore, Perry \& Gronhaug, 2001) and that a single objective reality exists that can be exposed by the researcher(s) using a scientific method of analysis (Frey \& Cissna, 2009). Governed by stated hypotheses and theories, positivist research focuses on describing and explaining through observation and measurement (O'Leary, 2004; Mackenzie \& Knipe, 2006). Therefore, the positivist paradigm involves applying the scientific methodology (Mukherji \& Albon, 2009). Taken directly from Mukherji and Albon (2009), the scientific method includes:

1. "Observation and collection of data,

2. Looking for patterns and developing a theory,

3. Forming a hypothesis to test the theory,

4. Conducting research to test the hypothesis, and

5. Support or adjustment of the theory" (p. 17).

\subsection{Quantitative research}

As positivism aligns with a scientific research approach, it lends itself to the use of quantitative methodology (Mackenzie \& Knipe, 2006; Mukherji \& Albon, 2009). 
Quantitative research involves collecting numerical data and analysing this data through mathematically based methods, such as statistics (Aliaga \& Gunderson, 2003). Quantiatitve research aims to generate explanations and predictions that will be applicable to other persons and places and arrive at more objective conclusions (Matveev, 2002; Williams, 2011). According to Leedy and Ormrod (2001) the intent is to "establish, confirm, or validate relationships and to develop generalisations that contribute to theory" (p. 102).

Although positivism also lends itself to the use of qualitative methodology, quantitative research was most appropriate for this study. This is primarily because of the nature of the study, as the researcher wanted to determine the extent to which metacognition had an effect on problem solving, memory retention, and lateral thinking ability. Quantitative methodology can measure this numerically through collecting numerical data, which can then be analysed through a number of statistical tests to determine cause and effect.

\subsection{Variables}

Quantitative research "is a means for testing objective theories by examining the relationship among variables" (Creswell, 2009, p. 4). Variables in this instance are defined as characteristics or attributes of either an individual or an organisation that can be measured or observed (Creswell, 2005; McFarland, 2013). The study of variables helps determine whether there is a relationship between them, directly addressing the research question. (Arnold, 2008). Variables also operationalise the constructs being studied (Drotar, 2013). Quantitative research generally examines at least two types of variables: independent and dependent (Creswell, 2005). The distinction between the two is essential, as independent variables are those that affect outcomes, whereas dependent variables are the outcomes or resulting from the influence of the dependent variable(s) (Creswell, 2009). Within this study the independent construct is the application of metacognitive strategies; the independent variables are the strategies think aloud and visualisation. The dependent construct is enhanced decision making; the dependent variables are problem solving, lateral thinking, and memory, which are measured through the questionnaire. 


\subsection{Experimental research}

The positivist research paradigm also supports the use of experimental methodology, as positivist research relies on the collection of empirical data (Mukherji \& Albon, 2009). Experimental research is an effective and appropriate method for obtaining information and drawing causal assumptions about instructional intervention (Odle \& Mayer, 2009). The purpose of experimental research is to determine the relationship between the independent variable and a dependent variable (Withrow, 2013). In particular, this study is an example of a quasi-experiment, which is founded on a positivist paradigm and can be used to determine casual relationships. The use of a quasi-experiment aims to evaluate the impact of a factor or factors on the participants of the experiment (Shadish, Cook \& Campbell, 2002).

\subsection{Setting, participants and sample description}

The sample used for this project was 90 students from four different business school classes at Victoria University of Wellington; 46 from MGMT320, 18 from MGMT202, 17 from HRIR201, and 9 from PUBL305, as shown in Table 4-1. The classes were each divided roughly in half to create a control group and an experimental group. There were 44 participants in the control group and 46 participants in the experimental group.

Demographic assessment was kept to a minimum because of time constraints. The only demographic factor that the participants were asked to identify was gender. There were 52 female participants and 38 male participants, as shown in table 4-2.

\begin{tabular}{|l|l|l|l|}
\hline & Control & Experiment & Total \\
\hline MGMT320 & 21 & 25 & 46 \\
\hline MGMT202 & 8 & 9 & 17 \\
\hline HRIR201 & 9 & 9 & 18 \\
\hline PUBL305 & 6 & 3 & 9 \\
\hline Total & 44 & 46 & 90 \\
\hline
\end{tabular}

Table 4-1: Control group and experimental group numbers 


\begin{tabular}{|l|l|l|l|}
\hline & Male & Female & Total \\
\hline MGMT320 & 21 & 25 & 46 \\
\hline MGMT202 & 6 & 11 & 17 \\
\hline HRIR201 & 10 & 8 & 18 \\
\hline PUBL305 & 1 & 8 & 9 \\
\hline Total & 38 & 52 & 90 \\
\hline
\end{tabular}

Table 4-2: Gender participant numbers

\subsection{Data collection}

Students were informed about the experiment through a notification on Blackboard, Victoria University's student website. This post explained that the researcher was coming at the end of their class to conduct a voluntary experiment. The students that stayed behind after class gave informed consent to participate in the project. Due to the timing and availability of the classes, the experiments were conducted on different days.

Data was collected between the $15^{\text {th }}$ of October and the $2^{\text {nd }}$ of December 2015. The researcher collected the data herself from each of the four classes. The questionnaires were collected as soon as the participant put up their hand to signal they had finished. This was to ensure that the participants did not go over the questions again, as this may have affected the results of the study. Participants were also asked to stay until the final questionnaires were collected, in order to discourage the participants, particularly those in the experimental group, from rushing the questionnaire.

Instructions for the experiment were projected on the whiteboard at the front of the class and were also explained verbally; refer to Appendix A. The participants were simply asked to answer the questions based on the instructions given in the questionnaire. They were not informed about the nature of the study before the experiment began. It was only at the end of the experiment when the participants were given an information sheet that they were made aware of the nature of the study. The information sheet - refer to Appendix B - explained that the experiment was testing participant's' metacognitive ability. Therefore, it deliberately was not given to the participants before the experiment began in case this information influenced them in any way. 
The completion time for the experiment ranged from 8 to 30 minutes, as shown in Table 4-3. The control group was generally faster than the experimental group. On average, it took the control group 15.14 minutes to finish the questionnaire, whereas it took the experimental group on average 18.75 minutes to finish. This was expected, as the experimental group was given more detailed instructions that encouraged them to think about the questions in more depth.

\begin{tabular}{|l|l|l|l|}
\hline & $\begin{array}{l}\text { Control average } \\
\text { time (minutes) }\end{array}$ & $\begin{array}{l}\text { Experiment average } \\
\text { time (minutes) }\end{array}$ & Range \\
\hline MGMT320 & 14.57 & 18.21 & $8-24$ \\
\hline MGMT202 & 14.28 & 24.00 & $5-30$ \\
\hline HRIR201 & 16.44 & 15.78 & $11-22$ \\
\hline PUBL305 & 16.17 & 16.00 & $14-20$ \\
\hline $\begin{array}{l}\text { Total } \\
\text { average }\end{array}$ & 15.14 & 18.75 & \\
\hline
\end{tabular}

Table 4-3: Experiment completion time

\subsection{The intervention}

The questions given to both the control and experimental groups were exactly the same; however, the two groups were given a different set of instructions for each section - refer to Appendix C and Appendix D. The control group was given basic instructions; for example, to read the problems and answer the questions, whereas the instructions for the experimental group were worded purposefully to encourage metacognitive strategy use. In particular, the instructions aimed to encourage the two different types of metacognitive strategies previously discussed, think aloud and visualisation. By doing so, the researcher created a way in which to test the effect(s) of metacognitive strategy use on decisionmaking ability.

\subsection{Instruments}

\subsubsection{Metacognition Awareness Inventory}

A Metacognition Awareness Inventory (MAI) was used in this study to test participants a prior metacognitive ability. The original MAI, created by Schraw and Dennison (1994), was examined first before creating the questionnaire in order to determine whether the 
instrument would accurately measure metacognitive awareness. This MAI is a 52-item questionnaire that was developed to measure adult metacognitive awareness. The items within the inventory are divided into eight scales, which ultimately assess the two components of metacognition (Schraw and Dennison, 1994). Knowledge of cognition is assessed through the three following factors: declarative knowledge, procedural knowledge, and conditional knowledge and regulation of cognition is assessed through the following five factors: planning, information management strategies, comprehension monitoring, debugging strategies and evaluation (Schraw and Dennison, 1994).

While the MAI has been used extensively to assess metacognitive awareness (e.g., Young \& Fry, 2012; Turan, Demirel \& Sayek, 2009) an adapted version by Teo and Lee (2012) was chosen for this study. Teo and Lee assessed the factorial validity of Schraw and Dennison's Metacognitive Awareness Inventory. Results from their study indicate that the eight-scale model does not adequately assess metacognitive awareness. Teo and Lee believe the MAI may be an example of complex model misspecification, "in which a misrepresentation of the relationship between items and factors has occurred" (p. 92). In response to their results, Teo and Lee proposed a 21-item, three factor model; refer to Appendix E. After an Exploratory Factor Analysis and a Confirmatory Factor Analysis the 21 remaining items were internally consistent. The findings from their analysis indicate that their adapted MAI is an acceptable model fit.

The participants were asked to answer the questions as honestly as they could and were given a five-point Likert scale measure to record the extent to which they believe each question is true or false, with 1 being always true and 5 being always false. The lowest score, 21, indicated the highest perception of metacognitive awareness. The highest score, 105 , indicated the lowest perception of metacognitive awareness. The data was used to see if there was a difference in metacognitive awareness. It was hoped that the total MAI scores from each group would be the same, as this would mean that neither group had greater metacognitive awareness, or perceived awareness, prior to the study. However, as metacognition has been shown to be a predictor of academic achievement (Dunning, Johnson, Ehrlinger \& Kruger, 2003; Koçak \& Boyacı, 2011), it was important to determine the metacognitive ability of participants in case participants who had higher metacognitive ability scored greater than those who did not, regardless of what group they were in. 


\subsubsection{Questionnaire}

A questionnaire was developed for the study by the researcher. The questionnaire contained four sections. The first section comprised five basic questions, next was a hiring scenario, followed by a lateral thinking question. Last was a memory recollection test based on the second section. The questions used in the questionnaire aimed to assess the decision-making ability of participants. The participants were told that they should not return to any question once they had completed the section.

The questionnaire booklet included both the questions and the MAI. The MAI was at the back of the questionnaire booklet and was completed once all questions had been answered to the participant's best ability. The instructions for the MAI specifically stated that it was an assessment of their metacognitive ability; therefore, the booklet was set out in this specific order to ensure that the MAI did not influence the participants in any way.

\subsection{Rationale for question formulation}

The questions were chosen to specifically test participants' decision-making ability in three areas of decision making: problem solving, memory retention and lateral thinking.

Section A consisted of five short-answer brain teasers. While brain teasers are simple, they exemplify a number of idiosyncrasies that affect decision-making ability. The control group was simply asked to read and answer the question, whereas the experimental group was asked to think aloud and repeat the questions as many times as they needed in their head. The questions used for section A were taken from an online article by Holly Green (Green, 2012) and from the website of Kepner-Tregoe, a multinational management consulting and training services company (Kepner-Tregoe, 2013). It was hoped that encouraging the experimental group to use the metacognitive strategy think aloud would increase problem solving ability.

The second section was a hiring scenario where the participants were asked who they would hire for a cleaning position, either Mary or Jack. There was a short paragraph describing each candidate, including their job history, heritage, hobbies, and general background information. The control group was told to read the information and answer 
the question, whereas the experimental group was asked to visualise a conversation with both Mary and Jack and role-play the scenario in their head. This question was linked with Section D, which asked the participants to recall as much information about Mary and Jack as they could. Section B and D were not taken from a previous study or from online; rather these sections were created by the researcher to test memory retention and recollection. The experimental group was encouraged to use visualisation, in particular visual imagery (imaging scenarios in the mind), in the hope that it would increase the participant's memory retention and recollection.

Section $\mathrm{C}$ was a lateral thinking problem taken from a study by Lester, Garofalo and Kroll (1989) that considers non-routine problems and observed the role of metacognition in mathematical problem solving. Types of non-routine problems are "problems with superfluous information, problems with insufficient information, and process problems" (Boekaerts, Pintrich, \& Zeidner, 2005, p. 707). Section C is an example of a process problem, where the solution to the problem requires the problem solver to do more than just "translate words to a mathematical expression, or apply an algorithm, or perform computations" (Lester et al., 1989, p. 30). Here the use of lateral thinking can be beneficial, as lateral thinking produces solutions that traditional modes of thinking may ignore. The control group was told to simply answer the question, whereas the experimental group was told to draw a map to visualise the question to help solve it. It was hoped that visualising the problem, through drawings, would increase the lateral thinking ability of the participants.

\subsection{Data analysis}

The researcher entered the data into SPSS v22.0 for analysis. An analysis plan, detailed in Table 4-4, was created before the data analysis to determine the appropriate steps to take.

\begin{tabular}{|l|l|}
\hline Stage & Action taken \\
\hline 1 & $\begin{array}{l}\text { Data was cleansed, and wrong and unfit data removed. A normality test was then } \\
\text { conducted to ensure the data set was well-modelled by a normal distribution. }\end{array}$ \\
\hline 2 & A preliminary analysis was conducted to determine the mean and variance of the data. \\
\hline 3 & Scale reliability was addressed using Cronbach's alpha \\
\hline
\end{tabular}




\begin{tabular}{|l|l|}
\hline 4 & $\begin{array}{l}\text { A t-test was conducted to determine whether the means of two groups were statistically } \\
\text { different. }\end{array}$ \\
\hline 5 & $\begin{array}{l}\text { An ANOVA test was conducted to determine if there was a significant difference } \\
\text { between the means of the groups. }\end{array}$ \\
\hline 6 & $\begin{array}{l}\text { A correlation table was created in order to investigate the association between multiple } \\
\text { variables. }\end{array}$ \\
\hline
\end{tabular}

Table 4-4: Analysis plan

\subsection{Ethical considerations/approval procedures}

Official approval was given for this research by the Pipitea Sub-Committee of the Human Ethics Committee. Correct procedures were taken to ensure the safekeeping of the results from the experiment. Results were kept in a secure locker at the Victoria University Pipitea Campus and will be kept there for 2 years. Participants were instructed twice to not disclose any personal information on the questionnaire booklet to ensure the responses to the questionnaire were anonymous.

\subsection{Summary}

This chapter presented the methodical approach of this study and provided rationale for the chosen methodology. A quantitative approach involving an experimental design was deemed most appropriate to examine and measure the effect of metacognitive strategy use on decision-making ability. Data from the results of the study was digitally recorded and analysed using a number of tests. The data collected from the experiment was used to validate the hypotheses set forth for this study. The next section, Chapter 5, will present the results of the data collection and analysis. 


\section{Chapter 5: Results}

As described in Chapter 1, the purpose of this study is to examine the relationship between metacognition and decision making with regards to three specific decision-making components: problem solving, memory retention and lateral thinking. This chapter analyses the data collected from the results of the experiment, detailed in Chapter 4, and measures it against established hypotheses. The three hypotheses presented in this study aim to determine whether there is a difference in decision making ability between the control group and the experimental group. It is expected that the experimental group will score higher in Section A, C and D of the questionnaire, exhibiting greater problem solving, memory retention, and lateral thinking ability. Encouraging participants to use particular metacognitive strategies will facilitate this ability. The hypotheses guiding this research are as follows:

Hypothesis 1 - Participants who have been encouraged to think aloud (the experimental group) will score higher on the problem-solving test relative to the control group.

Hypothesis 2 - Participants who have been encouraged to both visualise and think aloud (the experimental group) will exhibit higher memory retention than those in the control group.

Hypothesis 3 - Participants who have been encouraged to visualise (the experimental group) will score higher in lateral thinking ability than those in the control group.

The findings from this analysis help understand the cognitive process of metacognition. The findings also address relevant metacognitive strategies that can be harnessed to improve decision-making ability. To explore the findings, the chapter first presents a preliminary analysis of the quantitative data. Next, the results are validated through a series of statistical tests that determine statistical significance. Finally, a summary of the quantitative findings are presented as a preliminary to Chapter 6 , which consists of a discussion of the results. 


\subsection{Preliminary analysis}

The results from the questionnaire were entered into SPSS and examined for missing data. The data contained 44 responses from the control group and 46 responses from the experimental group. 52 participants were female and 38 were male. The researcher coded the data appropriately and then added this value as a discrete missing variable in SPSS to ensure missing data was not wrongly included in numeric calculations. 3 participants did not complete the MAI $(\mathrm{n}=87)$, and 2 did not provide the time it took for them to complete the questionnaire $(n=88)$. However, the rest of the data from these questionnaires was robust, therefore their results were kept for analysis. The researcher also coded the data for section C, as well as gender and group. The coding is shown in Table 5-1.

\begin{tabular}{|l|l|}
\hline Variable & Coding \\
\hline Group & $\begin{array}{l}0=\text { control } \\
1=\text { experimental }\end{array}$ \\
\hline Section C & $0=$ incorrect \\
& $1=$ correct \\
\hline Gender & $0=$ Female \\
& $1=$ Male \\
\hline
\end{tabular}

Table 5-1: Coding for the nominal variables

Once coding was complete, the researcher tested the data to ensure that there were no significant outliers and that the data fitted within a normal distribution. A number of histograms were created for each section of the questionnaire, as well as for the MAI. These histograms were examined, where the tails of the distribution were checked for data points that fell away as extremes. This test revealed that there were no significant outliers, therefore no results were removed.

An analysis of the histograms also revealed the degree of skewness and kurtosis in the data. These results helped determine normality. The coefficient of skewness measures the departure from symmetry and/or the degree of asymmetry of observations around the mean (Spiegel, 1961). Jain and Sandhu (2009) note that "its presence tells us that the 
value of mean, median and mode are not equal and quartiles are not equidistant from median" (p. 3.2).

The distribution of values is positively skewed if there is a positive coefficient of skewness and vice versa, where the distribution is negative if there is a negative coefficient of skewness (Evans \& Lindsay, 2012). Data can be treated as being normally distributed if skewness is between -0.5 and +0.5 (King, 2016). Results of the skewness test revealed that a variation in the degree of skewness within the data. For example, the data for the problem-solving section produced a skewness statistic of $\mathrm{SE}=0.164$, which falls well within the range for skewness. However, some data did show a slight negative skewness, such as the time data $(\mathrm{SE}=.707)$ and the MAI score data $(\mathrm{SE}=1.115)$.

Kurtosis is a measure of how flat or peaked the data is but can be further defined as "the fourth central moment of profile amplitude probability density function, measured over the assessment length" (Gadelmawla et al., 2002, p. 137). Data can be assumed to be normally distributed if kurtosis is between -0.5 and +0.5 (King, 2012). The results of the analysis revealed a slight positive kurtosis of the data in the problem-solving section (kurtosis = -.992) and MAI (kurtosis = 1.818) section. However, for the rest of the data the kurtosis was close to zero. An example of the skewness and kurtosis test can be found in Figure 5-1 and Figure 5-2.

In conclusion, from the analysis of the skewness and kurtosis of the data that it can be concluded that the distribution of the data can be treated as normal. 


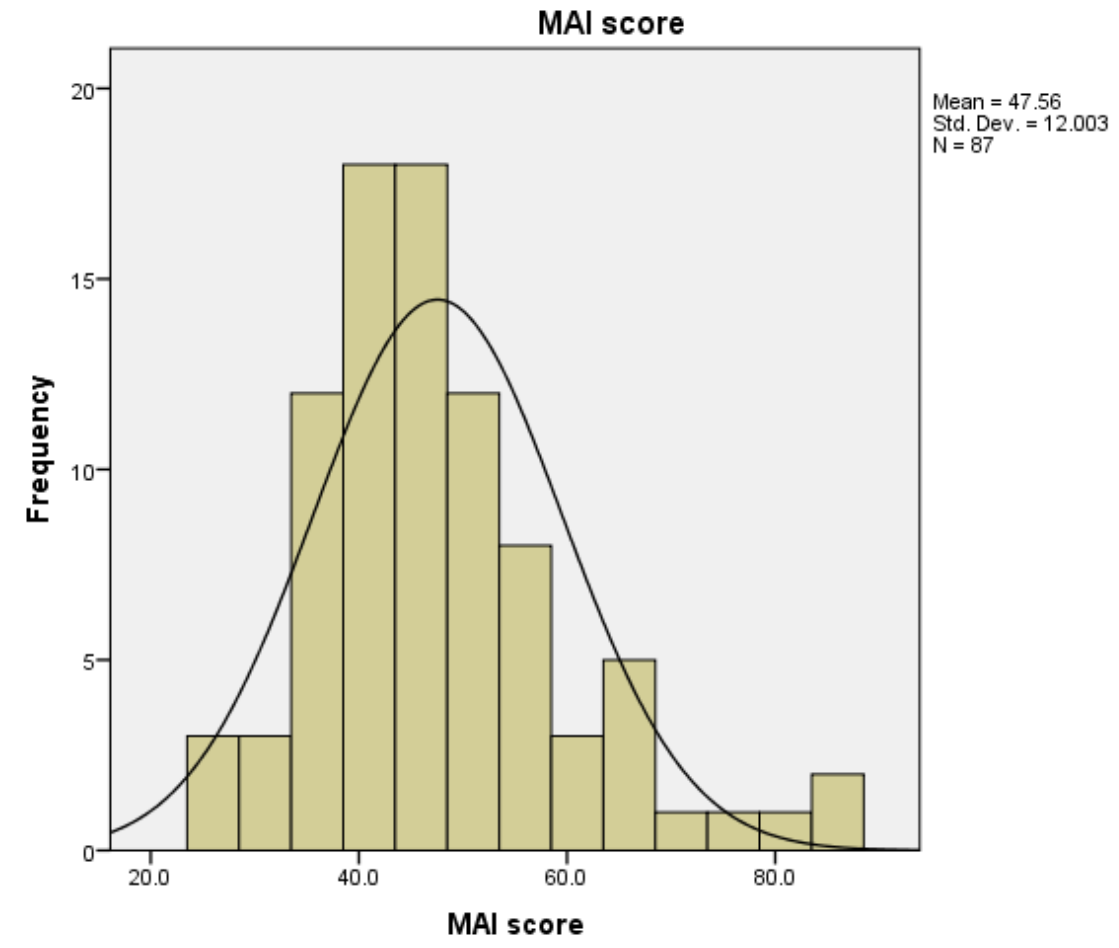

Figure 5-1: MAI skewness and kurtosis distribution

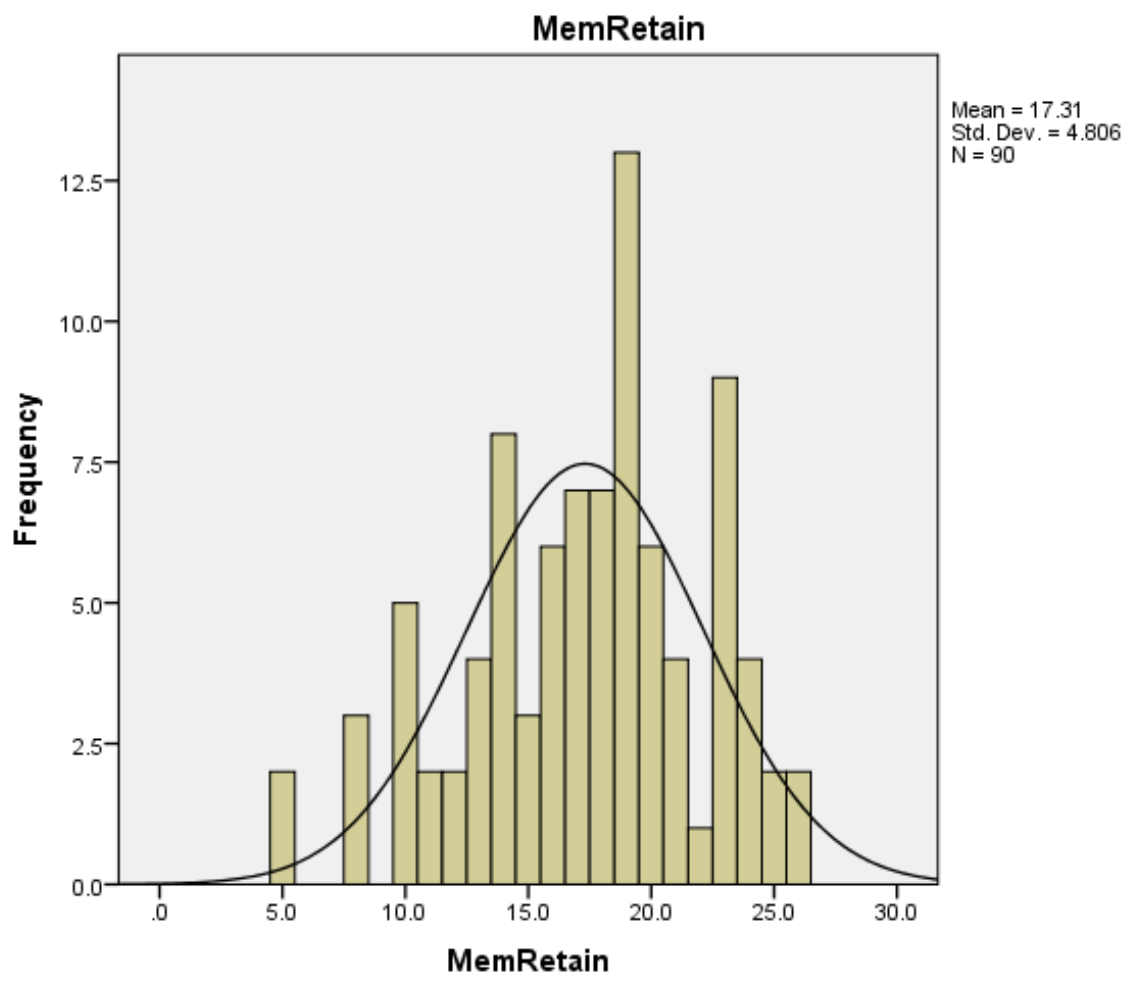

Figure 5-2: Memory retention skewness and kurtosis distribution 
Next a Cronbach's alpha test (Cronbach, 1951) was conducted on the MAI to ensure adequate internal consistency reinforced the reliability of the inventory. A Cronbach's alpha test is the most extensively used reliability statistics test (Tavakol \& Dennick, 2011). The standardised Cronbach's Alpha test tests the internal consistency or average correlation of items to determine reliability (Santos, 1999).

The alpha coefficients range from 0 to 1 , the latter score indicating greater reliability (Santos, 1999). In his work, Nunnally (1978) created a rule of thumb in which he states a score greater than 0.7 to be an acceptable level of reliability. The Cronbach's alpha test conducted on the 21 items in the MAI revealed a reliability score of 0.892 , therefore the scale was a reliable measure.

\subsection{Descriptive statistics}

Descriptive statistics, which include the range, mean, and standard deviation, were conducted on the data from both the control group and the experimental group. Table 52 presents the combined results of both groups. Table 5-3 and 5-4 present the results of the control and experimental group separately. Data from Section B was not analysed, as Section B aided Section D. Therefore, the results from Section B were extraneous.

\begin{tabular}{|l|l|l|l|l|l|l|}
\hline & $\mathrm{N}$ & Range & Minimum & Maximum & Mean & Std. Dev \\
\hline Group & 90 & 1 & 0 & 1 & 0.51 & 0.50 \\
\hline PSolve & 90 & 5 & 0 & 5 & 2.01 & 1.44 \\
\hline LatThink & 90 & 1 & 0 & 1 & 0.31 & 0.47 \\
\hline MemRet & 90 & 21 & 5 & 26 & 17.31 & 4.81 \\
\hline Gender & 90 & 1 & 0 & 1 & 0.42 & 0.49 \\
\hline Time & 87 & 22 & 8 & 30 & 16.97 & 4.14 \\
\hline MAI score & 87 & 60 & 26 & 86 & 47.56 & 12.00 \\
\hline
\end{tabular}

Table 5-2: Results of both the control and experimental groups

\begin{tabular}{|l|l|l|l|l|l|l|}
\hline & $\mathrm{N}$ & Range & Minimum & Maximum & Mean & Std. Dev \\
\hline Psolve & 44 & 5 & 0 & 5 & 1.61 & 1.48 \\
\hline LatThink & 44 & 1 & 0 & 1 & 0.34 & 0.48 \\
\hline MemRet & 44 & 19 & 5 & 24 & 16.14 & 5.04 \\
\hline Time & 43 & 14 & 8 & 22 & 15.13 & 3.08 \\
\hline Gender & 44 & 1 & 0 & 1 & 0.43 & 0.50 \\
\hline MAI score & 43 & 59 & 27 & 86 & 47.68 & 12.45 \\
\hline
\end{tabular}

Table 5-3: Control group results 


\begin{tabular}{|l|l|l|l|l|l|l|}
\hline & $\mathrm{N}$ & Range & Minimum & Maximum & Mean & Std. Dev \\
\hline Psolve & 46 & 5 & 0 & 5 & 2.39 & 1.31 \\
\hline LatThink & 46 & 1 & 0 & 1 & 0.28 & 0.46 \\
\hline MemRet & 46 & 16 & 10 & 26 & 18.43 & 4.33 \\
\hline Time & 44 & 19 & 11 & 30 & 18.75 & 4.92 \\
\hline Gender & 46 & 1 & 0 & 1 & 0.41 & 0.50 \\
\hline MAI score & 44 & 55 & 26 & 81 & 47.27 & 11.68 \\
\hline
\end{tabular}

Table 5-4: Experimental group results

Tables 5-2 and 5-3 reveal a difference between the control and experimental group. The control group results for Section A (PSolve) ranged from 0 to $5(M=1.61, S D=1.48)$, whereas the experimental group results ranged from 0 to $5(M=2.39, S D=1.31)$. These results show that those in the experimental group on average scored higher in the problem-solving section than the participants in the control group. This indicates that those who were encouraged to use metacognitive strategies had higher problem-solving ability.

For Section D (MemRetain), the results of the control group ranged from 5 to 25 ( $M=$ $16.14, S D=5.04)$, whereas the results from the experimental group ranged from 10 to 26 $(M=18.43, S D=4.33)$. This shows that participants in the experimental group on average could remember a higher number of attributes about the applicants for the job hiring scenario than those in the control group, indicating the experimental group had better memory retention ability. Both results from Section A and D support Hypothesis 1 and 2. Further tests were carried out to determine the statistical significance of the difference between the two means. These will be discussed in the later paragraphs.

Results from Section C (LatThink) did not reveal a significant difference between the means, therefore Hypothesis 3 was not supported by the initial analysis. On average, the control group scored higher on this problem, indicating that those in the control group had higher lateral thinking ability. However, a further inspection of the returned questionnaires revealed that those who used schematic visualisations, in both the control and experimental groups, were more likely to get the questions correct, as shown in Table 5-5. In total, 16 of the 28 participants who got the question correct, used schematic images to help them solve the question. Moreover, the lack of the use of schematic viualisations or lack of attempting the question can be attributed to the number of incorrect answers. 
The participants in both the control group and the experimental group who got the question incorrect (column 4) either did not attempt to use schematic visualisations to help them solve the question, drew pictorial visualisations, or did not attempt to draw anything.

\begin{tabular}{|l|l|l|l|l|l|}
\hline $\begin{array}{l}\text { Response to the lateral } \\
\text { thinking exercise }\end{array}$ & $\mathrm{N}$ & $\begin{array}{l}\text { Incorrect } \\
\text { answer }\end{array}$ & $\begin{array}{l}\text { Incorrect } \\
\text { answer }\end{array}$ & $\begin{array}{l}\text { Correct } \\
\text { answer }\end{array}$ & $\begin{array}{l}\text { Correct } \\
\text { answer }\end{array}$ \\
\hline Metacognitive strategy & $\begin{array}{l}\text { Visualisation } \\
\text { (schematic) }\end{array}$ & $\begin{array}{l}\text { No } \\
\text { visualisation }\end{array}$ & $\begin{array}{l}\text { Visualisation } \\
\text { (schematic) }\end{array}$ & $\begin{array}{l}\text { No } \\
\text { visualisation }\end{array}$ \\
\hline Control group & 44 & 0 & 29 & 7 & 8 \\
\hline Experimental group & 46 & 4 & 29 & 9 & 4 \\
\hline $\begin{array}{l}\text { Both control and } \\
\text { experimental group }\end{array}$ & 90 & 4 & 58 & 16 & 12 \\
\hline
\end{tabular}

Table 5-5: Section C (LatThink) results

Descriptive statistics for the MAI were also produced. Table 5-6 presents the results of this analysis. The items were individually assessed to determine if participants believed they were more or less able in particular areas of metacognitive knowledge and regulation. This analysis revealed that participants generally believed they had higher IMS (information management strategies) ability; that is, the "skills and strategy sequences used to process information more efficiently (e.g., organising, elaborating, summarising, selective focusing)" (Schraw \& Dennison, 1994, p. 474) and had higher DS (debugging strategy) ability, which is where "strategies are used to correct comprehension and performance errors" (Schraw \& Dennison, 1994, p. 475). They felt less competent in areas such as planning, which includes skills such as "goal setting, and allocating resources prior to learning" (Schraw \& Dennison, 1994, p. 474) and comprehension monitoring, which is the "assessment of one's learning or strategy use" (Schraw \& Dennison, 1994, p. 474). 


\begin{tabular}{|l|c|c|c|c|c|c|}
\hline & $\mathrm{N}$ & Range & Minimum & Maximum & Mean & SD \\
\hline CM4 & 87 & 4.0 & 1.0 & 5.0 & 2.54 & 1.07 \\
\hline EV2 & 87 & 4.0 & 1.0 & 5.0 & 2.228 & 0.95 \\
\hline EV3 & 87 & 4.0 & 1.0 & 5.0 & 2.598 & 1.08 \\
\hline PK4 & 87 & 4.0 & 1.0 & 5.0 & 2.276 & 0.96 \\
\hline PL1 & 87 & 4.0 & 1.0 & 5.0 & 2.793 & 1.14 \\
\hline PL2 & 87 & 4.0 & 1.0 & 5.0 & 2.529 & 1.03 \\
\hline PL2 & 87 & 4.0 & 1.0 & 5.0 & 2.494 & 1.13 \\
\hline PL4 & 87 & 4.0 & 1.0 & 5.0 & 2.632 & 0.98 \\
\hline PL7 & 87 & 4.0 & 1.0 & 5.0 & 2.563 & 1.08 \\
\hline CK4 & 87 & 4.0 & 1.0 & 5.0 & 2.264 & 1.01 \\
\hline CM2 & 87 & 4.0 & 1.0 & 5.0 & 2.256 & 1.00 \\
\hline PL5 & 87 & 4.0 & 1.0 & 5.0 & 2.333 & 1.12 \\
\hline PK1 & 87 & 4.0 & 1.0 & 5.0 & 1.885 & 0.93 \\
\hline CM6 & 87 & 4.0 & 1.0 & 5.0 & 2.034 & 0.95 \\
\hline DS3 & 87 & 4.0 & 1.0 & 5.0 & 1.897 & 0.94 \\
\hline DS4 & 87 & 4.0 & 1.0 & 5.0 & 1.701 & 0.89 \\
\hline IMS1 & 87 & 4.0 & 1.0 & 5.0 & 1.851 & 1.04 \\
\hline IMS3 & 87 & 3.0 & 1.0 & 4.0 & 1.977 & 0.88 \\
\hline IMS6 & 87 & 4.0 & 1.0 & 5.0 & 1.943 & 1.03 \\
\hline IMS7 & 87 & 4.0 & 1.0 & 5.0 & 2.448 & 0.95 \\
\hline IMS8 & 87 & 4.0 & 1.0 & 5.0 & 2.333 & 1.09 \\
\hline
\end{tabular}

Table 5-6: MAI descriptive statistics results

\subsection{T-test and ANOVA test}

The t-test is a parametric test of statistical significance that tests the validity of a hypothesis by comparing the mean differences of two groups (Hair, Wolfinbarger, Money, Samouel, \& Page, 2015; Rubin, 2012). One of the most common t-tests is a t-test for independent means, where the means are considered independent of one another (Martella, Nelson, Morgan \& Marchand-Martella, 2013). A number of t-tests were conducted to determine if the differences in the mean results of the control and experimental groups were statistically significant. The scores from the MAI were tested first, followed by analysing the results of the questionnaire and then an analysis was done of the time taken to complete the questionnaire. The results of the t-tests support the findings revealed from the descriptive statistics.

A one-tailed test was conducted for all t-tests, save for MAI. A one-tailed test is used to determine whether a mean of one group is greater than the mean of other, whereas a twotailed test determines if there is a difference between the two means (Norman \& Streiner, 
2008). As this study was examining whether or not the experimental group's ability was greater than the control group's ability a one-tailed test was most appropriate. The most commonly used significance level for t-tests is 0.05 (Vaughan, 2001). Therefore, results are significant at $\mathrm{p}<0.05$ (there is a 95\% chance that the means are statistically significant). Higher significance is indicated if $\mathrm{p}<0.01$ (there is a $99 \%$ chance that the means are statistically different).

Table 5-7 shows the results of the t-test conducted on the means of the scores from the MAI. Results from the test revealed a significance score of 0.82 , which does not confirm statistical significance. This shows no significant difference between the metacognitive ability of participants in the control and experimental groups, therefore both groups had more or less the same natural metacognitive ability. This provides some validity for the results, as neither group exhibited a greater metacognitive ability prior to the experiment.

\begin{tabular}{|l|l|l|l|l|l|}
\hline \multirow{2}{*}{} & \multicolumn{5}{|c|}{ t-test for Equality of Means } \\
\cline { 2 - 6 } & $\begin{array}{l}\text { Sig (2 } \\
\text { tailed) }\end{array}$ & $\begin{array}{l}\text { Mean } \\
\text { difference }\end{array}$ & $\begin{array}{l}\text { Std. Error } \\
\text { Difference }\end{array}$ & $\begin{array}{l}\text { 95\% confidence interval of } \\
\text { the Difference }\end{array}$ \\
\cline { 4 - 6 } & & 0.5877 & 2.5900 & -4.5625 & 5.7380 \\
\hline $\begin{array}{l}\text { Equal } \\
\text { variances } \\
\text { not } \\
\text { assumed }\end{array}$ & 0.821 & 0 Low & \\
\hline
\end{tabular}

Table 5-7: MAI t-test results

Next, the results of Section A, C and D of the questionnaire were tested. Hypothesis 1 is supported at $\mathrm{p} \leq 0.01$ (significance is $\mathrm{p}=0.005$ ), shown in Table 5-8. Here the problemsolving ability of the experimental group is greater than that of the control group. Results of the second t-test are shown in Table 5-9 and indicate a significance of $p=0.0115$. The result from this test supports Hypothesis 2 where $p \leq 0.05$, indicating a statistically significant difference between the means of the control and experimental group in regards to memory retention ability. However the t-test for the lateral thinking section (Table 510) did not reveal a statistically significant difference between the means of the control group and the experimental group (that is $\mathrm{P}$ is not less than 0.05 or 0.01 ); therefore, Hypothesis 3 is not supported. 


\begin{tabular}{|l|l|l|l|l|l|}
\hline & \multicolumn{5}{|c|}{ t-test for Equality of Means } \\
\cline { 2 - 6 } & $\begin{array}{l}\text { Sig (1 } \\
\text { tailed) }\end{array}$ & $\begin{array}{l}\text { Mean } \\
\text { difference }\end{array}$ & $\begin{array}{l}\text { Std. Error } \\
\text { Difference }\end{array}$ & $\begin{array}{l}\text { 95\% confidence interval of } \\
\text { the Difference }\end{array}$ \\
\cline { 4 - 6 } & & & Lower & Upper \\
\hline $\begin{array}{l}\text { Equal } \\
\text { variances } \\
\text { not } \\
\text { assumed }\end{array}$ & 0.005 & -0.7777 & 0.2951 & -1.3644 & -0.1910 \\
\hline
\end{tabular}

Table 5-8: Problem solving t-test results

\begin{tabular}{|l|l|l|l|l|l|}
\hline \multirow{2}{*}{} & \multicolumn{5}{|c|}{ t-test for Equality of Means } \\
\cline { 2 - 6 } & $\begin{array}{l}\text { Sig (1 } \\
\text { tailed) }\end{array}$ & $\begin{array}{l}\text { Mean } \\
\text { difference }\end{array}$ & $\begin{array}{l}\text { Std. Error } \\
\text { Difference }\end{array}$ & $\begin{array}{l}\text { 95\% confidence interval of } \\
\text { the Difference }\end{array}$ \\
\cline { 4 - 6 } & & & & Lower & Upper \\
\hline $\begin{array}{l}\text { Equal } \\
\text { variances } \\
\text { not } \\
\text { assumed }\end{array}$ & 0.0115 & -2.2984 & 0.9925 & -4.2719 & -0.3250 \\
\hline
\end{tabular}

Table 5-9: Memory retention t-test results

\begin{tabular}{|l|l|l|l|l|l|}
\hline & \multicolumn{5}{|c|}{ t-test for Equality of Means } \\
\cline { 2 - 6 } & $\begin{array}{l}\text { Sig (1 } \\
\text { tailed) }\end{array}$ & $\begin{array}{l}\text { Mean } \\
\text { difference }\end{array}$ & $\begin{array}{l}\text { Std. Error } \\
\text { Difference }\end{array}$ & \multicolumn{2}{|l|}{$\begin{array}{l}\text { 95\% confidence interval of } \\
\text { the Difference }\end{array}$} \\
\cline { 4 - 6 } & & & & Lower & Upper \\
\hline $\begin{array}{l}\text { Equal } \\
\text { variances } \\
\text { not } \\
\text { assumed }\end{array}$ & 0.278 & 0.0583 & 0.0985 & -0.1378 & 0.2541 \\
\hline
\end{tabular}

Table 5-10: Lateral thinking t-test results

A t-test was also conducted on the times of the groups to see if there was a statistically significant difference between the times of the two groups. The analysis revealed a p level of $\leq 0.05$, indicating a significant difference. Therefore, while metacognition may yield better lateral thinking and memory retention ability, it is more time consuming. Table 511 presents these results. 


\begin{tabular}{|l|l|l|l|l|l|}
\hline & \multicolumn{5}{|c|}{ t-test for Equality of Means } \\
\cline { 2 - 6 } & $\begin{array}{l}\text { Sig (2 } \\
\text { tailed) }\end{array}$ & $\begin{array}{l}\text { Mean } \\
\text { difference }\end{array}$ & $\begin{array}{l}\text { Std. Error } \\
\text { Difference }\end{array}$ & $\begin{array}{l}\text { 95\% confidence interval of } \\
\text { the Difference }\end{array}$ \\
\cline { 5 - 6 } & & -3.6105 & .7998 & -5.2028 & -2.0181 \\
\hline $\begin{array}{l}\text { Equal } \\
\text { variances } \\
\text { not } \\
\text { assumed }\end{array}$ & .000 & & & & \\
\hline
\end{tabular}

Table 5-11 Time t-test results

To determine if gender was an influence that affected the results of the questionnaire a ttest was conducted. The t-test tested for differences between gender for the three outcome variables and for time and MAI scores. As one would expect there were no statistically significant differences. Results are shown in table 5-12.

\begin{tabular}{|c|c|c|c|c|c|c|}
\hline & \multicolumn{5}{|c|}{ t-test for Equality of Means } \\
\hline & & \multirow[t]{2}{*}{$\begin{array}{l}\text { Sig (2 } \\
\text { tailed) }\end{array}$} & \multirow[t]{2}{*}{$\begin{array}{l}\text { Mean } \\
\text { difference }\end{array}$} & \multirow[t]{2}{*}{$\begin{array}{l}\text { Std. Error } \\
\text { Difference }\end{array}$} & \multicolumn{2}{|c|}{$\begin{array}{l}95 \% \text { confidence } \\
\text { interval of the } \\
\text { Difference }\end{array}$} \\
\hline & & & & & Lower & Upper \\
\hline PSolve & $\begin{array}{l}\text { Equal variances } \\
\text { not assumed }\end{array}$ & .275 & -.3451 & .3135 & -.9699 & .2654 \\
\hline LatThink & $\begin{array}{l}\text { Equal variances } \\
\text { not assumed }\end{array}$ & .936 & -.0081 & .1001 & -.2073 & .1905 \\
\hline MemRetain & $\begin{array}{l}\text { Equal variances } \\
\text { not assumed }\end{array}$ & .102 & 1.6771 & 1.0152 & -.3431 & 3.6958 \\
\hline Time & $\begin{array}{l}\text { Equal variances } \\
\text { not assumed }\end{array}$ & .187 & 1.627 & .8734 & -.5744 & 2.9421 \\
\hline MAI score & $\begin{array}{l}\text { Equal variances } \\
\text { not assumed }\end{array}$ & .280 & -2.8292 & 2.5997 & -.8 .0051 & 2.3467 \\
\hline
\end{tabular}

Table 5-12: Gender t-test results

An analysis of variance (ANOVA) test provides inferential statistics, which "consist[s] of procedures used to make inferences about population characteristics from information contained in a sample drawn from this population" (Mendenhall, Beaver, \& Beaver, 2008, p. 4). The ANOVA test and t-test are very alike, in that a t-test could be "considered a special case of the one-way ANOVA where k =2" (De Muth, 1999, p. 205). However, an ANOVA test is used to determine whether the between-group variation is greater than the within-group variation (Hammond, Malec, Nick \& Buschbacher, 2014). The variance between groups is significant at $\mathrm{p}<0.05$. 
An ANOVA test was conducted on the means of the control group and the experimental group. The results from the ANOVA test of the variables (problem solving (PSolve), memory retention (MemRetain), lateral thinking (LatThink), and time) are presented in Table 5-13, These results reinforce the findings from the t-tests, where there is a statistically significant difference between the control and experimental groups in regards to memory retention $(\mathrm{p}=0.022)$, problem solving $(\mathrm{p}=0.010)$ and time $(\mathrm{p}=0.000)$. The results from the ANOVA test support Hypothesis 1, in which those who were encouraged to think aloud scored higher on problem solving ability than those who simply answered the question. The results also support Hypothesis 2, in which the participants who were asked to both visualise and think aloud could recall more details about the candidate than participants who just read the passage. Hypothesis 3 was not supported as there was not a significant at $p<0.005$ (where $p=0.556$ ).

\begin{tabular}{|l|l|r|r|r|r|r|}
\hline & \multicolumn{1}{|c|}{$\begin{array}{c}\text { Sum of } \\
\text { Squares }\end{array}$} & df & $\begin{array}{c}\text { Mean } \\
\text { Square }\end{array}$ & F & Sig \\
\hline Psolve & Between Groups & 13.601 & 1 & 13.601 & 6.983 & 0.010 \\
& Within Groups & 171.388 & 88 & 1.948 & - & - \\
& Total & 184.989 & 89 & - & - & - \\
\hline MemRetain & Between Groups & 118.803 & 1 & 118.803 & 5.399 & 0.022 \\
& Within Groups & 1936.486 & 88 & 22.006 & - & - \\
& Total & 2055.289 & 89 & - & - & - \\
\hline LatThink & Between Groups & 0.076 & 1 & 0.076 & 0.350 & 0.556 \\
& Within Groups & 19.212 & 88 & 2.18 & - & - \\
& Total & 19.289 & 89 & - & - & - \\
\hline Time & Between Groups & 283.484 & 1 & 283.484 & 20.225 & 0.000 \\
& Within Groups & 1191.413 & 85 & 14.017 & - & - \\
& Total & 1474.897 & 86 & - & - & - \\
\hline
\end{tabular}

Table 5-13: ANOVA test results

\subsection{Correlations}

Karl Pearson's correlation measures the extent to which two variables are correlated (Pearson, 1895). A Pearson's correlation attempts to draw a trend line (a line of best fit) through the data from two particular variables. Findings from a Pearson's correlation test reveals the extent of the linear relationship between these variables; that is, how far the data is from the trend line. Table 5-14 shows the correlations of the variables. If the results 
are positive then there is a positive correlation, showing that as one variable increases so will the other. According to Cohen (1988) the following values indicate the level of correlation:

$r= \pm 0.5$ are considered strong;

$r= \pm 0.3$ are considered moderate;

$r= \pm 0.1$ are considered weak.

\begin{tabular}{|c|c|c|c|c|c|c|}
\hline Variables & & PSolve & $\begin{array}{l}\text { MemRet } \\
\text {-ain }\end{array}$ & LatThink & Time & $\begin{array}{l}\text { MAI } \\
\text { score }\end{array}$ \\
\hline PSolve & $\begin{array}{l}\text { Pearson's correlation } \\
\text { Sig. (2-tailed) } \\
\text { N }\end{array}$ & $\begin{array}{c}1 \\
90\end{array}$ & & & & \\
\hline MemRetain & $\begin{array}{l}\text { Pearson's correlation } \\
\text { Sig. (2-tailed) } \\
\text { N }\end{array}$ & $\begin{array}{r}.384 \\
.000 \\
90 \\
\end{array}$ & $\begin{array}{c}1 \\
90\end{array}$ & & & \\
\hline LatThink & $\begin{array}{l}\text { Pearson's correlation } \\
\text { Sig. (2-tailed) } \\
\text { N }\end{array}$ & $\begin{array}{r}.078 \\
.462 \\
90 \\
\end{array}$ & $\begin{array}{r}.127 \\
.233 \\
90 \\
\end{array}$ & 90 & & \\
\hline Time & $\begin{array}{l}\text { Pearson's correlation } \\
\text { Sig. (2-tailed) } \\
\text { N }\end{array}$ & $\begin{array}{r}.325 \\
.002 \\
87 \\
\end{array}$ & $\begin{array}{r}.491 \\
.000 \\
87 \\
\end{array}$ & $\begin{array}{r}.119 \\
.271 \\
87 \\
\end{array}$ & 1 & \\
\hline MAI score & $\begin{array}{l}\text { Pearson's correlation } \\
\text { Sig. (2-tailed) } \\
\text { N }\end{array}$ & $\begin{array}{r}.038 \\
.728 \\
87\end{array}$ & $\begin{array}{r}.010 \\
.928 \\
87\end{array}$ & $\begin{array}{r}-.061 \\
.576 \\
87\end{array}$ & $\begin{array}{r}.038 \\
.727 \\
85\end{array}$ & 87 \\
\hline
\end{tabular}

Table 5-14: Variable correlations

The results of the Pearson's correlation test revealed three statistically significant correlations: the correlation between memory retention and problem solving $(.384$, sig $=.000)$, the correlation between time and problem solving $(.325$, sig $=.002)$ and the correlation between time and memory retention $(.491, \mathrm{sig}=.000)$. These results show that these correlations have a positive, moderate linear relationship. Therefore, it can be concluded that as memory retention increases so does problem solving, as time increases so does problem solving, and as time increases so does memory retention, and vice versa. 


\subsection{Conclusion}

The results from this chapter helped support the validity of the hypotheses posed in Chapter 4. Results from the analysis of the data from the questionnaire revealed a number of key findings. Firstly, the results showed a statistically significant difference between the problem-solving and memory retention ability of the control group and the experimental group. From these findings, it is clear that using a metacognitive strategy had a positive impact on problem-solving and memory retention ability. Secondly, the results did not reveal a statistically significant difference between the lateral thinking ability of the control group and the experimental group. However, it did reveal that those who used schematic images to help them solve the problem question were more likely to correctly answer the question. Lastly, the results revealed correlations between particular variables. These correlations were between: memory retention and problem solving; time and problem solving; and time and memory retention. These findings are interpreted and discussed in the following chapter. 


\section{Chapter 6: Discussion and conclusions}

In a complex and changing environment businesses, now more than ever, need to be able to make effective decisions. To do so, decision makers need to maximise their decisionmaking performance. Using metacognitive strategies can facilitate this process, as metacognition has been proven to regulate and oversee learning, in which people can understand and regulate their strengths, weaknesses, and learning styles (Pintrich, 2002). These skills in turn help to ensure a cognitive goal is met (Livingston, 1997). Taking into consideration the current business environment and the metacognitive strategies think aloud and visualisation, this study aimed to: 1) to apply insights of metacognition to the process of decision making 2) to contribute to the current literature and research by providing a better understanding of how decision makers can use metacognitive strategies to improve their decision-making ability and 3) to offer practical impactions that support the use of particular metacognitive strategies to facilitate decision making ability.

In line with these objectives, four main research questions were proposed. Following this, three main hypotheses were generated, founded on relevant literature, and tested in the study. A quantitative research approach was used to examine the relationship between metacognition and decision-making ability. Using a quantitative methodology, this research aimed to generate explanations that could be applied to another context, in particular a business setting. Results of the analysis revealed a number of significant findings that support and contribute to the current literature. This chapter now provides a discussion of results of the hypotheses tested, with reference to relevant literature to support the findings.

\subsection{Summary of findings}

The purpose of the experiment was to examine the effect of metacognitive strategy use by encouraging the experimental group to use metacognitive strategies and comparing their results to the results of the control group. This empirical investigation was prompted by a growing body of research aimed at applying neuroscientific insights to business practices, specifically decision making. Findings from this experiment contribute to the current literature, where it is established that metacognition can facilitate better decision- 
making ability (Enos et al., 2003; Mitchell, Shepard \& Sharfman, 2011) and will contribute to the research in the growing area of organisational cognitive neuroscience. As predicted, an intervention led to an increase in decision-making ability for students in the experimental group, specifically in relation to their problem-solving and memory retention ability.

\subsection{Discussion of the theoretical model}

The findings from this study were compared to the theoretical and operational models presented in Chapter 3 to test the original propositions and determine the predictive ability of the models.

The theoretical model is robust, as it supports research findings that highlight a relationship between metacognition and decision making. While tying in findings from relevant research that highlights the relationship between metacognition and various decision making components, such as the works by Runco and Chand (1995), Whitebread (1999), Teong (2003), Autin and Croizet (2012), and Sahin and Kendir (2013), the theoretical model defines three main subcomponents of decision making ability problem solving, memory retention, and lateral thinking. Congruent with these studies, as well as others, metacognitive strategy use was found to be a predictor of decisionmaking ability in relation to these three main components. While the initial analysis of the results of the current study only supported two of the three hypotheses, further analysis of the returned questionnaires revealed results that supported all three. Therefore, the theoretical model was sound and no elements were changed after the results were analysed.

However, it was found that there may be some limitations in the operational model as it relies on only one measure to test the ability of participants. Many previous studies have used multiple ways to test metacognitive ability; for example Montague (1992) and Pugalee (2001) asked students to solve multiple mathematical problems to determine the influence of metacognition on their problem-solving ability. Therefore, to provide a more comprehensive understanding of the relationship between metacognition and the three identified components of metacognition the operational model must incorporate further tests of problem solving, memory retention, and lateral thinking ability. 


\subsection{Discussion of key relationships}

This section will examine the key relationships that directly address the research questions. In doing so it will generate explanations and answers to the research questions proposed in Chapter 1.

\subsubsection{The relationship between metacognition and problem solving}

While current research has offered extensive insight into the relationship between metacognition and problem solving, much of it has focused on assessing students at primary and secondary school level. Therefore, although the current research supports the literature that highlights the relationship between metacognition and problem solving, it aims to apply these findings to a broader business context.

Past research, such as Swanson (1990), and Sahin and Kendir (2013), has shown that metacognition can have a direct influence on problem-solving ability. Results from the study by Swanson (1990) show that metacognitive skills can compensate for aptitude skills "by providing certain knowledge about cognition" (p. 312). Moreover, results from the study by Sahin and Kendir (2013) reveal that metacognitive strategy use plays an important role in problem solving as it allows people to understand a problem by associating it with things they already know. The use of think aloud to aid problem solving ability has also been examined in a number of works, for example early studies such as Flaherty (1975) and Montague and Applegate (1993) and more recent studies such as Henjes (2007) and Teong (2003). Results from these studies suggest a clear linkage between the use of think aloud and problem solving ability, in that problem solving ability increases with the use of the think aloud strategy.

Results from the present study mirror findings such as these, as participants who were encouraged to use think aloud were able to correctly answer more problem-solving questions than those who were not encouraged to use the strategy. Therefore, as noted in Sahin and Kendir (2013), metacognitive strategy use in this particular section allowed these students to better understand the problem. In addressing the question "does metacognition improve the ability to solve problems?" it can be concluded that 
metacognitive strategy use, in particular think aloud, allows a person to consciously monitor and reflect upon what they are learning, which can be useful in understanding and comprehending what they are trying to learn.

\subsubsection{The relationship between metacognition and memory retention}

As information overload is a growing issue in modern day business it is important to be able to process and retain information for future decision making. The use of metacognitive strategies has been said to facilitate this process. The extent of the influence metacognition has on working memory and WMC has been analysed in a number of studies (Autin \& Croizet, 2012; Partanen et al., 2015; Whitebread, 1990). These authors, and many others, indicate a direct relationship between working memory and/or WMC performance and metacognition, with the former dependent on the latter. Findings from analysis of the results of the questionnaire support such literature, as the experimental group could recall more information about the candidates in the hiring scenario.

These results also validate the use of the metacognitive strategies think aloud and visualisation in conjunction with one another. The effect of think aloud has been evident in studies for decades (Conway \& Gathercole, 1987; Hopkins \& Edwards, 1972); however, only recently has this phenomenon been given greater attention (MacLeod, Gopie, Hourihan, Neary, \& Ozbuko, 2010). For example, MacLeod and colleagues coined the term "production effect" to explain the relationship between saying words aloud (think aloud) and memory retention, where thinking aloud increases memory retention. Moreover, other studies such as those by Whitney, Ritchie and Clark (1991), Whitney and Budd (1996), and Guará-Tavares (2016) show that the use of think aloud directly affects $\mathrm{WMC}$, while others have proposed that oral processing can have an effect on working memory as it can help retain information (Pressley \& Afflerbach, 1995; Swanson 1990, as cited in Hedin, 2008). In addressing how think aloud can improve memory it is clear that thinking aloud is an encoding strategy that helps process and emphasise important information (Ozubko, Hourihan \& MacLeod, 2012). A distinctness of the words whilst a person is trying to encode the information allows for better recollection (Icht, Mama \& Algom, 2014). In particular, as Icht et al. (2014) note that 
"this distinctiveness is attributable to the additional dimension(s) of encoding for the aloud items that can be subsequently used during retrieval.” (p. 1).

The use of visual imagery has also been shown to have positive associations with working memory. According to Kaski (2002), "visual imagery can be defined as the representation of perceptual information in the absence of visual input." (p. 717). There are some examples of studies that have addressed a specific subset of memory, visual working memory (VWM) (Keogh \& Pearson, 2014). VWM is the mechanism by which visual information is held (Keogh \& Pearson, 2011). There has been much debate regarding VWM capacity (Luck \& Vogel, 2013). As a result two main theories concerning VWM storage have been developed: the discrete resource model and the flexible resource model (Luck \& Vogel, 2013). There is substantial evidence for and against both. While interesting, it is outside of the scope of this study to debate the two areas.

However, importantly to note, capacity varies substantially across both individuals and groups (Luck \& Vogel, 2013). Both the discrete resource model and the flexible resource model fail to take this into consideration (Keogh \& Pearson, 2011). It is such a difference that may be caused by visual imagery. Keogh and Pearson (2011) argue this point:

...it is somewhat surprising that current models do not factor in potential causes behind such differences. If stronger imagery does in fact boost performance accuracy in visual working memory tasks, it may similarly have a modulatory effect on capacity limits. If this is the case, one may expect to find large individual differences in capacity limits that parallel the documented individual differences in imagery strength. (p. 6).

This relationship is evident within this study as participants who used visual imagery, that is they visualised the job candidates in the hiring scenario, were able to recall more information about the job applicants than those that didn't. Therefore, showing how the use of visualisation can improve memory capacity, in particular visual memory capacity.

\subsubsection{The relationship between metacognition and lateral thinking}

A number of theorists, such as Davidson and Sternberg (1998) and Feldhusen and Goh (1995), have directly associated metacognition with creative problem solving ability. The 
correlation between the two is said to be positive, that is the higher the metacognitive ability the greater the creative problem solving ability. Authors such as Hargrove and Nietfeld (2015) have also assessed this relationship to determine the effect of metacognition on creative performance. Others, such as Pesut (1990) and Runco and Chand (1995) have proposed models to understand the creative process and the role of metacognition within it.

However, while the importance of metacognition in creativity is apparent, there is a paucity of studies that directly assess the effects of metacognition on specific components of creative ability, such as lateral thinking. While lateral thinking is often viewed as creative problem solving and visualisation has been said to nurture problem solving (Rieber, 1995), lateral thinking alone has not often been individually assessed. Lateral thinking has often been viewed often as a creative strategy (Hargrove \& Nietfeld, 2015). Due to this, it is apparent that more research is needed to focus directly on lateral thinking. Lateral thinking is important as it can not only encourage mangers to think outside of the box and come up with innovative new solutions (Jesson, 2012) but can help in decisionmaking situations that may not lend themselves to a logical process (Butler, 2010).

This study is the beginning to such research as the results from Section C, which directly assesses lateral thinking ability, indicate a strong relationship between metacognition and lateral thinking ability. Not only this but the study emphasises visualisation is an effective tool to encouraging this ability. While initial results of the study did not support Hypothesis 3, as the experiment group did not out performance those in the control group, further visual inspects of the returned questionnaires revealed that the use visualization had a positive impact on the lateral thinking ability of the experimental participants. This may be due to numerous reasons. Authors Card, Mackinlay and Shneiderman (1999) summarise a number of studies that highlight these possibilities. For example, Larkin and Simon (1987) highlight that visualisation group's together information, results from the study by Tufte (1983) show that visualisation can minimise data into a graphical representation in one small space and the study by Hutchins (1996) notes that the use of visualisation can enable complex graphical computations.

In addition, it was found that participants who drew schematic visualisations portrayed a better understanding on the question and had a higher probability of getting the question 
correct. Despite the grouping, a number of the participants in the control group drew schematic visualisations to assist them in solving the question. Out of those who got the question correct in the control group $(n=14) 7$ of them drew schematic visualisations. This finding shows that metacognition, in particular the strategy visualisation, can improve the capacity to think laterally as schematic drawings can help process and understand information. This in turn allows the thinker to view the information in a way that can permit them to think of alternative solutions where one can look beyond the limits of how they would process a problem rationally and arrive more creative solutions.

\subsection{Correlations between the variables}

Results from the correlation test revealed three significant correlations at the 0.01 level. Correlations at this level are said to move in tandem. However correlation does not imply causation (Aldrich, 1995). Therefore, while problem solving and memory relation were positively correlated it cannot be assumed that one causes the other. This leads to what experts called a "third variable problem", in which the correlation between two variables is dependent on a third variable (Jackson, 2014). In this study, as results show that metacognition positively impacts both memory and problem solving, it can be assumed that metacognition is the third variable and therefore, can adversely affect the relationship between problem solving and memory retention, causing the correlation that is observed. So, while problem solving and memory move together, they are dependent on the use of metacognition.

Time was another variable that correlated positively with both problem solving and memory retention. Again it can be assumed that metacognition plays an important role in this. These results show that the time spent on these problems was an indication of participant performance. As shown by Tables 5-3 and 5-4 in Chapter 5 participants in the experimental group took on average three minutes longer than the control group, therefore, it can be said that metacognition is more time consuming. The more time spent on the questionnaire can be attributed to reflective thinking, which is a self-awareness attribute of metacognition. Reflective thinking can be defined as "the ability to plan, monitor success, and correct errors when appropriate and the ability to assess one's readiness for high level performance in the area one is studying and working to understand" (Bybee, 2002, p. 17). However, reflection often does not occur naturally due 
to either the restriction of time or lack of opportunity (Bybee, 2002). The lack of opportunity, which can be the absense of instructions, could have been a main cause as to why the control group spent less time on the questionnaire, as they were simply asked to answer the questions. Whereas the experimental group was encouraged to spend more time analysing the information and questions. Therefore these participants were more likely to think reflectively, as evident by the results of the questionnaire.

\subsection{Findings from an analysis the MAI results}

An analysis of the descriptive statistics of the MAI revealed a number of interesting findings. While overall participants believed they had better ability in regards to debugging ability and information management they lacked confidence in their ability in areas such as planning and comprehension monitoring. Interestingly, the researcher found that these results reflected her own experience at university, where feedback from lecturers and tutors regarding assignments or assessments often provided guidance as to how to set out assignments or prepare for exams and also provided direction to correct ones performance to achieve better results in the next assessment. Despite this her experience of university showed that while lecturers are tutors provided such guidance there was little encouragement to set goals or assess your own learning. Therefore, if these participants had similar experiences, it may be an explanation to the lack of confidence in such areas.

\subsection{Implications of the study}

In the 40 years since Flavell coined the term metacognition (Flavell, 1976) there has been significant progress and development in the field. While a lot of this work has implications for teaching and learning, particularly in the classroom, there is still a need for a greater application of metacognition to a business context. Some studies have begun to examine this, such as Kumar (1998), Enos and colleagues (2003) and Mitchell et al. (2011). However, few have specifically addressed the use of particular metacognitive strategies for various decision-making situations. This study offers greater insight into this as its findings indicate that metacognitive strategies can be used to facilitate managerial decision making. The strategies think aloud and visualisation are particularly 
effective tools in facilitating knowledge and awareness. This study has implications for future research, implications for students, and implications for practice. These three areas will be discussed accordingly.

Firstly, this study offers insight into the influence of metacognition on decision making, with particular reference to three specific measures of business decision making: problem solving, memory retention, and lateral thinking. While these areas have been explored before, this study provides insight into the growing body of research of organisational cognitive neuroscience. It also provides a greater understanding of particular metacognitive strategies that can be used to facilitate decision-making ability and how to use simple but effective instructions encouraging the use of these. Due to this, the study has opened up a number of pathways for future research to explore further aspects of metacognition in business practices and in classrooms. These will be discussed in the next section.

Most importantly, this study highlights the need to encourage strategy use. Authors such as Bransford, Brown and Cocking (2000), and Lin (2001) have found that students often do not naturally engage in metacognitive thinking unless they are given specific instruction to do so. Therefore, while metacognition has been proven effective, these authors suggest that students need more opportunities to help them develop and engage in metacognitive thinking. This was evident in the study as, for example, for Section $\mathrm{C}$ a greater number of participants in the experimental group used the metacognitive strategy visualisation as they were instructed to do so. However, in the control group, all but seven participants in the control group failed to show any use of a metacognitive strategy for the same question.

It is proposed that these findings can also be generalised and related to a business context. In particular, the findings from this study can be used to facilitate metacognitive strategy use for business decision makers. By doing so managers can harness effective strategies that have been reinforced by the literature and apply them to their decision-making practices. Students were used for this study as exemplars of future business decision makers. An early study by Gregory and Clemen (1999) noted the importance of decision making for students. 
Many educators view improvements in student decision-making capabilities as a critical element of secondary-school curriculum restructing efforts. Teachers feel that better decision making may improve study habits and aid classroom learning objectives. Parents and potential employers look to decision skills as a key component of successful and independent behaviour. (p. 1)

Therefore, being able to teach students to metacognate had wider implications for future business decision making practice.

\subsection{Limitations of the study and recommendations for future research}

The results of the current study demonstrate the relationship between metacognition and decision-making ability. The findings apply most specifically to a research sample comprising Victoria University business school students. However, a number of limitations raise the issue of whether or not these findings can be generalised. These limitations are: time restrictions, the limited number of measurements for the variables and the scope of the study. Due to this, and the nature of the study, a number of recommendations are proposed and areas for future research are proposed.

Timing was a design feature that limited the scope of the study. Studies such as those by Pugalee (2001) and Jacobse and Harskamp (2012) examined the training and use of metacognitive strategies over a longer period of time; results from their studies showed that the longer period of intervention was successful on student's problem solving ability. However, as the data was collected at the end of Trimester Two and the middle of Trimester Three, due to the availability of classes, a longer period of intervention was not possible. As the experimental group was only given a short set of instructions that aimed to encourage the participants to use particular strategies, the effect of metacognitive strategy use may have been limited in this study. Future research with a more extensive intervention is needed to better understand the effects of these strategies and provide a greater understanding of whether or not a longer period of intervention is more successful than a shorter period.

Another limitation of the study was the measures of the variables - problem solving, memory retention and lateral thinking - as each variable had only one assessment. As 
touched on in 6.2 this limited the extent to which a causal relationship could be shown between metacognition and each variable. While the results of the study indicate that the intervention was successful, future research should include more measures, such as a larger number of assessment questions that aim to examine the lateral thinking, problem solving and/or memory retention ability of participants.

While this study covered two main aspects of business decision making there are a vast number of opportunities for future research to explore metacognition in relation to other business decision-making practices. For example, business decision making can be measured against other areas of decision-making ability such decision evaluation or implementation. Moreover, other cognitive strategies, such summarising (self-review), questioning, clarifying, and predicting (Palinscar \& Brown, 1984), can be used to facilitate decision-making ability. The methodology of the present study can applied to a business context in which using think aloud and visualisation can be examined over various decision-making activities. Moreover, this kind of research could further investigate particular metacognitive strategies that effectively evoke metacognitive thinking in managers to reveal deeper insights into the cognitive process of metacognition and decision-making ability.

While this study was conducted on soon to be business graduates, who will, in the future, be managers it, was not conducted on mangers. Therefore, its generalisability to managers at large must be treated with some caution. Further research should directly assess the metacognitive ability of managers. As this field is largely untouched, there is great scope for this. For example, one could assess whether the influence of metacognitive strategies is different in more senior managers, or if decision-making ability, influenced by metacognition, does not change regardless of the job position one holds.

\subsection{Conclusion}

In conclusion, this study has contributed to the growing body of literature concerning metacognition and business practices by offering a number of insights into business decision making ability, with particular reference to the use of metacognitive strategies. Firstly, it proposes a theoretical model and an operational model to not only explain the 
nature and challenges accompanying the phenomenon but also to visually represent how the process works, and the measurements and strategies that can be used.

In addition to this, the study contributes to how metacognitive strategies can be harnessed to encourage better decision making, memory retention ability and lateral thinking. It showed that an adjustment to instructions, that is to encourage metacognitive strategy use, had a highly influential impact on the outcome of the results. Also, while only two strategies were used within this study, they were successful. However, a vast number of alternative strategies can be harnessed to facilitate this process.

Finally, the current study, while posing a number of limitations, provides the beginnings to a number of directions for future research. These are:

- Research assessing an extensive intervention

- Research assessing other decision making variables

- Research assessing other metacognitive strategies

- Research assessing metacognitive ability in an organisational context

- Research assessing the metacognitive ability of managers across different levels

While acknowledging that the field is still growing, the contributions of this study focus primarily on how future research should be conducted in a business context. It is work such as this that is fundamental for developing and expanding the field of organisational cognitive neuroscience. However, it is still important to focus on teaching and instructing students to use metacognitive strategies in their work as they are the future decision makers. Teaching students how to harness and increase their metacognitive ability will not only improve their school work but also can be applied to their work once they leave university. It is important to develop these skills young so they can be used later in a working environment. 


\section{References}

Ahmad, Z. A. (2010). Brain in business: The economics of neuroscience. The Malaysian Journal of Medical Sciences, 17(2), 1-3.

Akbaria, R., Khayerb, M., \& Abedi, J. (2014). Studying effect of educating state metacognition on learning mathematics. Reef Resources Assessment and Management Technical Paper, 40(2), 220-229.

Akturk, A. O., \& Sahin, I. (2011). Literature review on metacognition and its measurement. Procedia-Social and Behavioral Sciences, 15, 3731-3736.

Aldrich, J. (1995). Correlations genuine and spurious in Pearson and Yule. Statistical Science, 10, 364-376.

Alexander, J. M., Carr, M., \& Schwanenflugel, P. J. (1995). Development of metacognition in gifted children: Directions for future research. Developmental Review, 15(1), 1-37.

Aliaga, M. and Gunderson, B. (2003). Interactive Statistics (2nd ed.). Upper Saddle River, NJ: Prentice Hall.

Alloway, T. P., \& Alloway, R. G. (2013). Working memory: The connected intelligence. New York, NY: Psychology Press.

Andrews, E. (2014). Neuroscience and multilingualism. Cambridge, UK: Cambridge University Press.

Applefield, J. M., Huber, R., \& Moallem, M. (2000). Constructivism in theory and practice: Toward a better understanding. The High School Journal, 84(2) 3553. 
Arnold, G. E. (2008). Examining the relationship between leadership style and project success in virtual projects (Unpublished doctoral dissertation). University of Phoenix, Phoenix, AZ.

Arroio, A., \& Honório, K. (2008). Images and Computational Methods in Molecular Modelling Education. Problems of Education in the 21st Century, 9, 17-23.

Autin, F., \& Croizet, J. C. (2012). Improving working memory efficiency by reframing metacognitive interpretation of task difficulty. Journal of Experimental Psychology: General, 141(4), 610.

Band, J., \& Partridge, L. (1999). Advanced Decision-Making (Vol. 21). Hertfordshire, UK: Select Knowledge Limited.

Bannert, M., \& Mengelkamp, C. (2008). Assessment of metacognitive skills by means of instruction to think aloud and reflect when prompted. Does the verbalisation method affect learning?. Metacognition and Learning, 3(1), 39-58.

Barnard, C. I. (1938). The functions of the executive. Cambridge, MA: Harvard University Press.

Barrett, L. F., Tugade, M. M., \& Engle, R. W. (2004). Individual differences in working memory capacity and dual-process theories of the mind. Psychological Bulletin, 130(4), 553.

Batool, N., Riaz, M. N., \& Riaz, M. A. (2015). Integrated use of rational and intuitive decision-making style: modern trends in organizational decisionmaking. Pakistan Business Review, 17(1), 147-161.

Baxter, L., \& Babbie, E. (2003). The basics of communication research. Belmont, California: Cengage Learning. 
Becker, W. J., Cropanzano, R., \& Sanfey, A. G. (2011). Organizational neuroscience: Taking organizational theory inside the neural black box. Journal of Management, 37, 933-961.

Bellman, R. E., \& Zadeh, L. A. (1970). Decision-making in a fuzzy environment. Management Science, 17(4), 141-164.

Bereiter, C., \& Bird, M. (1985). Use of thinking aloud in identification and teaching of reading comprehension strategies. Cognition and Instruction, 2(2), 131-156.

Bishop, A J. (1989). Review of research on visualization in mathematics education. Focus on Learning Problems in Mathematics, 11(1), 7-16.

Boekaerts, M., Pintrich, P. R., \& Zeidner, M. (2005). Handbook of self-regulation. San Diego, CA: Academic Press.

Booth, R. D., \& Thomas, M. O. (1999). Visualization in mathematics learning: Arithmetic problem-solving and student difficulties. The Journal of Mathematical Behavior, 18(2), 169-190.

Borkowski, J. G., Carr, M., Rellinger, E., \& Pressley, M. (1990). Self-regulated cognition: Interdependence of metacognition, attributions, and self-esteem. Dimensions of Thinking and Cognitive Instruction, 1, 53-92.

Bransford, J. D., Brown, A. L., \& Cocking, R. R. (1999). How people learn: Brain, mind, experience, and school. Washington, DC: National Academy Press.

Brown, A. L. (1984). Metacognition, executive control, self- regulation, and other even more mysterious mechanisms. In F. E. Weinert \& R. H. Kluwe (Eds.), Metacognition, motivation, and learning (pp. 60-108). Stuttgart, Germany: Kuhlhammer.

Brown, A. L., Bransford, J. D., Ferrara, R. A., \& Campione, J. C. (1983). Learning, remembering, and understanding. In J. H. Flavell \& E. M. Markman (Eds.), 
Handbook of child psychology (Vol. 1): Cognitive development (pp. 77-166). New York, NY: Wiley

Brown, A. L., \& DeLoache, J. S. (1978). Skills, plans and self-regulation. In R. S. Siegler (Ed.), Children's thinking: What develops? (pp. 3-35). Hillsdale, NJ: Erlbaum.

Brown, A. L., \& Palincsar, A. S. (1989). Guided, cooperative learning and individual knowledge acquisition. Knowing, learning, and instruction: Essays in honor of Robert Glaser (pp. 393-451). Hillsdale, NJ: Erlbaum. In???

Bruer, J. T. (2009). Mapping cognitive neuroscience: Two-dimensional perspectives on twenty years of cognitive neuroscience research. The Cognitive Neurosciences IV, 83(3), 1221-1234.

Buchanan, D., \& Huczynski, A. (2004). Organizational behaviour: an introductory text. London, UK: Prentice Hall.

Buchanan, L., \& O Connell, A. (2006). A brief history of decision-making. Harvard business review, 84(1), 32.

Butler, S. A. (2010). Solving business problems using a lateral thinking approach. Management Decision, 48(1), 58-64.

Butler, M. J., \& Senior, C. (2007). Toward an organizational cognitive neuroscience. Annals of the New York Academy of Sciences, 1118(1), 1-17.

Butler, M. J., O'Broin, H. L., Lee, N., \& Senior, C. (2015). How organizational cognitive neuroscience can deepen understanding of managerial decision-making: A review of the recent literature and future directions. International Journal of Management Reviews, O0(1), 1-18.

Burke, L. A., \& Miller, M. K. (1999). Taking the mystery out of intuitive decisionmaking. The Academy of Management Executive, 13(4), 91-99. 
Bybee, R. W. (2002). Learning science and the science of learning: Science educators' essay collection. Arlington, VA: NSTA press.

Card, S. K., Mackinlay, J. D., \& Shneiderman, B. (1999). Readings in information visualization: using vision to think. Burlington, MA: Morgan Kaufmann.

Carson, D., Gilmore, A., Perry, C., \& Gronhaug, K. (2001). Qualitative marketing research. London, UK: Sage.

Cavanaugh, J. C., \& Perlmutter, M. (1982). Metamemory: A critical examination. Child Development, 53, 11-28.

Chakravarthy, B. S. and White, R. E. (2002). 'Strategy process: making, shaping and validating strategic decisions'. In Pettigrew, A., Thomas, H. and Whittington, R. (Eds.), Handbook of Strategy and Management. (pp. 182-205). Beverly Hills, CA: Sage.

Charters, E. (2003). The use of think-aloud methods in qualitative research an introduction to think-aloud methods. Brock Education Journal, 12(2), 68-82.

Cohen, J. (1988). Statistical power analysis for the behavioural sciences. Hillsdale, NJ: Lawrence Earlbaum Associates.

Conway, M., \& Gathercole, S. (1987). Modality and long-term memory. Journal of Memory and Language, 26, 341-361.

Cowan, N. (2010). The magical mystery four how is working memory capacity limited, and why? Current Directions in Psychological Science, 19(1), 51-57.

Cowan, W. M., Harter, D. H., \& Kandel, E. R. (2000). The emergence of modern neuroscience: some implications for neurology and psychiatry. Annual Review of Neuroscience, 23(1), 343-391. 
Creswell, J. W. (2005). Educational research. Upper Saddle River, NJ: Pearson Education.

Creswell, J. W. (2009). Research design: Qualitative, quantitative, and mixed methods approaches. Los Angeles, CA: Sage Publications.

Cronbach, L. J. (1951). Coefficient alpha and the internal structure of tests. Psychometrika, 16(3), 297-334.

Cross, D. R., \& Paris, S. G. (1988). Developmental and instructional analyses of children's metacognition and reading comprehension. Journal of Educational Psychology, 80(2), 131-142.

Cullen, J., \& Parboteeah, K. P. (2013). Multinational management. Boston, MA: Cengage Learning.

Cunningham, B. M., Nikolai, L. A., Bazley, J., Kavanagh, M., Slaughter, G., \& Simmons, S. (2011). Accounting: information for business decisions. Boston, MA: Cengage Learning.

Dane, E., \& Pratt, M. G. (2007). Exploring intuition and its role in managerial decision making. Academy of Management Review, 32(1), 33-54.

Dawson, T. L. (2008). Metacognition and learning in adulthood. Northampton, MA: Developmental Testing Service, LLC.

Davidson, J.E., \& Sternberg, R.J. (1998). Smart problem solving: How metacognition helps. In D.J. Hacker, J. Duniosky, \& A.C. Graesser (Eds.), Metacognition in educational theory and practice (pp. 47-68). Mahwah, NJ: Lawrence Erlbaum Associates.

de Bono, E. (1967). New think: The use of lateral thinking in the generation of new ideas. New York, NY: Basic Books. 
de Groot, A. D. (1946). Het denken van den schaker: een experimenteel-psychologische studie. Amsterdam, the Netherlands: Uitgevers Maatschappij.

De Muth, J. E. (1999). Basic statistics and pharmaceutical statistical applications. New York, NY: CRC Press.

Dean, J. W., \& Sharfman, M. P. (1993). The relationship between procedural rationality and political behavior in strategic decision making. Decision Sciences, 24(6), 1069-1083.

Devine, J., Railey, K., \& Boshoff, P. (1993). The implications of cognitive models in L1 and L2 writing. Journal of Second Language Writing, 2(3), 203-225.

Doede, K. (2013). Management: A European Perspective. Amsterdam, the Netherlands: Routledge.

Drost, R. (2013). Memory and Decision-making: Determining Action when the Sirens Sound. Weather, Climate, and Society, 5(1), 43-54.

Drotar, D. (2013). Handbook of research in paediatric and clinical child psychology: Practical strategies and methods. New York, NY: Kluwer Academic Publishers.

Duell, O. K. (1986). Metacognitive skills. In G. D. Phye \& T. Andre (Eds.), Cognitive classroom learning: Understanding, thinking, and problem solving (pp. 205242). Orlando, FL: Academic Press.

Dunning, D., Johnson, K., Ehrlinger, J., \& Kruger, J. (2003). Why people fail to recognize their own incompetence. Current Directions in Psychological Science, 12(3), 83-87.

Edgar, D. W. (2012). Learning Theories and Historical Events Affecting Instructional Design in Education. Sage Open, 2(4), 1-9. 
Eggen, P., \& Schellenberg, S. (2010). Human memory and the new science of learning. In M. S. Khine and I. M. Saleh (Eds.), New Science of Learning (pp. 97-107). London, UK: Springer

Elbanna, S., \& Younies, H. (2008). The relationships between the characteristics of the strategy process: evidence from Egypt. Management Decision, 46(4), 626639.

Eling, K., Langerak, F., \& Griffin, A. (2015). The Performance effects of combining rationality and intuition in making early new product idea evaluation decisions. Creativity and Innovation Management, 24(3), 464-477.

Endsley, M. R. (1995). Toward a theory of situation awareness in dynamic systems. Human Factors: The Journal of the Human Factors and Ergonomics Society, 37(1), 32-64.

Enos, M. D., Kehrhahn, M. T., \& Bell, A. (2003). Informal learning and the transfer of learning: How managers develop proficiency. Human Resource Development Quarterly, 14(4), 369-387.

Eppler, M. J., \& Mengis, J. (2004). The concept of information overload: A review of literature from organization science, accounting, marketing, MIS, and related disciplines. The Information Society, 20(5), 325-344.

Ericsson, K. A., \& Simon, H. A. (1980). Verbal reports as data. Psychological review, 87(3), 215-251.

Feldhusen, J. F., \& Goh, B. E. (1995). Assessing and accessing creativity: An integrative review of theory, research, and development. Creativity Research Journal, 8(3), 231-247.

Ferreira, C., \& Arroio, A. (2009). Teacher's education and the use of visualizations in chemistry instruction. Problems of Education in the 21st Century, 16, 48-53. 
Ferrell, O. C., \& Fraedrich, J. (2016). Business ethics: Ethical decision making \& cases. Boston, MA: Houghton Mifflin.

Field, A. (2005). Regression. Discovering Statistics Using SPSS, 2, 143-217.

Fisher, R. (1990). The social psychology of intergroup and international conflict resolution. New York, NY: Springer-Verlag.

Flaherty, E. G. (1975). The thinking aloud technique and problem solving ability. The Journal of Educational Research, 68(6), 223-225.

Flavell, J. H. (1963). The developmental psychology of Jean Piaget. Princeton, NJ: Van Nostrand.

Flavell, J. H. (1976). Metacognitive aspects of problem solving. In L. B. Resnick (Ed.), The nature of intelligence (pp. 231-235). Hillsdale, NJ: Lawrence Erlbaum Associates.

Flavell, J. H. (1979). Metacognition and cognitive monitoring: A new area of cognitivedevelopmental inquiry. American Psychologist, 34(10), 906-911.

Fleming, S. M., \& Dolan, R. J. (2012). The neural basis of metacognitive ability. Philosophical Transactions of the Royal Society B: Biological Sciences, 367(1594), 1338-1349.

Fleming, S. M., \& Frith, C. D. (Eds.). (2014). The cognitive neuroscience of metacognition. Berlin, Germany: Springer.

Fleming, S. M., Huijgen, J., \& Dolan, R. J. (2012). Prefrontal contributions to metacognition in perceptual decision-making. The Journal of Neuroscience, 32(18), 6117-6125. 
Fletcher, J. M., Marks, A. D., \& Hine, D. W. (2011). Working memory capacity and cognitive styles in decision-making. Personality and Individual Differences, 50(7), 1136-1141.

Fogarty, R. (1994). The mindful school: How to teach for metacognitive reflection. Palatine, IL: Skylight Publishing.

Forrest-Pressley, D. L., \& MacKinnon, G. E. (1985). Metacognition, cognition, and human performance: Theoretical perspectives (Vol. 1). New York, NY: Academic Press.

Frey, L. R., \& Cissna, K. N. (Eds.). (2009). Routledge handbook of applied communication research. New York, NY: Routledge.

Gadelmawla, E. S., Koura, M. M., Maksoud, T. M. A., Elewa, I. M., \& Soliman, H. H. (2002). Roughness parameters. Journal of Materials Processing Technology, 123(1), 133-145.

Gall, M. D., Gall, J. P., \& Borg, W. R. (2003). Education research: An introduction (7th ed.). White Plains, NY: Longman.

Garner, R. (1987). Metacognition and reading comprehension. Norwood, NJ: Ablex Publishing.

Garner, R., \& Alexander, P. A. (1989). Metacognition: Answered and unanswered questions. Educational Psychologist, 24(2), 143-158.

Gilbert, J. K. (2005). Visualization in science education (Vol. 1). Dordrecht, the Netherlands: Springer Science \& Business Media.

Goldstein, M. (1994). Decade of the brain. An agenda for the nineties. Western Journal of Medicine, 161(3), 239-241. 
Goos, M., \& Galbraith, P. (1996). Do it this way! Metacognitive strategies in collaborative mathematical problem solving. Educational Studies in Mathematics, 30(3), 229-260.

Gregory, R. S., \& Clemen, R. T. (1999). Improving students' decision making skills. Unpublished manuscript, Decision Research, Eugene, OR.

Gross, C. G. (1987). Neuroscience, early history of. In G. Adelmart (Ed.), Encyclopaedia of Neuroscience. (pp. 843-847). Boston, USA: Birkhäuser,

Gross, D., Akaiwa, F., \& Nordquist, K. (2010). Succeeding in Business with Microsoft Excel 2010: A Problem-Solving Approach. Independence, KY: Cengage Learning.

Guo, P., \& Pedrycz, W. (Eds.). (2014). Human-Centric Decision-Making Models for Social Sciences. Heidelberg, Germany: Springer.

Green, H. (2012, May 15). 10 Brainteasers To Test Your Mental Sharpness. Retrieved from http://www.forbes.com/sites/work-in-progress/2012/05/15/10brainteasers-to-test-your-mental-sharpness/.

Guará-Tavares, M. D. G. (2016). Learners' processes during pre-task planning and working memory capacity. Ilha do Desterro, 69(1), 79-94.

Hacker, D. J., Dunlosky, J., \& Graesser, A. C. (Eds.) (1998). Metacognition in educational theory and practice. Mahwah, NJ: Erlbaum.

Hagner, M., \& Borck, C. (2001). Mindful practices: On the neurosciences in the twentieth century. Science in Context, 14(4), 507-510.

Hair Jr, J. F., Wolfinbarger, M., Money, A. H., Samouel, P., \& Page, M. J. (2015). Essentials of business research methods. New York, NY: Routledge. 
Hall, D. J. (1996). The role of creativity within best practice manufacturing. Technovation, 16(3), 115-121.

Hammond, F., Malec, J., Nick, T., \& Buschbacher, R. (2014). Handbook for clinical research: Design, statistics, and implementation. New York, NY: Demos Medical Publishing.

Hannah, S. T., Balthazard, P. A., Waldman, D. A., Jennings, P. L., \& Thatcher, R. W. (2013). The psychological and neurological bases of leader self-complexity and effects on adaptive decision-making. Journal of Applied Psychology, 98(3), 393-411.

Hargrove, R. A. (2013). Assessing the long-term impact of a metacognitive approach to creative skill development. International Journal of Technology and Design Education, 23(3), 489-517.

Hargrove, R. A., \& Nietfeld, J. L. (2015). The impact of metacognitive instruction on creative problem solving. The Journal of Experimental Education, 83(3), 291-318.

Hart, J. T. (1965). Memory and the feeling-of-knowing experience. Journal of Educational Psychology, 56(4), 208-216.

Harvey, S., \& Goudvis, A. (2007). Strategies that work: Teaching comprehension for understanding and engagement. Portland, ME: Stenhouse Publishers.

Haynie, J. M., Shepherd, D., Mosakowski, E., \& Earley, P. C. (2010). A situated metacognitive model of the entrepreneurial mindset. Journal of Business Venturing, 25(2), 217-229.

Hedin, L. R. (2008). The effects of thinking aloud on the comprehension and monitoring of sixth graders (Unpublished doctoral dissertation). University of Illinois, Champaign, IL. 
Heller, F. A., \& Yukl, G. (1969). Participation, managerial decision-making, and situational variables. Organizational Behavior and Human Performance, 4(3), 227-241.

Henjes, L. M. (2007). The use of think-aloud strategies to solve word problems (Unpublished master's dissertation). University of Nebraska-Lincoln, Lincoln, NE.

Hennessey, M. G. (1999). Probing the dimensions of metacognition: Implications for conceptual change teaching-learning. Paper presented at the National Association for Research in Science Teaching, Boston, MA. Abstract retrieved from http://files.eric.ed.gov/fulltext/ED446921.pdf.

Hernandez, J. S., \& Varkey, P. (2008). Vertical versus lateral thinking. Physician Executive, 34(3), 26-28.

Hicks, M. J. (2013). Problem solving in business and management: hard, soft and creative approaches. London, UK: Chapman and Hall.

Hirst, W. (1982). The amnesic syndrome: Descriptions and explanations. Psychological Bulletin, 91(3), 435-460.

Holley, K. A. (2006). The cultural construction of interdisciplinarity: Doctoral student socialization in an interdisciplinary neuroscience program (Unpublished doctoral dissertation). University of Southern California, Los Angeles, CA.

Holton, D., \& Clarke, D. (2006). Scaffolding and metacognition. International Journal of Mathematical Education in Science and Technology, 37(2), 127-143.

Hopkins, R. H., \& Edwards, R. E. (1972). Pronunciation effects in recognition memory. Journal of Verbal Learning and Verbal Behavior, 11(4), 534-537.

Horan, J. J. (1979). Counseling for effective decision-making: A cognitive-behavioral perspective. North Scituate, MA: Brooks/Cole. 
Huczynski, A., \& Buchanan, D. (2001). Organizational behaviour: An introductory text (instructor's manual). London, UK: Prentice Hall.

Hutchins, E. 1996. Cognition in the wild. Cambridge, MA: MIT Press.

Inagaki, K. (1992). Piagetian and post-Piagetian conceptions of development and their implications for science education in early childhood. Early Childhood Research Quarterly, 7(1), 115-133.

Isenberg, D. (1984). How senior managers think. Harvard Business Review, 62 (6) 8190.

Ivancevic, V. G., \& Ivancevic, T. T. (2007). Computational mind: A complex dynamics perspective (Vol. 60). Berlin, Germany: Springer.

Jääskeläinen, I. (Ed.). (2012). Introduction to cognitive neuroscience. London, UK: Bookboon.

Jackson, S. (2014). Research methods: A modular approach. Englewood Cliffs, NJ: Cengage Learning.

Jacobs, J. E., \& Paris, S. G. (1987). Children's metacognition about reading: Issues in definition, measurement, and instruction. Educational Psychologist, 22(3-4), $255-278$.

Jacobse, A. E., \& Harskamp, E. G. (2012). Towards efficient measurement of metacognition in mathematical problem solving. Metacognition and Learning, 7(2), 133-149.

Jacoby, J. (1977). Information load and decision quality: Some contested issues. Journal of Marketing Research, 14(4), 569-573.

Jain, T. R., \& Sandhu, A. S. (2009). Quantitative methods. New Delhi, India: V.K Publications. 
Jesson, J. (2012). Developing creativity in the primary school. Berkshire, UK: McGrawHill Education.

Johnson, M. H., \& De Haan, M. (2015). Developmental cognitive neuroscience: An introduction. Chichester, UK: Blackwell Publishers Ltd.

Jorgenson, L. A., Newsome, W. T., Anderson, D. J., Bargmann, C. I., Brown, E. N., Deisseroth, ... \& Marder, E. (2015). The BRAIN Initiative: Developing technology to catalyse neuroscience discovery. Philosophical Transactions of the Royal Society of London B: Biological Sciences, 370(1668), 1-12.

Kaski, D. (2002). Revision: Is visual perception a requisite for visual imagery? Perception, 31(6), 717-731.

Katalin, E. (2000). Please, keep talking: The 'think-aloud' method in second language reading research. Novelty, 7(3), 4-14.

Keast, S., \& Towler, M. (2009). Rational decision-making for managers: An introduction. West Sussex, UK: John Wiley \& Sons.

Keogh, R., \& Pearson, J. (2011). Mental imagery and visual working memory. PloS One, 6(12), 1-8.

Keogh, R., \& Pearson, J. (2014). The sensory strength of voluntary visual imagery predicts visual working memory capacity. Journal of Vision, 14(12), 7-7.

Kepner-Tregoe. (2013). Brain teasers - Kepner-Tregoe. Retrieved from http://www.kepner-tregoe.com/lp/brain-teasers/?mobileformat=true

Kessler, E. H. (Ed.). (2013). Encyclopaedia of management theory. Los Angeles, CA: Sage Publications.

King, M. (2016). Process Control: A Practical Approach 2e. West Sussex, UK: John Wiley \& Sons. 
Klein, G. (1999). Sources of power: How people make decisions. Cambridge, MA: MIT press.

Kluwe, R. (1982). Cognitive knowledge and executive control: Metacognition. In D. R. Griffin (Ed.), Animal mind-human mind (pp. 201-224). New York: Springer Verlagg.

Koçak, R., \& Boyac1, M. (2010). The predictive role of basic ability levels and metacognitive strategies of students on their academic success. ProcediaSocial and Behavioral Sciences, 2(2), 767-772.

Kolić-Vehovec, S., \& Bajšanski, I. (2001). Children's metacognition as predictor of reading comprehension at different developmental levels. Croatia. Retrieved from: http://eric.ed.gov/?id=ED456422

Koriat, A. (2006). Metacognition and consciousness. In P.D. Zelazo, M. Moscovitch, E. Thompson (Eds.). The Cambridge handbook of consciousness (pp. 289-325). Cambridge, UK: Cambridge University Press.

Kumar, A. E. (1998). The influence of metacognition on managerial hiring decisionmaking: Implications for management development (Unpublished doctoral dissertation). Virginia Polytechnic Institute and State University: Blacksburg, Virginia.

Larkin, S. (2009). Metacognition in young children. Abingdon, Oxon: Routledge.

Larkin, J. H., \& Simon, H. A. (1987). Why a diagram is (sometimes) worth ten thousand words. Cognitive Science, 11(1), 65-100.

Lee, N., Senior, C., \& Butler, M. J. (2012). The domain of organizational cognitive neuroscience theoretical and empirical challenges. Journal of Management, 38(4), 921-931. 
Leedy, P., \& Ormrod, J. (2001). Practical research: Planning and design (7th ed.). Upper Saddle River, NJ: Merrill Prentice Hall.

Lester, F. K., Garofalo, J., \& Kroll, D. L. (1989). The role of metacognition in mathematical problem solving: A study of two grade-seven classes. Retrieved from ERIC database (ED314255).

Li, B. (2009). The classical model of decision-making has been accepted as not providing an accurate account of how people typically make decisions. International Journal of Business and Management, 3(6), 151-154.

Liebowitz, J. (Ed.). (2014). Bursting the big data bubble: The case for intuition-based decision making. Boca Raton, FL: CRC Press.

Lin, X. (2001). Designing metacognitive activities. Educational Technology, Research and Development, 49(2), 23-40.

Livingston, J. A. (1997). Metacognition: An overview. Retrieved from http://www.gse.buffalo.edu/fas/shuell/cep564/Metacog.htm.

Luck, S. J., \& Vogel, E. K. (2013). Visual working memory capacity: From psychophysics and neurobiology to individual differences. Trends in cognitive sciences, 17(8), 391-400.

Lysaker, P. H., Gumley, A., Luedtke, B., Buck, K. D., Ringer, J. M., Olesek, K., \& Dimaggio, G. (2013). Social cognition and metacognition in schizophrenia: Evidence of their independence and linkage with outcomes. Acta Psychiatrica Scandinavica, 127(3), 239-247.

McBride, D. K., \& Schmorrow, D. (2005). Quantifying human information processing. Lanham, MD: Lexington Books.

McCurdy, L. Y., Maniscalco, B., Metcalfe, J., Liu, K. Y., de Lange, F. P., \& Lau, H. (2013). Anatomical coupling between distinct metacognitive systems for 
memory and visual perception. The Journal of Neuroscience, 33(5), 18971906.

McFarland, M. G. (2013). Increasing the metacognitive awareness of high school students (Unpublished doctoral dissertation). Texas Tech University, Lubbock, TX.

McKeachie, W. J. (1988). The need for study strategy training. In C. E. Weinstein, E. T. Goetz, \& P. A. Alexander (Eds.), Learning and study strategies: Issues in assessment, instruction, and evaluation (pp. 3-9). San Diego, CA: Academic Press.

McKeown, R. G., \& Gentilucci, J. L. (2007). Think-aloud strategy: Metacognitive development and monitoring comprehension in the middle school secondlanguage classroom. Journal of Adolescent \& Adult Literacy, 51(2), 136-147.

McLeod, S. (2007). Cognitive psychology. Retrieved from http://www.simplypsychology.org/cognitive.html

Mackenzie, N., \& Knipe, S. (2006). Research dilemmas: Paradigms, methods and methodology. Issues in Educational Research, 16(2), 193-205.

MacLeod, C. M., Gopie, N., Hourihan, K. L., Neary, K. R., \& Ozubko, J. D. (2010). The production effect: Delineation of a phenomenon. Journal of Experimental Psychology: Learning, Memory, and Cognition, 36(3), 671-685.

Mann, D. (1976). Policy decision-making in education. New York, NY: Teachers College Press.

March, J. G. (1978). Bounded rationality, ambiguity, and the engineering of choice. The Bell Journal of Economics, 9 (2), 587-608.

March, J. G., \& Simon, H. A. (1958). Organizations. New York, NY: Wiley. 
Markman, E. M. (1981). Comprehensive monitoring. In W. P. Dickson (Ed.), Children's oral communication skills (pp. 61-84). New York, NY: Academic Press.

Martella, R. C., Nelson, J. R., Morgan, R. L., \& Marchand-Martella, N. E. (2013). Understanding and interpreting educational research. New York, NY: Guilford Press.

Matveev, A. V. (2002). The advantages of employing quantitative and qualitative methods in intercultural research: Practical implications from the study of the perceptions of intercultural communication competence by American and Russian managers. Bulletin of Russian Communication Association Theory of Communication and Applied Communication, 1, 59-67.

Matzler, K., Uzelac, B., \& Bauer, F. (2014). The role of intuition and deliberation for exploration and exploitation success. Creativity and Innovation Management, 23(3), 252-263.

Mason, R. B. (2007). A marketing mix model for a complex and turbulent environment. Acta Commercii, 7(1), 236-254.

Mendenhall, W., Beaver, R., \& Beaver, B. (2008). Introduction to probability and statistics. Belmont, CA: Duxbury Press.

Miller, G. A., Galanter, E., \& Pribram, K. H. (1960). Plans and the structure of behavior. New York, NY: Holt, Rinehart \& Winston.

Miller, P. H., \& Weiss, M. G. (1982). Children's and adults' knowledge about what variables affect selective attention. Child Development, 53 (2), 543-549.

Mitchell, R. J., Shepherd, D. A., \& Sharfman, M. P. (2011). Erratic strategic decisions: When and why managers are inconsistent in strategic decision making. Strategic Management Journal, 32(7), 683-704. 
Montague, M. (1992). The effects of cognitive and metacognitive strategy instruction on the mathematical problem solving of middle school students with learning disabilities. Journal of Learning Disabilities, 25(4), 230-248.

Montague, M., \& Applegate, B. (1993). Middle school students' mathematical problem solving: An analysis of think-aloud protocols. Learning Disability Quarterly, 16(1), 19-32.

Morcol, G. (Ed.). (2006). Handbook of decision making. London, UK: CRC Press.

Mukherji, P., \& Albon, D. (2009). Research methods in early childhood: An introductory guide. Los Angeles, CA: Sage.

Naqvi, N., Shiv, B., \& Bechara, A. (2006). The role of emotion in decision-making a cognitive neuroscience perspective. Current Directions in Psychological Science, 15(5), 26-264.

Naylor, J. C., Pritchard, R. D., \& Ilgen, D. R. (1980). A theory of behavior in organizations. New York, NY: Academic Press.

Negulescu, O. (2014). Using a decision-making process model in strategic management. Review of General Management, 15, 111-123.

Nelson, T. O., \& Narens, L. (1990). Metamemory: A theoretical framework and new findings. The Psychology of Learning and Motivation, 26, 125-141.

Newell, A., \& Simon, H. A. (1972). Human problem solving (vol. 104, no. 9). Englewood Cliffs, NJ: Prentice-Hall.

Nolde, S. F., Johnson, M. K., \& D'Esposito, M. (1998). Left prefrontal activation during episodic remembering: An event-related fMRI study. NeuroReport, 9(15), 3509-3514. 
Norman, G. R., \& Streiner, D. L. (2008). Biostatistics: The bare essentials. St. Louis, MO: Mosby-Year Book Inc.

North, M. J., \& Macal, C. M. (2007). Managing business complexity: Discovering strategic solutions with agent-based modeling and simulation. Dordrecht, the Netherlands: Oxford University Press.

Northoff, G. (2014). Minding the brain: A guide to philosophy and neuroscience. Hampshire, UK: Palgrave Macmillan.

Novicevic, M. M., Hench, T. J., \& Wren, D. A. (2002). "Playing by ear ... in an incessant din of reasons": Chester Barnard and the history of intuition in management thought. Management Decision, 40(10), 992-1002.

Nunnally, J. C. (1978), Psychometric methods. New York, NY: McGraw Hill.

Nutt, P. C., \& Wilson, D. C. (Eds.). (2010). Handbook of decision making (vol. 6). New York, NY: John Wiley \& Sons.

O’Connor, C., \& Joffe, H. (2013). How has neuroscience affected lay understandings of personhood? A review of the evidence. Public Understanding of Science, 22(3), 254-268.

O'Leary, Z. (2004). The essential guide to doing your research project. London, UK: Sage.

O'Sullivan, T. (2010). Decision-making in social work. London, UK: Palgrave Macmillan.

Ochsner, K. N., \& Kosslyn, S. M. (1999). The cognitive neuroscience approach. Handbook of Cognition and Perception, 10, 319-365.

Odle, T., \& Mayer, R. (2009). Experimental research. Retrieved from http://www.education.com/reference/article/experimental-research/ 
Okpara, F. O. (2007). The value of creativity and innovation in entrepreneurship. Journal of Asia Entrepreneurship and Sustainability, 3(2), 1-14.

Ormond, C., Luszcz, M. A., Mann, L., \& Beswick, G. (1991). A metacognitive analysis of decision-making in adolescence. Journal of Adolescence, 14(3), 275-291.

Ozubko, J. D., Hourihan, K. L., \& MacLeod, C. M. (2012). Production benefits learning: The production effect endures and improves memory for text. Memory, 20(7), 717-727.

Palinscar, A. S., \& Brown, A. L. (1984). Reciprocal teaching of comprehension-fostering and comprehension-monitoring activities. Cognition and Instruction, 1(2), $117-175$.

Papageorgiou, C., \& Wells, A. (2001). Metacognitive beliefs about rumination in recurrent major depression. Cognitive and Behavioral Practice, 8(2), 160164.

Papleontiou-louca, E. (2003). The concept and instruction of metacognition. Teacher Development, 7(1), 9-30.

Pardo, M. S., \& Patterson, D. M. (2013). Minds, brains, and law: The conceptual foundations of law and neuroscience. New York, NY: Oxford University Press.

Parrillo, A. L. (2008). Parental attachment and involvement as predictors of high school students' career thoughts (Doctoral dissertation). Retrieved from ProQuest Dissertations and Theses database. (Accession Order No. AAT 3346360).

Partanen, P., Jansson, B., Lisspers, J., \& Sundin, Ö. (2015). Metacognitive strategy training adds to the effects of working memory training in children with special educational needs. International Journal of Psychological Studies, 7(3), 130-140 
Pearson, K. (1895). Note on regression and inheritance in the case of two parents. Proceedings of the Royal Society of London, 58, 240-242.

Peña-Ayala, A. (Ed.). (2014). Metacognition: Fundaments, applications, and trends: A profile of the current state-of-the-art (vol. 76). New York, NY: Springer.

Perfect, T. J., \& Schwartz, B. L. (2002). Applied metacognition. Cambridge, UK: Cambridge University Press.

Pesut, D. J. (1990). Creative thinking as a self-regulatory metacognitive process: A model for education, training and further research. The Journal of Creative Behavior, 24(2), 105-110.

Petroselli, C. L. (2008). Science education issues and developments. New York, NY: Nova Publishers.

Piaget, J. (1950). The psychology of intelligence. London, UK: Routledge and Kegan Paul.

Pink, D. H. (2005). A whole new mind: Moving from the information age into the conceptual age. New York, NY: Warner Books.

Pintrich, P. R. (2002). The role of metacognitive knowledge in learning, teaching, and assessing. Theory into Practice, 41(4), 219-225.

Pol, L. G., \& Thomas, R. K. (1997). Demography for business decision making. Westport, CT: Greenwood Publishing Group.

Pondy, L. R. (1983). Union of rationality and intuition in management action. In S. Srivastva and Associates (eds.), The Executive Mind: (pp. 169-19). San Francisco, CA: Jossey-Bass.

Pownall, I. (2012). Effective management decision-making. London, UK: Bookboon. 
Pressley, M., \& Afflerbach, P. (1995). Verbal protocols of reading: The nature of constructively responsive reading. Hillsdale, NJ: Erlbaum.

Pressley, M., Borkowski, J. G., \& Schneider, W. (1987). Cognitive strategies: Good strategy users coordinate metacognition and knowledge. In R. Vasta (ed.), Annals of Child Development: Vol. 4 (pp. 89-129). Greenwich, CT: JAI Press.

Proctor, T. (2014). Creative problem solving for managers: Developing skills for decision-making and innovation. London, UK: Routledge.

Pugalee, D. K. (2001). Writing, mathematics, and metacognition: Looking for connections through students' work in mathematical problem solving. School Science and Mathematics, 101(5), 236-245.

Rainer, R. K., \& Cegielski, C. G. (2009). Introduction to information system: Enabling and transforming business. New York, NY: John Wiley \& Sons.

Rapp, D. N., \& Kurby, C. A. (2008). The 'ins' and 'outs' of learning: Internal representations and external visualizations. In A. Editor and B. Editor (Eds.), Visualization: Theory and practice in science education (pp. 29-52). Dordrecht, the Netherlands: Springer Netherlands.

Richardson, J. T., Engle, R. W., Hasher, L., Logie, R. H., Stoltzfus, E. R., \& Zacks, R. T. (1996). Working memory and human cognition. New York, NY: Oxford University Press.

Rieber, L. P. (1995). A historical review of visualization in human cognition. Educational Technology Research and Development, 43(1), 45-56.

Roam, D. (2009). The back of the napkin (expanded edition): Solving problems and selling ideas with pictures. New York, NY: Penguin. 
Robbins, S. P. (2014). Decide and conquer: The ultimate guide for improving your decision making. Cranbury, NJ: Pearson Education.

Rubin, A. (2012). Statistics for evidence-based practice and evaluation. Belmont, CA: Cengage Learning.

Rubman, C. N., \& Salatas Waters, H. (2000). A, B seeing: The role of constructive processes in children's comprehension monitoring. Journal of Educational Psychology, 92(3), 503-514.

Ruff, J. (2002). Information overload: Causes, symptoms and solutions. Harvard Graduate School of Education, 1-13. Retrieved from http://www.newsmaster.be/flow/dw/ciel/2011/aout11/infooverloadbrief.pdf

Rugg, M. D., Fletcher, P. C., Chua, P. M., \& Dolan, R. J. (1999). The role of the prefrontal cortex in recognition memory and memory for source: An fMRI study. Neuroimage, 10(5), 520-529.

Runco, M. A., \& Chand, I. (1995). Cognition and creativity. Educational Psychology Review, 7(3), 243-267.

Sadler-Smith, E., \& Shefy, E. (2004). The intuitive executive: Understanding and applying 'gut feel'in decision-making. The Academy of Management Executive, 18(4), 76-91.

Sahin, S. M., \& Kendir, F. (2013). The effect of using metacognitive strategies for solving geometry problems on students' achievement and attitude. Educational Research and Reviews, 8(19), 1777-1792.

Santos, J. R. A. (1999). Cronbach's alpha: A tool for assessing the reliability of scales. Journal of Extension, 37(2), 1-5.

Sauter, V. L. (1999). Intuitive decision-making. Communications of the ACM, 42(6), 09115. 
Scarlett, H. (2016). Neuroscience for organizational change: An evidence-based practical guide to managing change. Croydon, UK: CPI Group.

Schinka, J. A., Velicer, W. F., \& Weiner, I. B. (2003). Handbook of psychology, Volume 2: Research methods in psychology. Hoboken, NJ: John Wiley and Sons.

Schraw, G., \& Dennison, R. S. (1994). Assessing metacognitive awareness. Contemporary Educational Psychology, 19(4), 460-475.

Schraw, G., \& Moshman, D. (1995). Metacognitive theories. Educational Psychology Review, 7(4), 351-371.

Schunk, D. H. (2008). Metacognition, self-regulation, and self-regulated learning: Research recommendations. Educational Psychology Review, 20(4), 463467.

Schunk, D. H., \& Rice, J. M. (1985). Verbalization of comprehension strategies: Effects on children's achievement outcomes. Human Learning: Journal of Practical Research \& Applications, 4(1), 1-10.

Schwartz, B. L. (1994). Sources of information in metamemory: Judgments of learning and feelings of knowing. Psychonomic Bulletin \& Review, 1(3), 357-375.

Scott, B. M., \& Levy, M. G. (2013). Metacognition: Examining the components of a fuzzy concept. Educational Research eJournal, 2(2), 120-131.

Seijts, G., Crossan, M., \& Billou, N. (2010). Coping with complexity. Ivey Business Journal, 74(3), (Online Journal)

http://www.iveybusinessjournal.com/\%20topics/leadership/copingwithcomplexity\#.UTZEbjCG18E

Senior, C., Lee, N., \& Butler, M. (2011). Organizational cognitive neuroscience. Organization Science, 22(3), 804-815. 
Shadish, W. R., Cook, T. D., \& Campbell, D. T. (2002). Experimental and quasiexperimental designs for generalized causal inference. Boston, MA: Houghton Mifflin.

Shimamura, A. P. (2000). Toward a cognitive neuroscience of metacognition. Consciousness and cognition, 9(2), 313-323.

Shimamura, A. P., \& Squire, L. R. (1986). Memory and metamemory: A study of the feeling-of-knowing phenomenon in amnesic patients. Journal of Experimental Psychology: Learning, Memory, and Cognition, 12(3), 452460.

Shirley, D. A., \& Langan-Fox, J. (1996). Intuition: A review of the literature. Psychological Reports, 79(2), 563-584.

Siegler, R. S. (1978). The origins of scientific reasoning. In R. S. Siegler (Ed.), Children's thinking: What develops? (pp. 104-149). Hillsdale, NJ: Erlbaum.

Simon, H. A. (1957). Models of man; social and rational. New York, NY: Wiley.

Simon, H. A. (1987). Making management decisions: The role of intuition and emotion. The Academy of Management Executive, 1(1), 57-64.

Sirageldin, I. (2001) Sustainable Human Development in the Twenty-First Century: An Evolutionary Perspective. In I. Sirageldin (ed.), Our Fragile World Challenges and Opportunities for Sustainable Development. Oxford, UK: Eolss Publishers.

Smith, G. F. (2003). Beyond critical thinking and decision-making: Teaching business students how to think. Journal of Management Education, 27(1), 24-51.

Smyth, M. M., Collins, A. F., Morris, P. E., \& Levy, P. (1994). Cognition in action. East Sussex, UK: Psychology Press. 
Spiegel, M. R. (1961). Statistics: Theory and Problems. New York, NY: McGraw-Hill.

Steinhouse, R. (2014). Business Express: Making effective decisions: A rigorous process for making choices that works. Edinburgh, UK: Pearson Education Limited.

Swanson, H. L. (1990). Influence of metacognitive knowledge and aptitude on problem solving. Journal of Educational Psychology, 82(2), 306-314.

Tavakol, M., \& Dennick, R. (2011). Making sense of Cronbach's alpha. International Journal of medical education, 2, 53-55.

Teo, T., \& Lee, C. B. (2012). Assessing the factorial validity of the Metacognitive Awareness Inventory (MAI) in an Asian country: A confirmatory factor analysis. International Journal of Educational and Psychological Assessment, 10(2), 92-103.

Teong, S. K. (2003). The effect of metacognitive training on mathematical word-problem solving. Journal of Computer Assisted Learning, 19(1), 46-55.

Thagard, P. (2008). Hot thought: Mechanisms and applications of emotional cognition. Cambridge, MA: MIT Press.

Thamraksa, C. (2005). Metacognition: A key to success for EFL learners. BU Academic Review, 4(1), 95-99.

Thomas, D. W. (1955). Sociological aspects of the decision making process. Journal of Farm Economics, 37(5), 1115-1118.

Tribe, J. (2015). The economics of recreation, leisure and tourism. Oxford, UK: Routledge.

Tucker, P., \& Warr, P. (1996). Intelligence, elementary cognitive components, and cognitive styles as predictors of complex task performance. Personality and Individual Differences, 21(1), 91-102. 
Tufte, E. R., \& Graves-Morris, P. R. (1983). The visual display of quantitative information (vol. 2, no. 9). Cheshire, CT: Graphics Press.

Turan, S., Demirel, Ö. \& Sayek, İ. (2009). Metacognitive awareness and self-regulated learning skills of medical students in different medical curricula. Medical Teacher, 31(10), 477-483.

Van Meter, P. (2001). Drawing construction as a strategy for learning from text. Journal of Educational Psychology, 93(1), 129-140.

Van Meter, P., Aleksic, M., Schwartz, A., \& Garner, J. (2006). Learner-generated drawing as a strategy for learning from content area text. Contemporary Educational Psychology, 31(2), 142-166.

Van Someren, M., Barnard, Y. F., \& Sandberg, J. A. (1994). The think aloud method: A practical approach to modelling cognitive processes. London, UK: Academic Press.

Vaughan, L. (2001). Statistical methods for the information professional: A practical, painless approach to understanding, using, and interpreting statistics (vol. 367). Medford, NJ: Information Today, Inc.

Vavra, K. L., Janjic-Watrich, V., Loerke, K., Phillips, L. M., Norris, S. P., \& Macnab, J. (2011). Visualization in science education. Alberta Science Education Journal, 41(1), 22-30.

Viswanathan, V., Lee, S., Gilman, J. M., Kim, B. W., Lee, N., Chamberlain, L., ... \& Stern, D. B. (2015). Age-related striatal BOLD changes without changes in behavioral loss aversion. Frontiers in Human Neuroscience, 9, 1-12.

Volet, S. E. (1991). Modelling and coaching of relevant metacognitive strategies for enhancing university students' learning. Learning and Instruction, 1(4), 319336. 
Vygotsky, L. S. (1962), Thought and language. Cambridge, MA: M.I.T. Press.

Wang, M., \& Jacobson, M. J. (2011). Guest editorial-knowledge visualization for learning and knowledge management. Educational Technology \& Society, 14(3), 1-3.

Wang, Y., \& Ruhe, G. (2007). The cognitive process of decision-making. International Journal of Cognitive Informatics and Natural Intelligence, 1 (2), 73-85.

Weinert, F. E., \& Kluwe, R. H. (1987). Metacognition, motivation, and understanding. Hillsdale, NJ: Erlbaum.

Wellman, H. (1983). Metamemory revisited. In M. Chi (Ed.), What is memory development the development of? A look after a decade (pp. 31-51). Basel, Switzerland: Karger

Wetherly, P., \& Otter, D. (2014). The business environment: Themes and issues in a globalizing world. Oxford, UK: Oxford University Press.

Whitebread, D. (1999). Interactions between children's metacognitive abilities, working memory capacity, strategies and performance during problemsolving. European Journal of Psychology of Education, 14(4), 489-507.

Whitebread, D., Coltman, P., Pasternak, D. P., Sangster, C., Grau, V., Bingham., ... \& Demetriou, D. (2009). The development of two observational tools for assessing metacognition and self-regulated learning in young children. Metacognition and Learning, 4(1), 63-85.

Whitney, P., \& Budd, D. (1996). Think-aloud protocols and the study of comprehension. Discourse Processes, 21(3), 341-351.

Whitney, P., Ritchie, B. G., \& Clark, M. B. (1991). Working-memory capacity and the use of elaborative inferences in text comprehension. Discourse Processes, 14(2), 133-145. 
Williams, C. (2011). Research methods. Journal of Business \& Economics Research (JBER), 5(3), 65-72.

Withrow, B. L. (2013). Research methods in crime and justice. Oxon, UK: Routledge.

Yeung, N., \& Summerfield, C. (2012). Metacognition in human decision-making: Confidence and error monitoring. Philosophical Transactions of the Royal Society B: Biological Sciences, 367(1594), 1310-1321.

Young, A., \& Fry, J. (2012). Metacognitive awareness and academic achievement in college students. Journal of the Scholarship of Teaching and Learning, 8(2), $1-10$.

Zadeh, L. A., Klir, G. J., \& Yuan, B. (1996). Fuzzy sets, fuzzy logic, and fuzzy systems: selected papers (vol. 6). River Edge, N. J: World Scientific.

Zohar, A., \& Dori, Y. J. (Eds.). (2011). Metacognition in science education: Trends in current research (vol. 40). Dordrecht, the Netherlands: Springer Science \& Business Media. 


\section{Appendices}

\section{Appendix A- Instructions for students}

Thank you all for participating in this study. By staying behind you have given informed consent to participate. Two different questionnaires will be distributed shortly. An information sheet that outlines the nature of this study will be distributed once everyone has finished. The questionnaire will take around 30 minutes to complete.

Please read the following instructions:

- Do not open the booklet until asked

- Do not use any electronic devices in the experiment

- Record your start and end time

- Do not leave the room until told 


\author{
SCHOOL OF MANAGEMENT \\ LEVEL 10, RUTHERFORD HOUSE, PIPITEA CAMPUS, 23 LAMBTON QUAY, \\ Wellington \\ PO Box 600, Wellington 6140, New Zealand \\ Phone + 64-4-463 5397 Fax +64-4-463 5084 Email som@vuw.ac.nz Website \\ www.victoria.ac.nz/som
}

\title{
Participant Information Sheet
}

Research Project Title: Metacognition in Management

Researcher: Evie Turner-Walker, School of Information Management, Victoria University of Wellington

As part of the completion of my Masters of Commerce, this study is designed to determine whether the use of metacognition improves management performance, specifically in relation to decision making. Victoria University requires, and has granted, approval from the School's Human Ethics Committee.

I am inviting all students enrolled in MGMT320, MGMT202, HRIR 201 \& PUBL305 to participate in this research. Participants will be asked to take part in a half an hour experiment, which will consist of filling out a survey on the student's metacognitive ability and completing a problem situation. Permission will be asked to take part in the research, and a summary of the research can be provided for the participants.

Participation is voluntary, and you will not be identified personally in any written report produced as a result of this research. All material collected will be kept confidential, and will be viewed only by myself and my supervisor, Dr Paul McDonald - Senior Lecturer School of Management. The thesis will be submitted for marking to the School of Information Management, and subsequently deposited in the University Library. Should any participant wish to withdraw from the project, they may do so until Friday the $12^{\text {th }}$ of February, and the data collected up to that point will be destroyed. All data collected from participants will be destroyed within 5 years after the completion of the project.

If you have any questions or would like to receive further information about the project, please contact me at [researcher contact information], or you may contact my supervisor Dr Paul McDonald [supervisor contact information].

Evie Turner-Walker 


\section{Appendix C- Control group questionnaire}
Gender:
Male

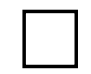
Female

Write your start time here:

(i.e. 11:20 am)

\section{Section A: $\quad$ Short - Answer Questions}

Please answer the following five questions. Once finished, move on to Section B. Please do not return to Section A - once you have finished.

Questions:

1. Johnny's mother had three children. The first child was named April. The second child was named May. What was the third child's name?

Answer:

2. How much dirt is there in a hole that measures two feet by three feet by four feet?

Answer:

3. If you were running a race and you passed the person in $2^{\text {nd }}$ place, what place would you be in now?

Answer:

4. A farmer has five haystacks in one field and four haystacks in another. How many haystacks would he have if he combined them all in one field?

Answer:

5. A cup and teapot set costs $\$ 110$. The teapot costs $\$ 100$ more than the cup. How much does the cup cost?

Answer: 


\section{Section B: Job Hiring Decision}

The following scenario is a job hiring exercise. Read the advertisement and the information about the two candidates and then decide which candidate would be your first choice to hire and why. (Write your response below)

Once finished, move on to Section C. Please do not return to any previous sections - once you have finished.

\section{$\underline{\text { Job advertisement: Cleaner Wanted! }}$}

Cleaning position available. Local restaurant is seeking applicants for a full-time cleaner, 35 hours per week. Work schedule will include nights and some weekends, primarily after busy periods. Job requirements include: mopping floors, vacuuming, wiping down tables and benches and equipment, cleaning windows and sanitising bathrooms. The successful applicant must be able to work unsupervised and complete the tasks required within specific time frames. Flexibility to be available as required during busy periods of the year is needed. Previous experience in a commercial cleaning environment is a must. Starting pay is $\$ 17.40$ an hour. Apply in person.

\section{The applicants:}

Jack (24) is a tall, gangly lad supporting ginger hair and a goatee beard. He is just back from London, where he was a cleaner for a year after completing a Contiki tour of Europe. He decided to go on his "OE" after dropping out of Massey University, where he was originally studying Journalism. One day he hopes to return to finish his degree, but for now he is looking for work to become financially secure. Jack was born and raised in Invercargill and is very proud of his parents Scottish heritage. He supports a Scottish thistle tattoo on his left forearm. Currently flatting in Aro Valley, Jack likes to enjoy hanging out with his fellow flatmates, drinking local craft beer and listening to Indie music.

Mary (47) is originally from Fiji but has lived in New Zealand for 9 years. Mary and her husband, Temo, moved to New Zealand to be closer to their family and chose to settle down in the quiet suburb of Petone. The couple have recently adopted two Greyhounds from a rescue shelter for retired racing dogs. Mary is a small women with dark black hair and a cheeky grin who gets along with everyone she meets. In her free time Mary likes painting landscapes and occasionally sells them at an art gallery in Carterton. She also likes listening to classical music and enjoys going to the occasional orchestral performance in Wellington. For the past four years, Mary has been a cleaner at a Wellington Insurance company, however, due to recent staffing cuts, she was made redundant.

Please write a short answer as to who would be your first choice for this job and why. 


\section{Section C: Puzzle Solving}

Please solve the following puzzle. Once finished, move on to Section D. Please do not return to any previous sections - once you have finished.

Question: A caravan is stranded in the desert with a 6 day walk back to civilization. Each person in the caravan can carry a 4 day supply of food and water. A single person cannot carry enough food and water and would die. What is the minimum number of people that must start out in order for one person to get help and for the others to get back to the caravan safely? (Bear in mind that at any stage a person can return to the caravan).

\section{Answer:}


Section D: to be completed WITHOUT looking back at Section B

Without looking back at Section B, use your memory to recall as many details as possible about Jack and Mary (the cleaners).

Once finished, move on to section E. Please do not return to any previous sections - once you have finished.
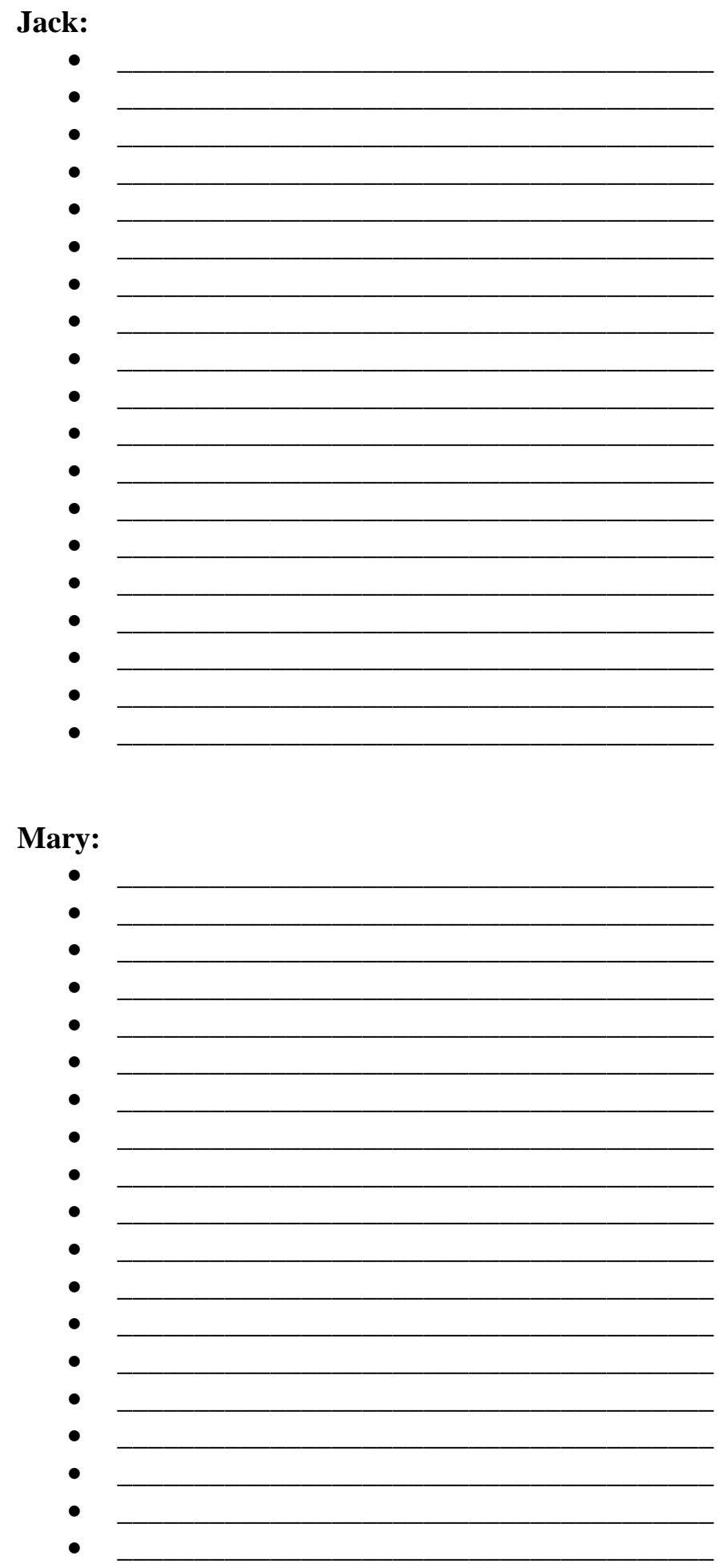


\title{
Appendix D- Experimental group questionnaire
}

\author{
Gender: $\quad$ Male $\square \quad$ Female $\square$
}

Write your start time here:

(i.e. 11:20 am)

Section A: Short - Answer Questions

Please answer the following five questions. Do not simply read the question. Instead, say each question to yourself (in your mind) and listen slowly to the sound of your own voice. You can repeat this process "speaking aloud to yourself", as many times as necessary, in order to formulate your answers. Once finished, move on to Section B.

Please do not return to Section A - once you have finished.

\section{Questions:}

6. Johnny's mother had three children. The first child was named April. The second child was named May. What was the third child's name?

Answer:

7. How much dirt is there in a hole that measures two feet by three feet by four feet?

Answer:

8. If you were running a race and you passed the person in $2^{\text {nd }}$ place, what place would you be in now?

Answer:

9. A farmer has five haystacks in one field and four haystacks in another. How many haystacks would he have if he combined them all in one field?

Answer:

10. A cup and teapot set costs $\$ 110$. The teapot costs $\$ 100$ more than the cup. How much does the cup cost?

Answer: 


\section{Section B: Job Hiring Decision}

The following scenario is a job hiring exercise. Read the advertisement and the information about the two candidates. Using your imagination, visualize yourself sitting down with each of the candidates and role play the conversation that would take place with each of them. Play the interview scene in your head in as much detail as possible from the time you meet each candidate (e.g. visualise them entering the room) until the time they leave (e.g. visualise them shaking hands and departing), including your thoughts and observations as to how they look, sound, respond to your questions, etc.

Decide which candidate would be your first choice to hire and why. (Write your response below) Once finished, move on to Section C. Please do not return to any previous sections - once you have finished.

\section{Job advertisement: Cleaner Wanted!}

Cleaning position available. Local restaurant is seeking applicants for a full-time cleaner, 35 hours per week. Work schedule will include nights and some weekends, primarily after busy periods. Job requirements include: mopping floors, vacuuming, wiping down tables and benches and equipment, cleaning windows and sanitising bathrooms. The successful applicant must be able to work unsupervised and complete the tasks required within specific time frames. Flexibility to be available as required during busy periods of the year is needed. Previous experience in a commercial cleaning environment is a must. Starting pay is $\$ 17.40$ an hour. Apply in person.

\section{The applicants:}

Jack (24) is a tall, gangly lad supporting ginger hair and a goatee beard. He is just back from London, where he was a cleaner for a year after completing a Contiki tour of Europe. He decided to go on his "OE" after dropping out of Massey University, where he was originally studying Journalism. One day he hopes to return to finish his degree, but for now he is looking for work to become financially secure. Jack was born and raised in Invercargill and is very proud of his parents Scottish heritage. He supports a Scottish thistle tattoo on his left forearm. Currently flatting in Aro Valley, Jack likes to enjoy hanging out with his fellow flatmates, drinking local craft beer and listening to Indie music.

Mary (47) is originally from Fiji but has lived in New Zealand for 9 years. Mary and her husband, Temo, moved to New Zealand to be closer to their family and chose to settle down in the quiet suburb of Petone. The couple have recently adopted two Greyhounds from a rescue shelter for retired racing dogs. Mary is a small women with dark black hair and a cheeky grin who gets along with everyone she meets. In her free time Mary likes painting landscapes and occasionally sells them at an art gallery in Carterton. She also likes listening to classical music and enjoys going to the occasional orchestral performance in Wellington. For the past four years, Mary has been a cleaner at a Wellington Insurance company, however, due to recent staffing cuts, she was made redundant.

Please write a short answer as to who would be your first choice for this job and why. 


\section{Section C: $\quad$ Puzzle Solving}

Using the blank space below, draw a simple map showing the caravan stranded in the centre of the desert, 6 days walk from civilization. Then, using your map and any additional drawings/sketches, as required, carefully think through the puzzle.

Once finished, move on to Section D. Please do not return to any previous sections - once you have finished.

Question: A caravan is stranded in the desert with a 6 day walk back to civilization. Each person in the caravan can carry a 4 day supply of food and water. A single person cannot carry enough food and water and would die. What is the minimum number of people that must start out in order for one person to get help and for the others to get back to the caravan safely? (Bear in mind that at any stage a person can return to the caravan).

\section{Answer:}


Section D: to be completed WITHOUT looking back at Section B

Without looking back at Section B, use your memory to recall as many details as possible about Jack and Mary (the cleaners).

Once finished, move on to section E. Please do not return to any previous sections - once you have finished.
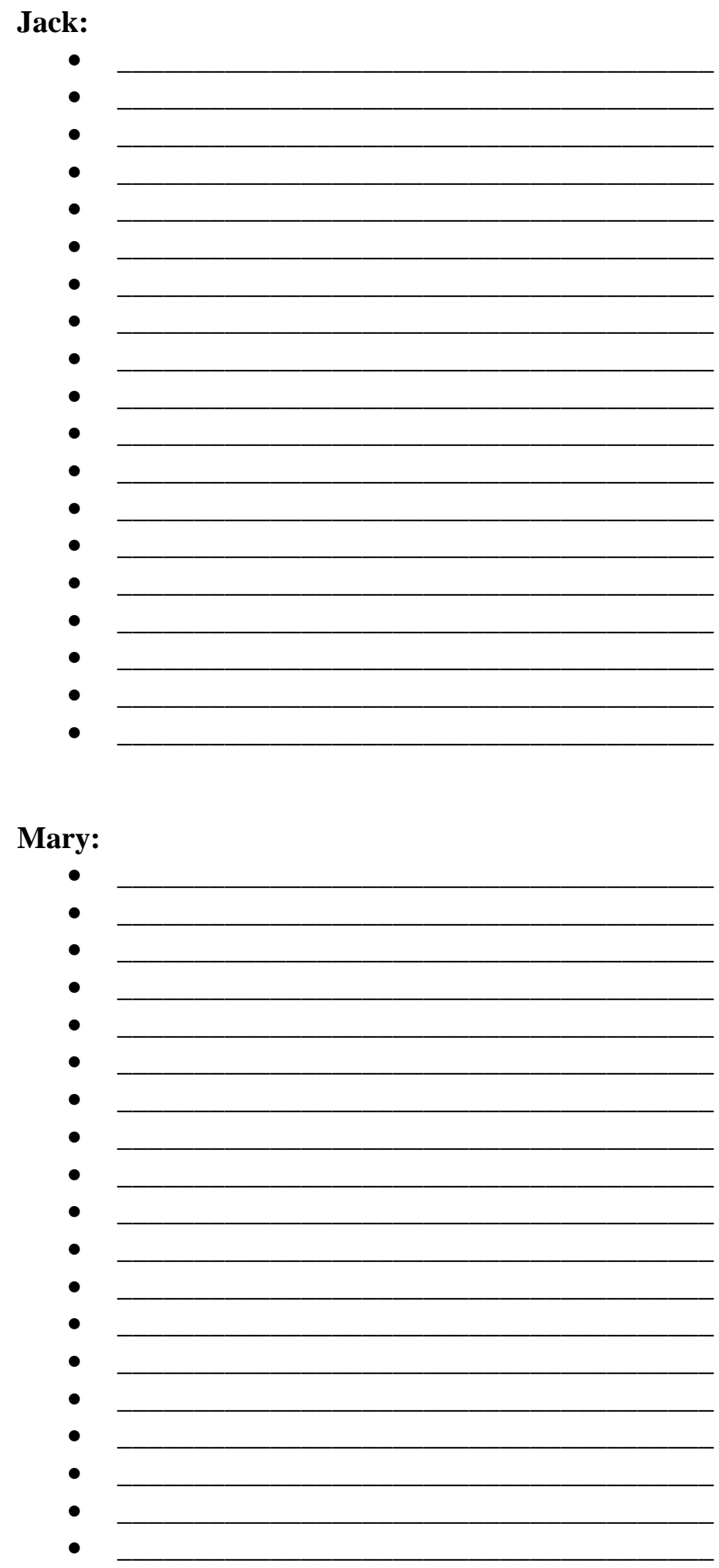


\section{Appendix E- Metacognitive Awareness Inventory}

\section{Metacognitive Awareness Inventory}

The following questionnaire will assess the degree of your metacognitive ability. Please answer each question as carefully and truthfully as you can by indicating the extent to which you believe each statement is either true or false, in relation to your own decision making style.

\begin{tabular}{ccccc}
\hline 1 & 2 & 3 & 4 & 5 \\
\hline Always true & Sometimes & Neutral & Sometimes \\
& True & False & Always false \\
& & & \\
\hline
\end{tabular}

Using the scale above please indicate the EXTENT TO WHICH YOU BELIEVE each statement is true or false:

\begin{tabular}{|c|c|c|c|c|c|}
\hline & \multicolumn{4}{|c|}{$\begin{array}{c}\text { Please } \\
\text { tick one } \\
\square\end{array}$} & \\
\hline & 1 & 2 & 3 & 4 & \\
\hline \multirow[t]{2}{*}{$\begin{array}{l}\text { 1. I periodically review to help me understand important relationships. } \\
\text { 2. I ask myself if there was an easier way to do things after I finish a task. } \\
\text { 3. I summarize what I've learned after I finish. } \\
\text { 4. I find myself using helpful learning strategies automatically. } \\
\text { 5. I pace myself while learning in order to have enough time. } \\
\text { 6. I think about what I really need to learn before I begin a task. } \\
\text { 7. I set specific goals before I begin a task. }\end{array}$} & $\begin{array}{l}\square \\
\square \\
\square \\
\square \\
\square \\
\square \\
\square\end{array}$ & $\begin{array}{l}\square \\
\square \\
\square \\
\square \\
\square \\
\square \\
\square\end{array}$ & $\begin{array}{l}\square \\
\square \\
\square \\
\square \\
\square \\
\square \\
\square\end{array}$ & $\begin{array}{l}\square \\
\square \\
\square \\
\square \\
\square \\
\square \\
\square\end{array}$ & $\begin{array}{l}\square \\
\square \\
\square \\
\square \\
\square \\
\square \\
\square\end{array}$ \\
\hline & 1 & 2 & 3 & 4 & 5 \\
\hline $\begin{array}{l}\text { 8. I ask myself questions about the material before I begin. } \\
\text { 9. I organise my time to best accomplish my goals. } \\
\text { 10. I use my intellectual strengths to compensate for my weaknesses. } \\
\text { 11. I consider several alternatives to a problem before I answer. } \\
\text { 12. I think of several ways to solve a problem and choose the best one. } \\
\text { 13. I try to use strategies that have worked in the past. } \\
\text { 14. I find myself pausing regularly to check my comprehension. }\end{array}$ & $\begin{array}{l}\square \\
\square \\
\square \\
\square \\
\square \\
\square \\
\square\end{array}$ & $\begin{array}{l}\square \\
\square \\
\square \\
\square \\
\square \\
\square \\
\square\end{array}$ & $\begin{array}{l}\square \\
\square \\
\square \\
\square \\
\square \\
\square \\
\square\end{array}$ & $\begin{array}{l}\square \\
\square \\
\square \\
\square \\
\square \\
\square \\
\square\end{array}$ & $\begin{array}{l}\square \\
\square \\
\square \\
\square \\
\square \\
\square \\
\square\end{array}$ \\
\hline & 1 & 2 & 3 & 4 & \\
\hline $\begin{array}{l}\text { 15. I re-evaluate my assumptions when I get confused. } \\
\text { 16. I stop and go back over new information that is not clear. } \\
\text { 17. I slow down when I encounter important information. } \\
\text { 18. I focus on the meaning and significance of new information. } \\
\text { 19. I try to translate new information into my own words. } \\
\text { 20. I use the organisational structure of the text to help me learn. } \\
\text { 21. I ask myself if what I'm reading is related to what I already know. }\end{array}$ & $\begin{array}{l}\square \\
\square \\
\square \\
\square \\
\square \\
\square \\
\square\end{array}$ & $\begin{array}{l}\square \\
\square \\
\square \\
\square \\
\square \\
\square \\
\square\end{array}$ & $\begin{array}{l}\square \\
\square \\
\square \\
\square \\
\square \\
\square \\
\square\end{array}$ & $\begin{array}{l}\square \\
\square \\
\square \\
\square \\
\square \\
\square \\
\square\end{array}$ & $\begin{array}{l}\square \\
\square \\
\square \\
\square \\
\square \\
\square \\
\square\end{array}$ \\
\hline
\end{tabular}

Write your completion time here: (i.e. 11:50 am)

Thank You - raise your hand and your questionnaire will be picked up. 